Florida International University

FIU Digital Commons

FIU Electronic Theses and Dissertations

University Graduate School

$11-10-2016$

\title{
Exploratory Assessment of Roadway Infrastructure Adaptation to the Impacts of Sea-level Rise
}

\author{
Mostafa Batouli \\ Florida International University, sbato001@fiu.edu
}

Follow this and additional works at: https://digitalcommons.fiu.edu/etd

Part of the Civil and Environmental Engineering Commons, and the Infrastructure Commons

\section{Recommended Citation}

Batouli, Mostafa, "Exploratory Assessment of Roadway Infrastructure Adaptation to the Impacts of Sealevel Rise" (2016). FIU Electronic Theses and Dissertations. 3166.

https://digitalcommons.fiu.edu/etd/3166

This work is brought to you for free and open access by the University Graduate School at FIU Digital Commons. It has been accepted for inclusion in FIU Electronic Theses and Dissertations by an authorized administrator of FIU Digital Commons. For more information, please contact dcc@fiu.edu. 


\section{FLORIDA INTERNATIONAL UNIVERSITY}

Miami, Florida

EXPLORATORY ASSESSMENT OF ROADWAY INFRASTRUCTURE ADAPTATION

TO THE IMPACTS OF SEA-LEVEL RISE

A dissertation submitted in partial fulfillment of

the requirements for the degree of

DOCTOR OF PHILOSOPHY

in

CIVIL ENGINEERING

by

Mostafa Batouli

2017 
To: Interim Dean Ranu Jung

College of Engineering and Computing

This dissertation, written by Mostafa Batouli, and entitled Exploratory Assessment of Roadway Infrastructure Adaptation to the Impacts of Sea-Level Rise, having been approved in respect to style and intellectual content, is referred to you for judgment.

We have read this dissertation and recommend that it be approved.

Samuel Labi

Irtishad Ahmad

Berrin Tansel

Xia Jin

Arindam G. Chowdhury, Co-Major Professor

Ali Mostafavi, Co-Major Professor

Date of Defense: November 10, 2016

The dissertation of Mostafa Batouli is approved.

Interim Dean Ranu Jung College of Engineering and Computing

Andrés G. Gil

Vice President for Research and Economic Development And Dean of the University Graduate School

Florida International University, 2017 
ABSTRACT OF THE DISSERTATION

\title{
EXPLORATORY ASSESSMENT OF ROADWAY INFRASTRUCTURE ADAPTATION \\ TO THE IMPACTS OF SEA-LEVEL RISE
}

\author{
by \\ Mostafa Batouli \\ Florida International University, 2017 \\ Miami, Florida \\ Professor Ali Mostafavi, Co-Major Professor \\ Professor Arindam G. Chowdhury, Co-Major Professor
}

Transportation agencies in coastal urban areas face a significant challenge to enhance the long-term resilience of their networks to flooding and storm surge events exacerbated by sea level rise. The problem of sea-level rise adaptation is characterized by deep uncertainty that makes it complex to assess the value of adaptation investments. To enable informed adaptation decisions, the present study created a dynamic stochastic modeling framework based on the theoretical underpinnings of complex adaptive systems that integrates: (i) stochastic simulation of sea-level rise stressors based on the data obtained from downscaled climate studies pertaining to future projections of sea-level and precipitation; (ii) dynamic modeling of roadway conditions by considering regular decay of roadways, as well as structural damages caused by storm surge events; and (iii) a decision-theoretic modeling of agency infrastructure management and adaptation processes based on cognitive psychology, bounded rationality, and regret theories. In this framework, resilience is examined based on trend changes in the network performance measures (e.g., life cycle costs and performance). The created framework and model were tested in a case study 
related to the road network of the city of Miami-Beach, which global assessments rank first among the world's urban areas most exposed to sea-level rise risks. The results indicated that: (i) SLR Adaptation investment and life cycle costs of roadway infrastructure are negatively correlated. In addition, it was shown that the sensitivity of network's life cycle cost to actual sea-level rise scenario decreases when adaptation investment increases. These finding emphasize the importance of proactive improvement of the network resilience to alleviate the long-term costs of sea-level rise. (ii) When funding is sufficient for all required adaptation actions, mid-term adaptation planning yields lower life cycle cost. When funding is insufficient, aggregated investment in long-term adaptation planning intervals yields lower network LCC. These findings imply that different adaptation planning approaches should be taken for different levels of adaptation investment. (iii) The agency's perception of SLR and risk attitude do not have significant effect on life cycle cost of roadway networks. Hence, implementation of adaptation action based on any perception of sea-level rise and risk attitude can significantly reduce the life cycle costs of roadway networks under the impacts of SLR. (iv) The devised performance target has negative correlation with life cycle cost of a roadway network affected by SLR impacts. Therefore, compromising the network performance condition will never result in lower life cycle costs. 


\section{TABLE OF CONTENTS}

CONTENT

PAGE

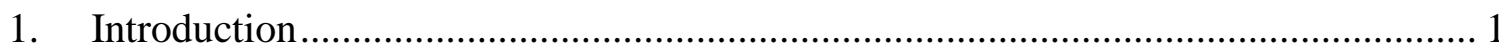

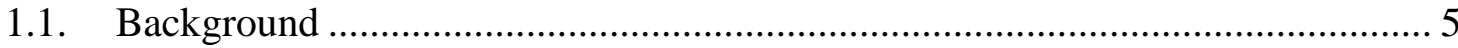

1.1.1. Sea-level Rise and Roadway Infrastructure: State of Knowledge ……........ 5

1.2. Knowledge Gap ...................................................................................... 10

1.2.1. Lack of consideration of the evolving conditions of networks .................... 10

1.2.2. Lack of understanding of adaptive behaviors of decision makers ............... 11

1.2.3. Lack of consideration of the interconnections between assets ................... 12

1.3. Problem Statement …………….................................................................. 12

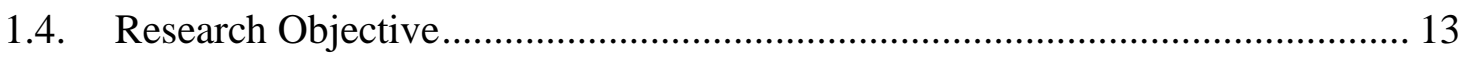

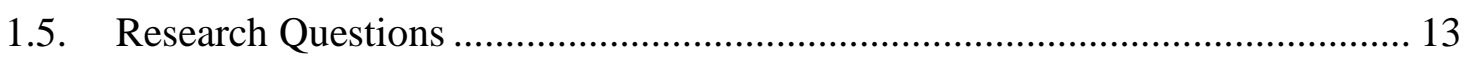

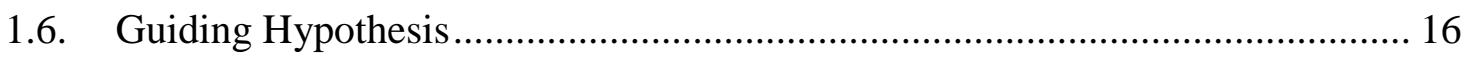

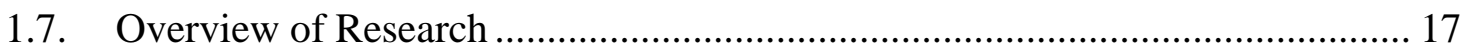

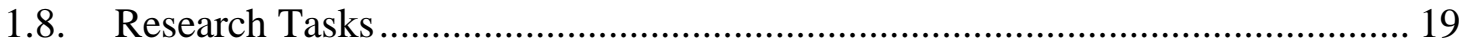

1.9. Organization of the Dissertation Document ..................................................... 20

2. A Simulation Framework For Network Level Cost Analysis in Infrastructure

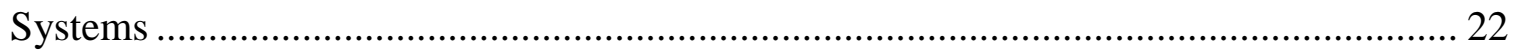

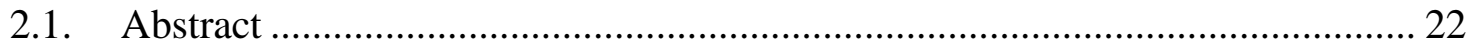

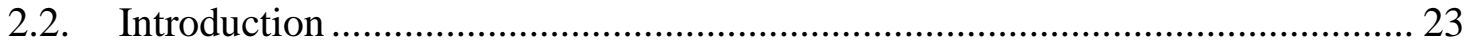

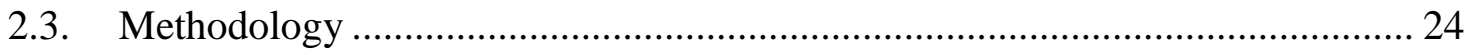

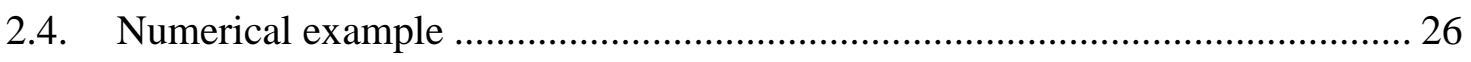

2.4.1. Simulating agency/asset/user interactions ............................................... 27

2.4.2. Calculation of asset-level life cycle costs ................................................. 29

2.4.3. Annuitizing costs related to every life cycle of each asset ......................... 30

2.4.4. Aggregation of cost annuities to acquire network-level cost...................... 30

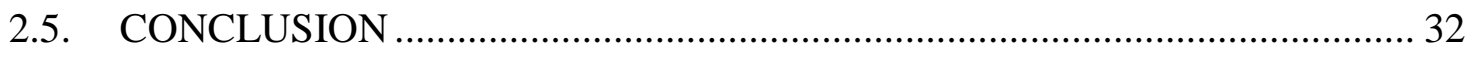

3. Service and Performance Adjusted Life Cycle Assessment: A Methodology for Dynamic Assessment of Environmental Impacts in Infrastructure Systems .................... 33

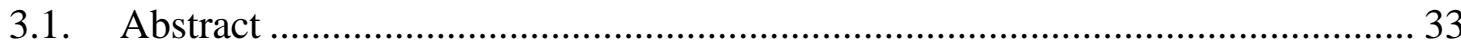

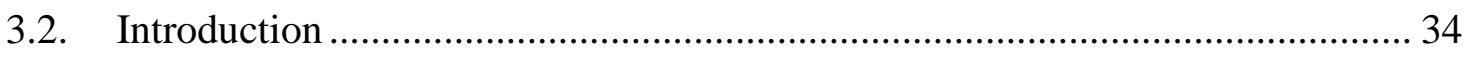


3.3. Limitations of LCA for Environmental Assessment of Infrastructure Systems 36

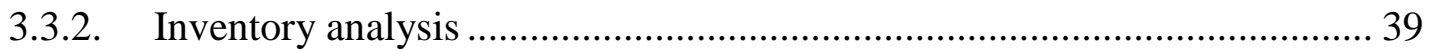

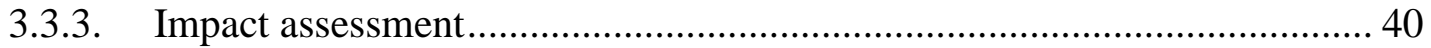

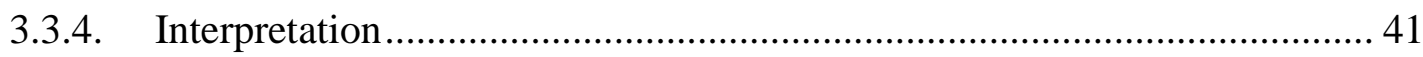

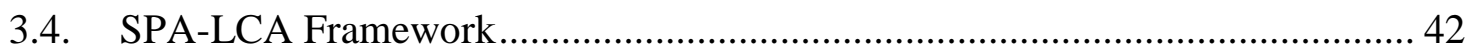

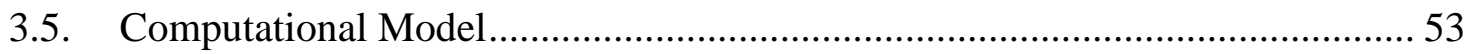

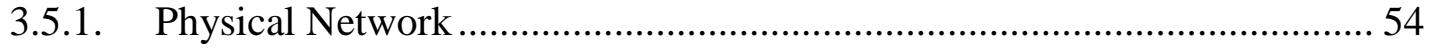

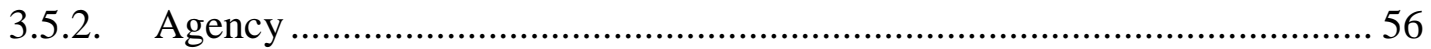

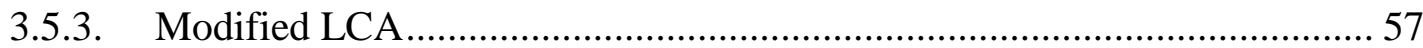

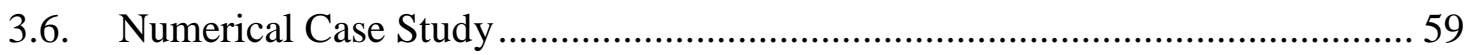

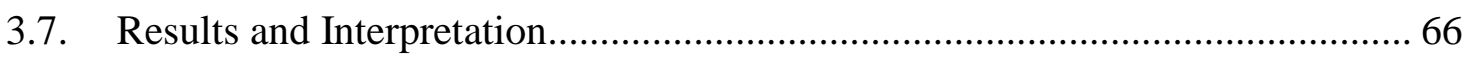

3.7.1. Impact of demand growth on sustainability performance of the network .. 66

3.7.2. Impact of M\&R budget on sustainability of the network ........................ 67

3.7.3. Impact of timing of decisions on sustainability of the network .................. 69

3.7.4. Impact of Performance Condition on sustainability of the network .......... 71

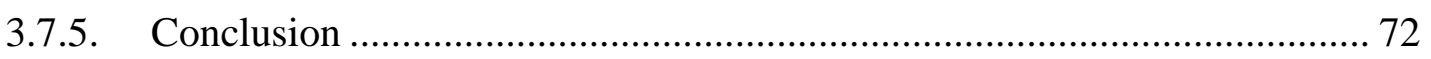

4. Assessment of Sea-Level Rise Adaptation in Coastal Infrastructure Systems:

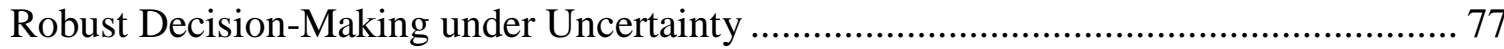

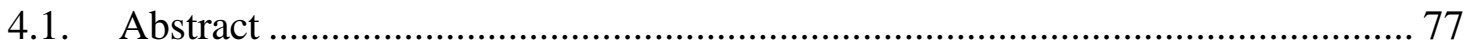

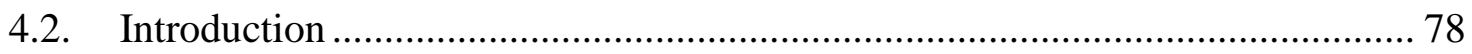

4.3. Infrastructure Adaptation Analysis Framework ............................................. 79

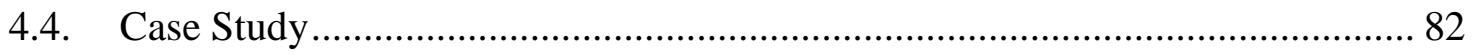

4.4.1. Identifying Sea-Level Rise Scenarios .................................................... 84

4.4.2. Selecting Adaptation Alternatives ............................................................. 84

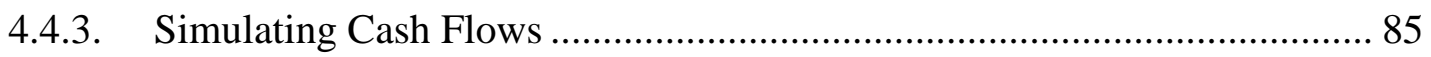

4.4.4. Calculating the Present Value of the Adaptation Investment .................... 87

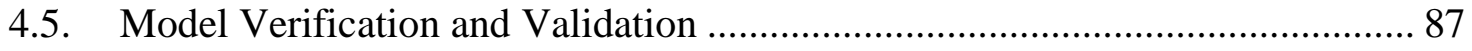

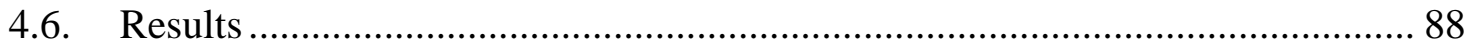

4.6.1. Evaluating the Effectiveness of Adaptation Investments ......................... 88

4.6.2. Prioritizing and Timing of Adaptation Implementation ........................... 89

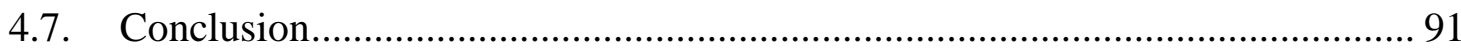


5. A Complex Adaptive Modeling of Road Infrastructure Resilience to Sea-Level Rise Impacts in Coastal Urban Areas .......................................................................... 93

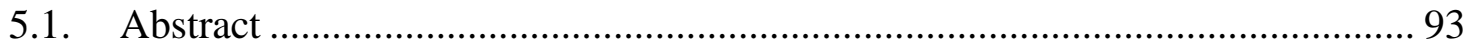

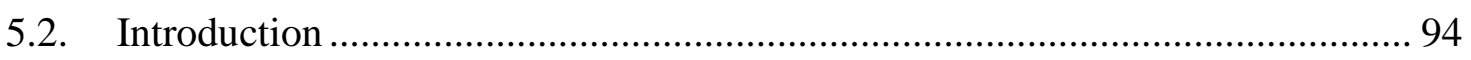

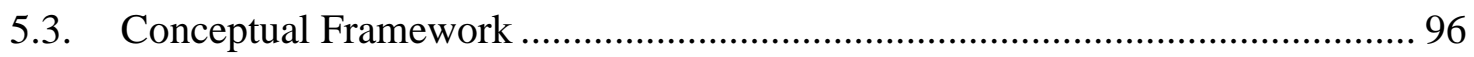

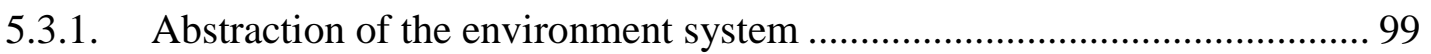

5.3.2. Abstraction of the physical network system ........................................ 100

5.3.3. Abstraction of the agency system ..................................................... 102

5.4. Computational Model............................................................................. 107

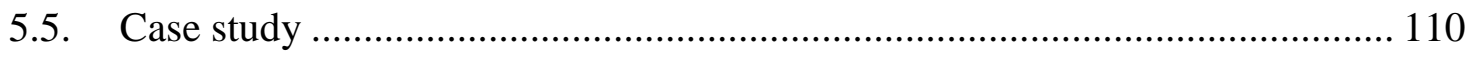

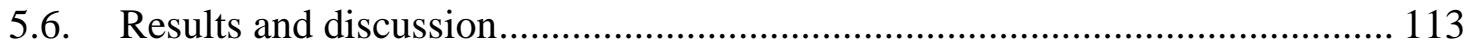

5.6.1. Impacts of the size of adaptation budget.............................................. 113

5.6.2. Impacts of adaptation planning approach .......................................... 114

5.6.3. Impacts of decision making behaviors.............................................. 117

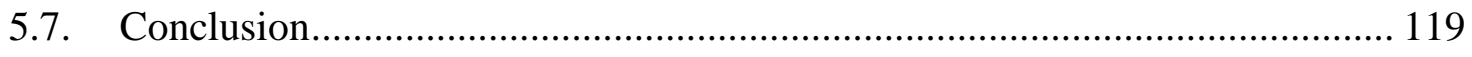

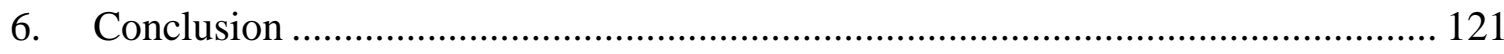

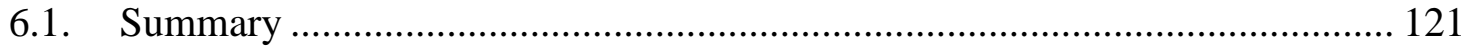

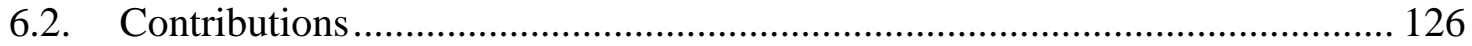

6.2.1. Contributions to the body of knowledge ............................................. 126

6.2.2. Contributions to the body of practice.................................................. 127

6.2.3. Limitations and future work.............................................................. 128

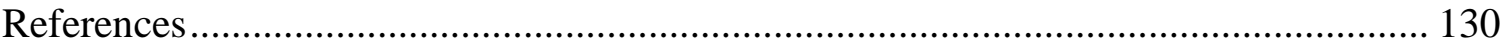

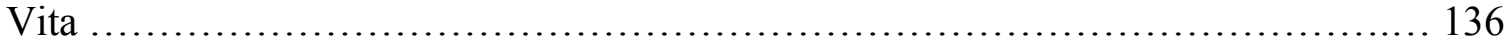




\section{LIST OF TABLES}

TABLE

PAGE

Table 1-1: NIPP framework for assessing infrastructure risks and corresponding streams of research related to SLR adaptation of roadway infrastructure 7

Table 1-2: Overview of the dissertation document .................................................... 21

Table 2-1. Characteristics of the Case Network ........................................................ 27

Table 3-1: Limitations of LCA for assessing environmental impacts of infrastructure

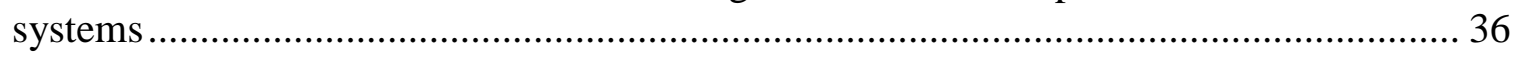

Table 3-2: The proposed service-based accounting is analogues to accrual accounting. . 49

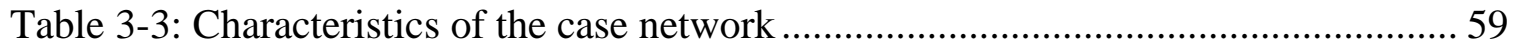

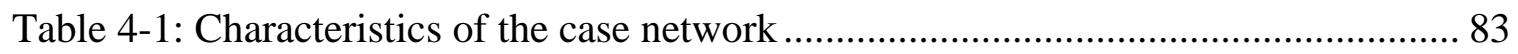

Table 5-1: Expected cost of alternative adaptation actions under different precipitation

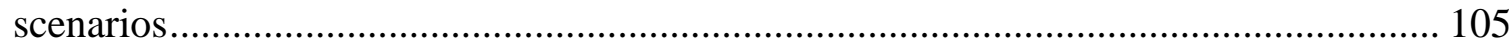

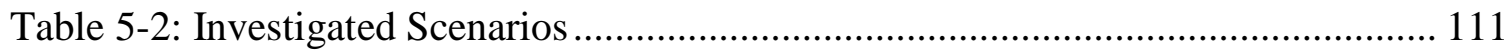

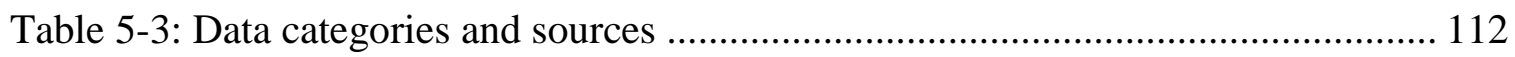

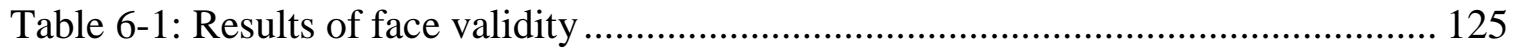




\section{LIST OF FIGURES}

FIGURE

PAGE

Figure 1-1:Global Thermosteric Sea-Level since Mid-Twentieth................................. 2

Figure 1-2: Sea-level rise projections by 2100 (Parris et al. 2012b) .............................. 2

Figure 1-3: Loss of drainage capacity of roads due to SLR ....................................... 4

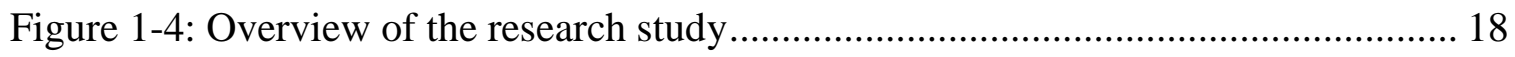

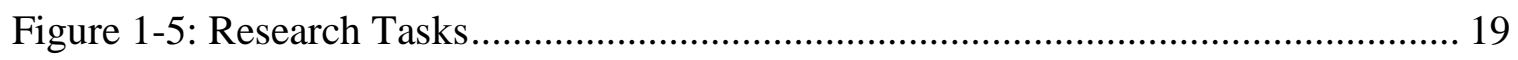

Figure 2-1. Discrepancy between service lives of individual assets and continuous

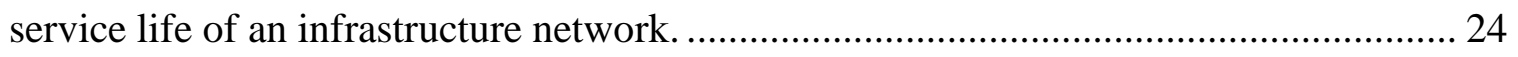

Figure 2-2. The proposed framework for calculating network-level costs................... 26

Figure 2-3. Simulated performance condition of pavement assets. ............................. 29

Figure 2-4: Impacts of availability of M\&R funding on the network........................... 32

Figure 3-1: Framework for Service and Performance Adjusted Life Cycle Assessment

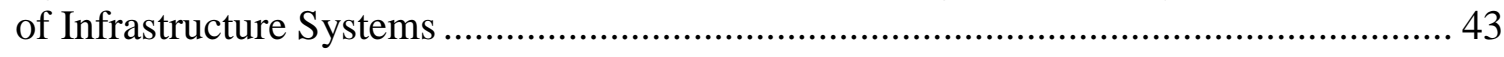

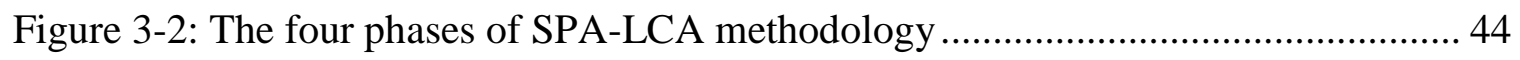

Figure 3-3: The two steps of SPA-LCA for addressing limitations of goal and scope

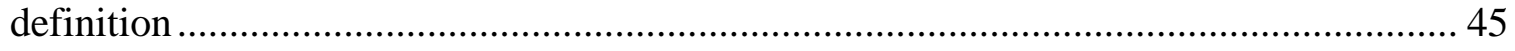

Figure 3-4: The Life Cycle Inventory Analysis phases of SPA-LCA methodology ........ 48

Figure 3-5: From simulated environmental events to dynamic environmental impacts

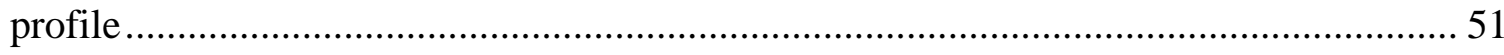

Figure 3-6: Aggregation of impacts into environmental profile of the network.............. 52

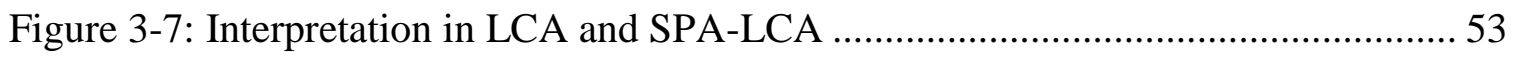

Figure 3-8: Class diagram of the simulation model................................................. 54

Figure 3-9: Action chart to model the condition based maintenance behavior of the agency 
Figure 3-10: Global Warming Potential of the Network under Different Demand

Scenarios

Figure 3-11: Global warming potential and PSI of the network under different budget scenarios 68

Figure 3-12: Impact of M\&R budget on environmental performance of the network under different demand scenarios

Figure 3-13: Reduction in GWP by increasing M\&R budget in different years of analysis. 70

Figure 3-14: Changes in network performance over the analysis horizon 71

Figure 3-15: Relationship between network performance and global warming potential 72 Figure 4-1: Transformation of CIS network under the impacts of sea level rise. 80

Figure 4-2: Simulation framework for calculating the value of adaptation..................... 82

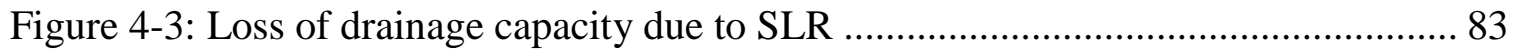

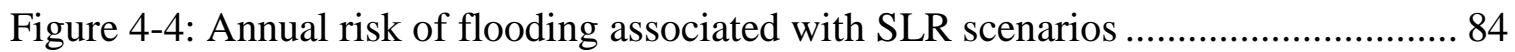

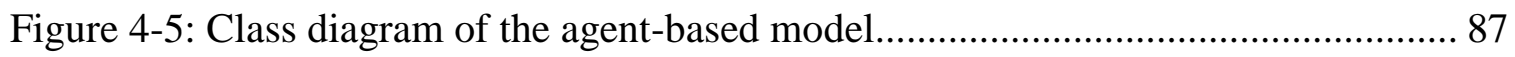

Figure 4-6: The impact of adaptation investment on network cost ............................ 89

Figure 4-7: Present value of the adaptation investment............................................ 91

Figure 5-1: Different types of environmental stressors and reaction of physical network

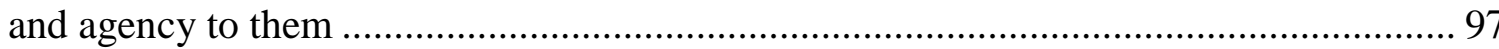

Figure 5-2: The System of Systems Framework for Capturing the Long-Term

Transformation of Infrastructure Systems under Sea Level Rise ............................... 98

Figure 5-3: The decision making processes of the agency ...................................... 103

Figure 5-4: Class diagram of the simulation model.............................................. 108

Figure 5-5:Sequence diagram of the simulation Model............................................. 109

Figure 5-6: Components of the computational model ............................................. 110

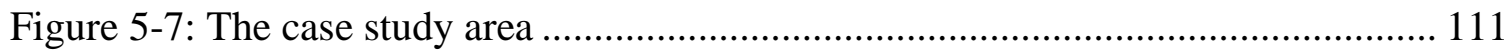


Figure 5-8: Impact of adaptation budget on life cycle cost of the network

Figure 5-9: Life cycle cost of the network with adaptation equal or more than $\$ 75$ million.....

Figure 5-10: Life cycle cost of the network with adaptation equal or less than $\$ 25$ million 116

Figure 5-11: The impact of SLR perception on life cycle costs of the network 118

Figure 5-12: Impact of risk attitude on life cycle cost of the network 118

Figure 5-13: Impact of performance target. 119

Figure 6-1: Verification and validation of the research components 124 


\section{INTRODUCTION}

There is clear scientific evidence that sea level is rising due to melting of glaciers and thermal expansion of oceans caused by global warming (Council, Southeast Florida Regional Planning 2013). The fifth assessment report of Intergovernmental Panel on Sealevel rise (IPCC) reviewed several published studies of historic tide gauge and satellite radar altimeter records and concluded that despite some significant seasonal and decadal fluctuations there has been an unequivocal upward trend in average global sea levels (Figure 1.1) (Stocker et al. 2013). In fact, global sea level has risen at an average rate of $1.7 \mathrm{~mm}$ per year since 1901(Rhein et al. 2013). The extent of sea-level rise (SLR) varies in different parts of the world. For example, sea-level has been rising faster along the Atlantic and Gulf Coasts of U.S. compared to the pacific coasts (Gallivan et al. 2009). However, a study of thermal expansion of oceans has shown that not only sea-level is rising all around the world but also the increasing trend of sea-level rise (SLR) has accelerated globally since 1970 (Figure 1.1) (Domingues et al. 2008). While the mechanism and the causes of SLR are still hotly debated, overwhelming consensus exists among the scientific community that the upward trend of sea-levels will continue in the $21^{\text {st }}$ century (Church et al. 2013). In addition, there is a great deal of uncertainty about the extent of future SLR. For example, the fifth assessment report of IPCC suggests that a range of 42-98 cm SLR would be likely by 2100 (Church et al. 2013) while the projections made by the National oceanic and atmospheric administration (NOAA) supports a 0.2-2 m sea-level rise by 2100 (Figure 1.2). 


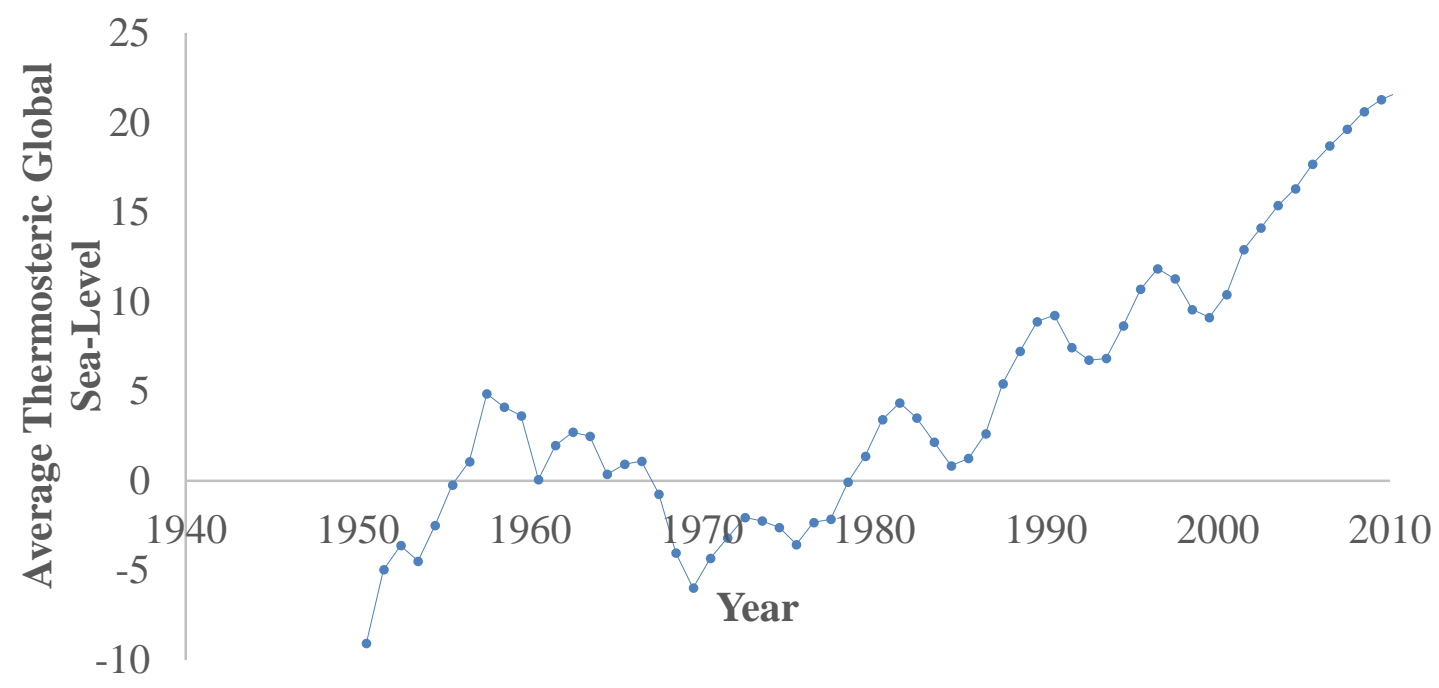

Figure 1-1:Global Thermosteric Sea-Level since Mid-Twentieth (Domingues et al. 2008).

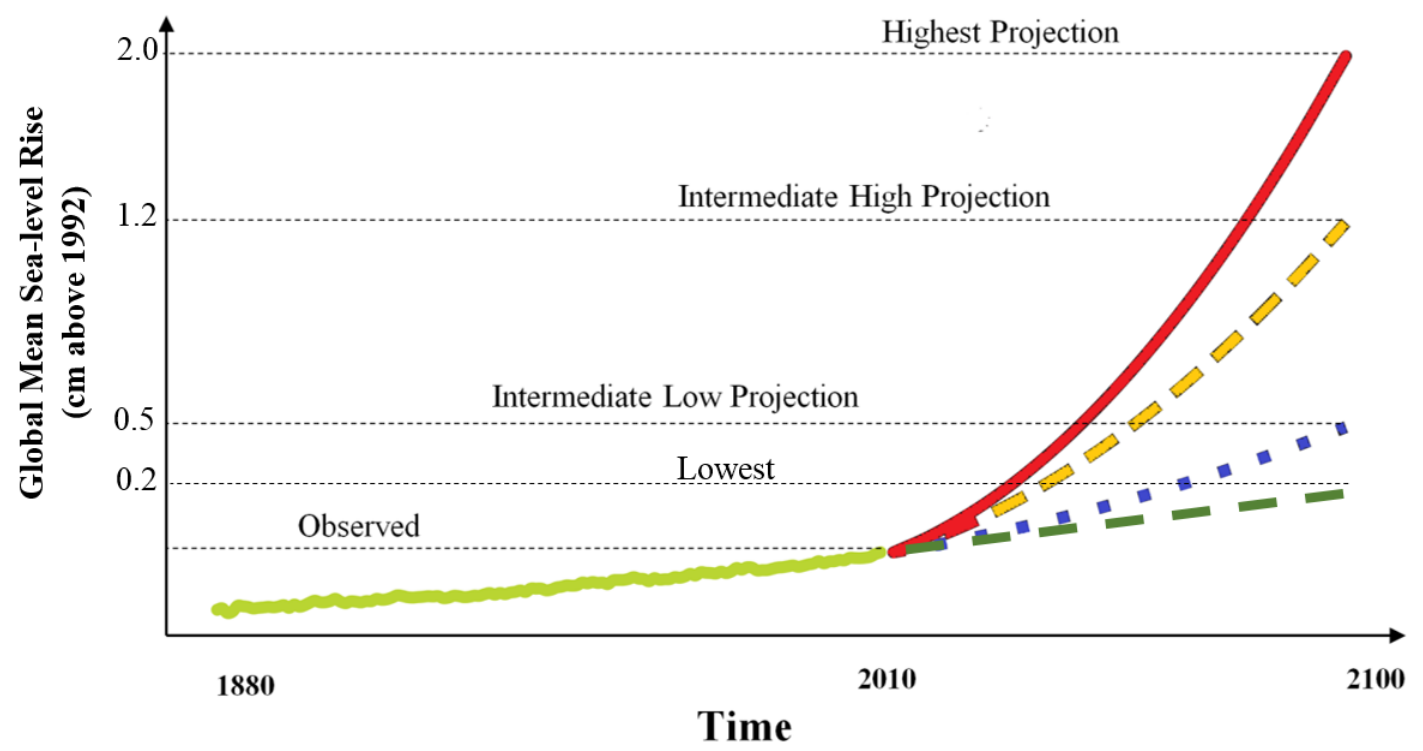

Figure 1-2: Sea-level rise projections by 2100 (Parris et al. 2012b)

Despite uncertainty in its magnitude, sea-level rise is recognized as a major threat to densely populated communities in low-lying coastal areas. For example, with $39 \%$ of U.S. population living in 452 counties located along Atlantic and Pacific oceans and the Gulf of Mexico, about 3\% of the nation's population are at direct risk of flooding hazard 
induced by sea-level rise (Crowell et al. 2010; NOAA 2015). In particular, sea-level rise adversely affects the functionality and performance of critical infrastructure on which societies rely for economic and social development.

One of the infrastructure systems which is significantly affected by the impacts of sea-level rise is roadway infrastructure system. For example, in Southeast Florida alone about 900 miles of roadway are at risk of permanent inundation (Compact, Southeast Florida Regional Climate Change 2011) and even a wider range of roads will be affected by other impacts of SLR (Li et al. 2011). SLR not only reduces the drainage capacity of the road assets, but also increases the risk of storm surge on low lying roads which may cause temporary closure or permanent failure of the roads (Kleinosky et al. 2007). Most significantly SLR increases the risk of flood damage to critical roads in coastal regions (Karl et al. 2009). Figure 1.3 shows how sea-level rise increases the likelihood of flood damage in coastal roads. Sea-level rise elevates water table in low-lying coastal areas. The increased elevation of water table leaves less room for draining excess storm water from the surface layer of the roadway assets. The loss of drainage capacity may lead to saturation of the base layer during heavy precipitation or storm surge events, and thus, cause damage to structural strength of roads (Berry et al. 2012). In low lying coastal lands the ground water may breakout during the high tide periods and create seasonal flooding and, in extreme cases, can permanently inundate coastal roads (Roshani et al. 2013). 


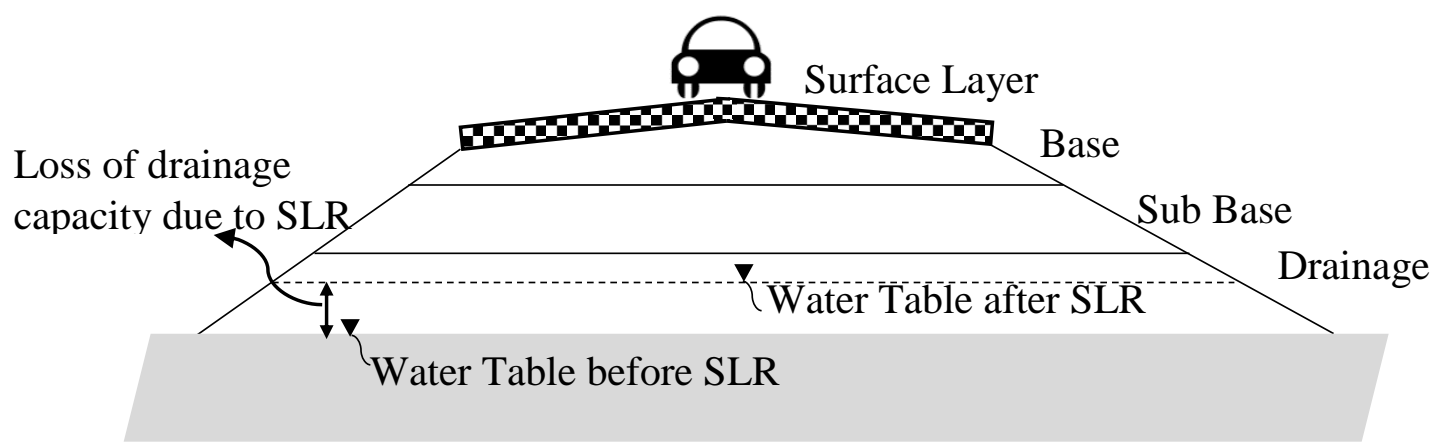

Figure 1-3: Loss of drainage capacity of roads due to SLR

The degradation and failure of roadway infrastructure under the impacts of sealevel rise creates socio-economic and environmental problems in several ways. First, intrusion of saline water into the base and subbase layers of roadways can reduce the useful life of the road's pavements by as much as four times (Roshani et al. 2013); hence increasing the need for more frequent reconstruction of the roads. Second, sea-level rise is expected to increase the frequency and intensity of extreme events such as flooding and storm surges of the roads. A study has shown that a one-meter sea level rise will triple the flooding damage to the roads in Atlantic coast of U.S. (Koetse and Rietveld 2009). In addition to contributing to accelerated damage of the pavements, flooding events lead to disruption of the traffic on roads. The traffic disruption causes social and economic costs in terms of lost time due to taking detours as well as lost work-days, lost sales, or lost production which ultimately create dissatisfaction of the general public from the roadway service (Suarez et al. 2005). Third, the pavement condition has strong correlation with increased fuel consumption of travelling vehicles creating both economic and environmental problems (Zaabar and Chatti 2010). 


\subsection{BACKGROUND}

Over the past few years several research studies have been done on assessing the impacts of sea-level rise on roadway infrastructure. This section provides a brief overview of the literature and discusses the limitations of the existing knowledge for better understanding sea-level rise adaptation and impacts as pertained to roadway infrastructure systems.

\subsubsection{Sea-level Rise and Roadway Infrastructure: State of Knowledge}

The challenge of confronting the impacts of sea-level rise on roadway infrastructure has been developed in the existing body of knowledge around the two potential actions that human society can take: mitigation and adaptation. Mitigation involves any action that slows down sea-level rise and through which reduces the risk of sea-level rise. Since the main driver of sea-level rise is increased concentration of greenhouse gases in the earth's atmosphere, IPCC defines mitigation as: "An anthropogenic intervention to reduce the sources or enhance the sinks of greenhouse gases" (IPCC 2014). On the other hand, adaptation is defined as "The process of adjustment to actual or expected climate and its effects" (IPCC 2014). Hence, adaptation is a means to reduce the likelihood or magnitude of potential impacts rather than reducing the risk itself.

The mitigation research pertaining to reduction of emissions related to service life of roadway infrastructure has been widely studied in the literature under a research field known as sustainable or green roadway infrastructure (Demuzere et al. 2014). Assessing the global warming potential of pavement infrastructure (Santero and Horvath 2009a; Noshadravan et al. 2013; Labi and Sinha 2005; Huang et al. 2009) and investigating 
methods to reduce the carbon footprint of roadway drainage systems (Friedrich et al. 2009; Lim and Park 2008) are examples of this stream of research. The studies related to the impacts of changing design or material type on the energy consumption and global warming potential of infrastructures [e.g.(Calkins 2008; Muench 2010; Zapata and Gambatese 2005)] are other examples of the mitigation research.

Despite the crucial importance of mitigation for reducing the long-term risk and hazards of sea-level rise to human society, sea-level rise adaptation is a matter of greater urgency for management of roadway networks in coastal regions. First because even if we stop emitting today, the greenhouse gases that have already accumulated in the atmosphere will continue to cause global warming for an extended period of time. Second, the impacts of sea-level rise directly threaten the functionality and performance of roadway networks (Bhamidipati 2014a).

Effective adaptation to sea-level rise requires a good understanding of the risk of SLR hazards and their potential impacts on roadway infrastructure. National Infrastructure Protection Plan (Chertoff 2009), and the Risk Analysis and Management for Critical Asset Protection framework suggest that the risk of an external disturbance to infrastructure assets could be calculated from Equation 1:

Risk $=($ Threat $) \times($ Vulnerability $) \times($ Consequence $)$ Or $\mathrm{R}=\mathrm{T} \times \mathrm{V} \times \mathrm{C} \quad$ Equation (1)

Relying on this definition, the existing approaches for assessing the impacts of climate hazards such as SLR-induced flooding on infrastructure systems is developed in four distinctive, though related, streams of research as shown in Table XX (Labi 2014). The first three streams of research are respectively, focused on assessing probability of threat 
occurrence, evaluating level of exposure of infrastructure networks to the threats, and Assessing Level of Facility Structural and/or Functional Vulnerability of the networks. The last stream, uses combination of the first three streams to identify an overall level of risk to infrastructure systems. These research streams are discussed in detail in the remainder of this section.

Table 1-1: NIPP framework for assessing infrastructure risks and corresponding streams of research related to SLR adaptation of roadway infrastructure

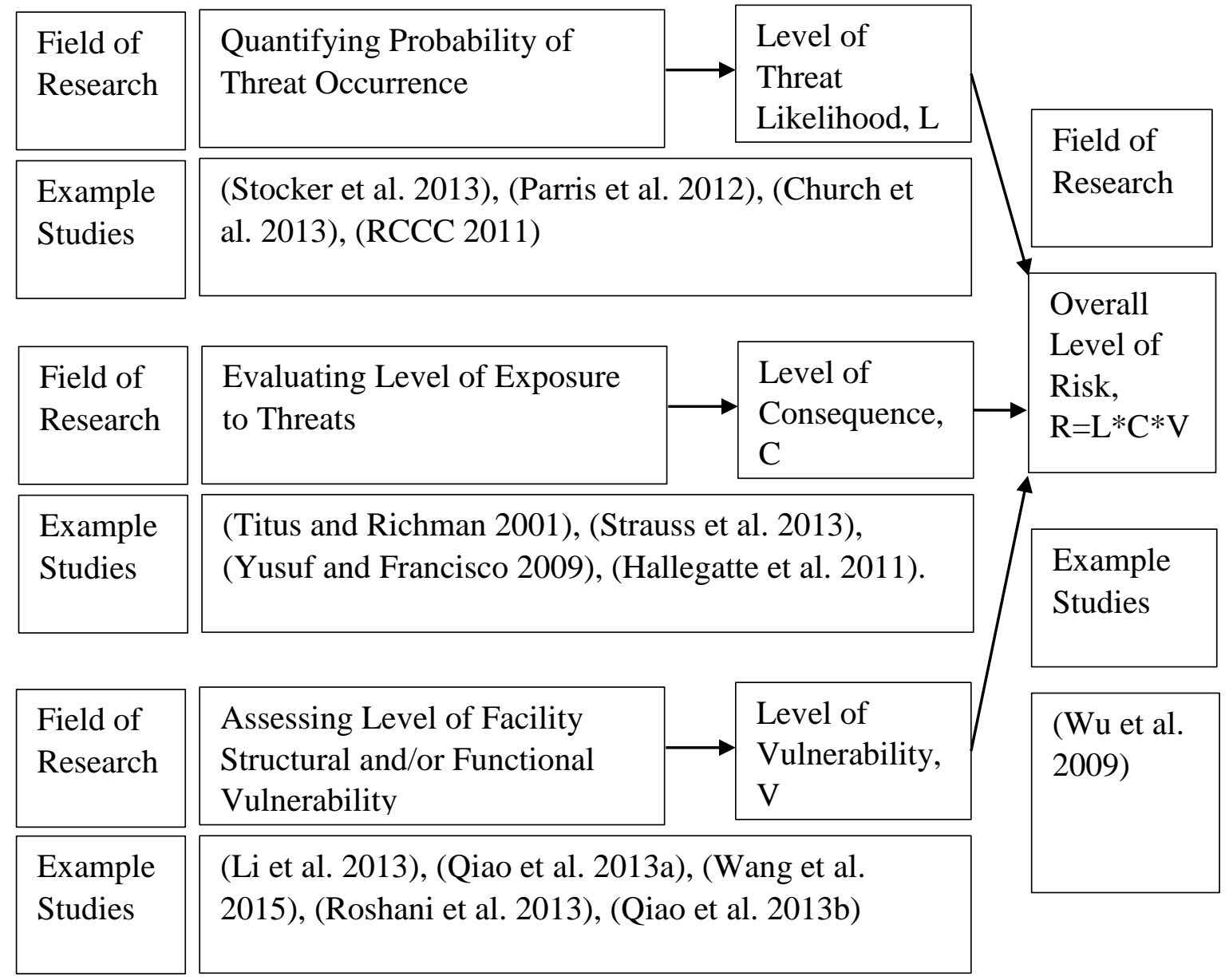


(i) The first stream of research focuses on quantifying probability of SLR threat occurrence. Long term changes in the SLR threats depend on various anthropogenic and natural forces that could alter the climate over the coming decades (Stocker et al. 2013). Therefore, a great deal of uncertainty exists in projections of the future state of the environment (Church et al. 2013). To be able to cope with this level of uncertainty, it is advisable to consider a number of alternative scenarios for different trajectories of climate change (Stocker et al. 2013). Several down-scaled climate studies have projected global and local trends of sea-level rise based on different scenarios of climate change. Among these studies, the projections of slow, moderate, and fast sea-level rise suggested by fifth assessment report of intergovernmental panel for climate change (Stocker et al. 2013), National Oceanic and Atmospheric Administration, and US Army Corps of Engineers (Parris et al. 2012a), and Southeast Florida Regional Compact RCCC (2011) are among the most widely referred studies.

(ii) The second stream of research focuses on evaluating level of exposure of roadway networks to SLR threats. The common approach for assessing exposure is to establish maps of lands below threshold elevations associated with different sea-level rise scenarios. These maps are then used to identify critical infrastructure at risk of inundation or storm surge flooding driven by each sea-level rise scenario. This approach has been used to pinpoint the infrastructure at risk of sea-level rise damage all around the world including U.S. Atlantic and Gulf coasts (Titus and Richman 2001), Florida (Strauss et al. 
2013), Southeast Asia (Yusuf and Francisco 2009), and Europe (Hallegatte et al. 2011).

(iii) The third stream of research focuses on Structural and/or Functional Vulnerability of roadway networks. Vulnerability is defined by IPCC as "the degree to which a system is susceptible to, and unable to cope with, adverse effects of sea-level rise, including climate variability and extremes" (Parry et al., 2007). The common approach for assessing sensitivity of roadway networks to the impacts of SLR is to consider climate related stressors as input variables into the existing asset performance measures in order to estimate the performance condition and functionality of roadway assets under the impacts of sea-level rise. For example, climatic parameters such as air temperature, precipitation, elevation and water table depth have been integrated into mechanistic-empirical models for quantifying pavement performance conditions under the impacts of sea-level rise ( $\mathrm{Li}$ et al. 2013). After climatic parameters are brought into performance models, such models are used to quantify the impact of different sea-level rise scenarios on the deterioration and functionality of infrastructure assets [e.g. (Qiao et al. 2013a; Wang et al. 2015; Roshani et al. 2013; Qiao et al. 2013b)].

(iv) Finally, a few studies considered an integration of the threat likelihood, consequences, and vulnerability to identify an overall risk of SLR for roadway networks. An example of this stream is the study by (Wu et al. 2009) in which two different scenarios of sea-level rise are considered and using the current conditions of the roadway network in Upper and Mid-Atlantic States of U.S. it 
is concluded that by 2100 about $1000 \mathrm{~km}$ of roads will be permanently damaged due to inundating by elevated water levels. Surprisingly fewer number of studies have conducted an integrated assessment of the impacts of SLR on infrastructure systems (Suarez et al. 2005).

\subsection{Knowledge Gap}

A review of the literature pertaining to the impacts of sea-level rise on roadway networks shows three major gaps in the existing knowledge. First, the existing approaches assess the risks of sea-level rise assuming that the vulnerability is a static state of the network. However, in fact, vulnerability is a dynamic trait of infrastructure networks that evolves over time due to the changes in the structural and functional conditions of infrastructure assets (Sahin and Mohamed 2013). Second, the existing approaches do not consider the adaptive behaviors of decision makers in response to SLR threats (Tol et al. 2008). Third, the existing approaches assess the impacts of sea-level rise on isolated assets. Nonetheless, roadway infrastructure systems are interconnected networks in which damage to part of the network will affect the performance of the entire network (Bhamidipati 2014a). Each of these three gaps is discussed in further detail in the rest of this section.

\subsubsection{Lack of consideration of the evolving conditions of networks}

The first limitation of existing approaches for identification of long-term impacts of sealevel rise on roadway infrastructure is that they consider vulnerability as a static state of assets in reference to a target year and sea-level rise scenario. However, in reality, vulnerability is a dynamic process which is affected by the dynamic interactions between the physical conditions of asset and uncertain climatic perturbations (Sahin and Mohamed 
2013a). The static assessment of vulnerability causes a mismatch between assessed values of threat and vulnerability. For example, the existing knowledge provides insight about the likelihood of a $2 \mathrm{ft}$ flood in a certain area (threat) and it also determines what would be the likely impacts of a $2 \mathrm{ft}$. flooding on a pavement with known structural and performance condition (consequences). However, due to uncertainty in the timing of flood events and the performance condition of assets at any exact time in future, the exiting knowledge is unable to match the long-term vulnerability of assets to the assessed threat and known consequences. Hence, while the existing approaches are well suited for disaster preparedness and short-term assessment of SLR impacts, they provide little insight into the long-term impacts of SLR on roadway networks.

\subsubsection{Lack of understanding of adaptive behaviors of decision makers}

The existing literature pertaining to the impacts of sea-level rise on roadway networks has been focused on the threat to the physical networks. A typical example of the existing research (e.g., Rinaldi et al. 2001, Haimes et al. 2005; O'Rourke 2007; Reed et al. 2009; Zhang and Peeta 2011) is investigating the degradation and failure of the physical networks under extreme events such as floods and hurricanes induced by sea-level rise. Study of the possible damage to the physical networks provides a valuable insight into the vulnerability of infrastructure systems. However, the long-term impacts of sea-level rise on roadway infrastructure also depend on the adaptive decision making processes of institutional actors (e.g., city managers, utility infrastructure agencies, regional planners, etc.) who design, manage, and operate these systems. Decision processes related to SLR

adaptation are complex and affected by various factors such as the existing conditions of 
the networks (Adegar, 2010), past exposure to hazards (Nelson et. al., 2007; Wise et. al, 2014), institutional rules and priorities, and the personal and institutional beliefs and biases of decision makers (Grothmann and Patt, 2005; Measham et. al, 2011). The existing literature does not fully explore the decisions of institutional agencies whose actions affect roadway infrastructure resilience to the impacts of sea-level rise.

\subsubsection{Lack of consideration of the interconnections between assets}

The existing approaches for assessing the impacts of sea-level rise on roadway networks assess these impacts against the damage they make on individual assets. However, sea-level rise impacts affect networks of interconnected infrastructure rather than isolated assets. Hence, their impacts go far beyond the damage they make on individual assets. Thus, sea-level rise impacts in long-term cannot be predicted solely by the established deterioration profile of assets (Bhamidipati 2014b). For example, flood damage to a road network not only affects performance condition of assets, but also disturbs the normal maintenance and rehabilitation practice of the entire network. Understanding this type of impacts requires capturing the dynamic transformation of infrastructure networks under the impacts of sea-level rise. This information is missing in the existing body of knowledge.

\subsection{Problem Statement}

To moderate the potential impacts of sea-level rise on roadway infrastructure, planning and implementation of effective adaptation strategies is critically required. Evaluating the effectiveness of adaptation actions is critical to avoid maladaptation in infrastructure systems. Maladaptation is poor selection of adaptation actions such that the 
changes in the infrastructure systems become less and less effective as time goes until the infrastructure systems on which a society depends become dysfunctional. Maladaptation may occur due to failure to anticipate the true impacts of sea-level rise and take timely actions. On the other hand, making adaptation decisions is a complex task that requires substantial investments under significant uncertainty. Also, making adaptation decisions would require making trade-offs between the normal condition and sea-level rise requirements over the long-term. Hence, making robust adaptation decisions is contingent upon evaluation of the long-term transformation of roadway infrastructure systems under different adaptation strategies and sea-level rise scenarios. This important knowledge is missing in the existing body of knowledge.

\subsection{Research Objective}

The objective of the present research is to provide a better understanding of the evolution of roadway infrastructure systems under the impacts of sea-level rise to enable proactive adaptation to the potential impacts of SLR on long-term functionality and cost of roadway systems. In particular, this research contributes to the body of knowledge by developing the theoretical and methodological foundations needed for evaluating the longterm impacts of sea-level rise considering the interrelations among uncertain SLR stressors, evolving conditions of physical networks, and adaptive behaviors of decision makers.

\subsection{Research Questions}

This research seeks answers for the following three important questions related to adaptation of roadway infrastructure systems to the long-term impacts of sea-level rise: 
Question 1: What size of adaptation investment can minimize the life cycle costs of roadway infrastructure systems affected by the impacts of sea-level rise?

\section{Question 1 Explanation:}

"Adaptation means anticipating the adverse effects of sea-level rise and taking appropriate action to prevent or minimize the damage they can cause" (IPCC 2015). The adaptation actions usually include implementing different types of capital improvement projects. Hence, both sea-level rise and sea-level rise adaptation can impose significant cost to roadway infrastructure systems. On this account, (De Bruin et al. 2009) suggested that decision makers should seek an optimal balance between investments in adaptation actions and accepting potential future sea-level rise impacts. Therefore, the present study investigates the effects of different levels of adaptation investment on the long-term costs of roadway infrastructure systems.

Question 2: What adaptation planning approach (long-term or short-term planning) is more effective for dealing with the impacts of sea-level rise?

\section{Question 2 Explanation:}

Long-term planning for adaptation actions enables making single capital investment to mitigate SLR impacts for a long time. It also enables identification of the capital investment with highest return on investment (ROI) over a long-term (Hayes and Garvin 1982). However, due to the great deal of uncertainty associated with sea-level rise projections, long-term adaptation planning increases the Value at Risk (VAR) of the capital 
investment (Jorion 1999). An alternative adaptation planning approach is to make the adaptation investments for shorter period of time in which less uncertainty exists pertaining to the magnitude of future sea-level rise. With this approach the adaptation decision for further future will be made at the time when more updated information regarding the sealevel rise scenarios becomes available. This approach reduces the risk of the adaptation investment. However, it may ultimately lead to higher cost of adaptation investment. The answer to this question identifies which of these adaptation planning approaches provide higher value for a roadway network.

Question 3: What are the impacts of the behavioral traits of decision makers on the longterm consequences of adaptation decisions?

\section{Question 3 Explanation:}

While different factors contributing to the physical damage of SLR on roadway infrastructure are well studied, little is known about the adaptive decision making of institutional actors in response to SLR impacts. The International Panel on Climate Change (IPCC) has identified various decision-making behaviors that affect the response of institutional actors to climate change stressors (Kunreuther et. al 2014). Significantly, the decision making behaviors of institutional actors depend on their perception of SLR risk and their attitude towards the perceived risk. Risk perception is defined as the decision maker's subconscious interpretation of the world, based on organizational norms, experiences, and value systems. Conversely, risk attitude refers to the deliberate process of assessing a risk situation in a favorable or unfavorable way and to act accordingly (Rohrmann 2008). The present study investigates the effects of overestimation, or 
underestimation of future SLR (i.e. perception), as well as the risk seeking or risk averse attitude of decision makers on the life cycle costs of roadway networks affected by the impacts of SLR.

\subsection{Guiding Hypothesis}

This research aims to investigate three specific hypotheses corresponding to each of the research questions. The three hypothesis of the research are listed below:

Hypothesis 1: There is an optimal balance between investments in adaptation actions and accepting potential future sea-level rise impacts on roadway infrastructure systems.

Hypothesis 2: Life cycle cost of roadway networks threatened by the impacts of sea-level rise is sensitive to the adaptation planning approach (short-term vs. long-term planning).

Hypothesis 3: Life cycle cost of roadway networks threatened by the impacts of sea-level rise is sensitive to adaptation-related decision making behaviors including SLR-perception, risk attitude and performance target.

Hypothesis 3.1: Adaptation investment based on overestimation of future SLR can significantly increase life cycle cost of roadway infrastructure systems.

Hypothesis 3.2: Risk tolerance toward SLR adaptation can significantly affect life cycle costs of roadway infrastructure systems.

Hypothesis 3.3: There is a trade-off between the performance target and life cycle costs of a roadway system threatened by the impacts of SLR. 


\subsection{Overview of Research}

The present research essentially seeks to contribute to the body of knowledge by developing the theoretical and methodological constructs required for understanding the sea-level rise adaptation and impacts on roadway infrastructure systems. The key element to achieve the objectives of this research is a better understanding of the transformation of roadway infrastructure under the impacts of sea-level rise. To this end, the present research will adopt a system of systems framework, based on the theories of complex dynamic systems, to capture the dynamic transformation of roadway infrastructure under uncertain impacts of SLR and various adaptation strategies. For implementing the proposed system of systems framework, a simulation approach for theory development is adopted as the overarching methodology of the present research (Davis et al. 2007). Figure 1.4 shows an overview of the different components of the proposed research. The simulation methodology includes (i) stochastic models related to the uncertain impacts of sea-level rise to enable conducting scenario analysis pertaining to different sea-level rise and adaptation strategies. (ii) decision and behavioral models based on agent-based and dynamic mathematical simulation to capture the infrastructure-agency interactions; (iii) performance assessment models based on life cycle analysis (LCA), life cycle cost analysis (LCCA), and Present Serviceability Index to determine the environmental, economic, and social performance of roadway networks based on the outcomes of the behavioral and decision models; and (iv) Monte Carlo simulation to identify likely range of the outcomes under each scenario in order to enable testing the research hypotheses. 


\section{Research Objective}

Provide a better understanding of SLR adaptation and impacts on roadway infrastructure systems.

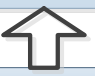

\section{Theoretical Constructs}

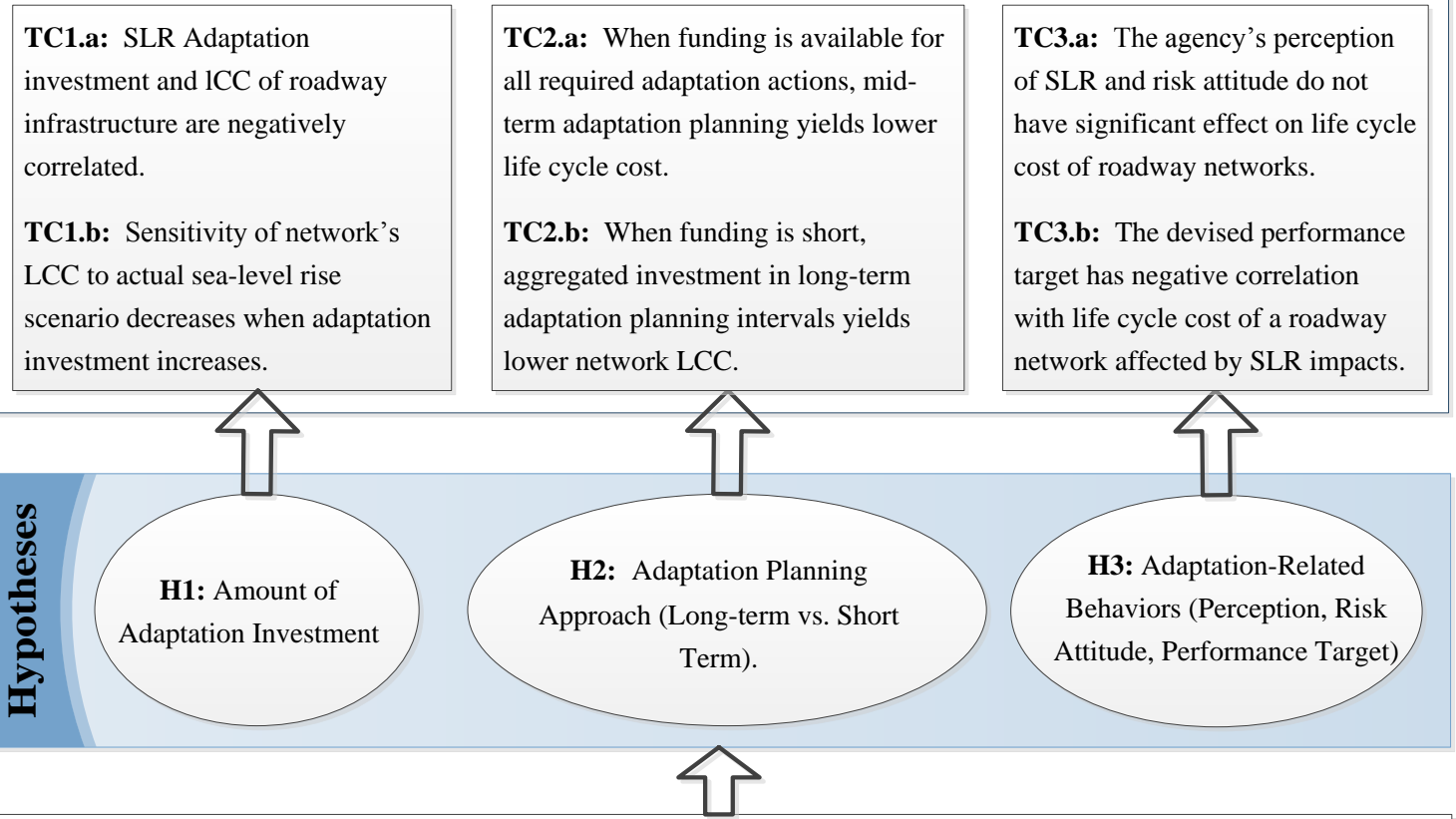

Classification and Regression Tree (CART) Analysis

\section{Simulation Experimentation}
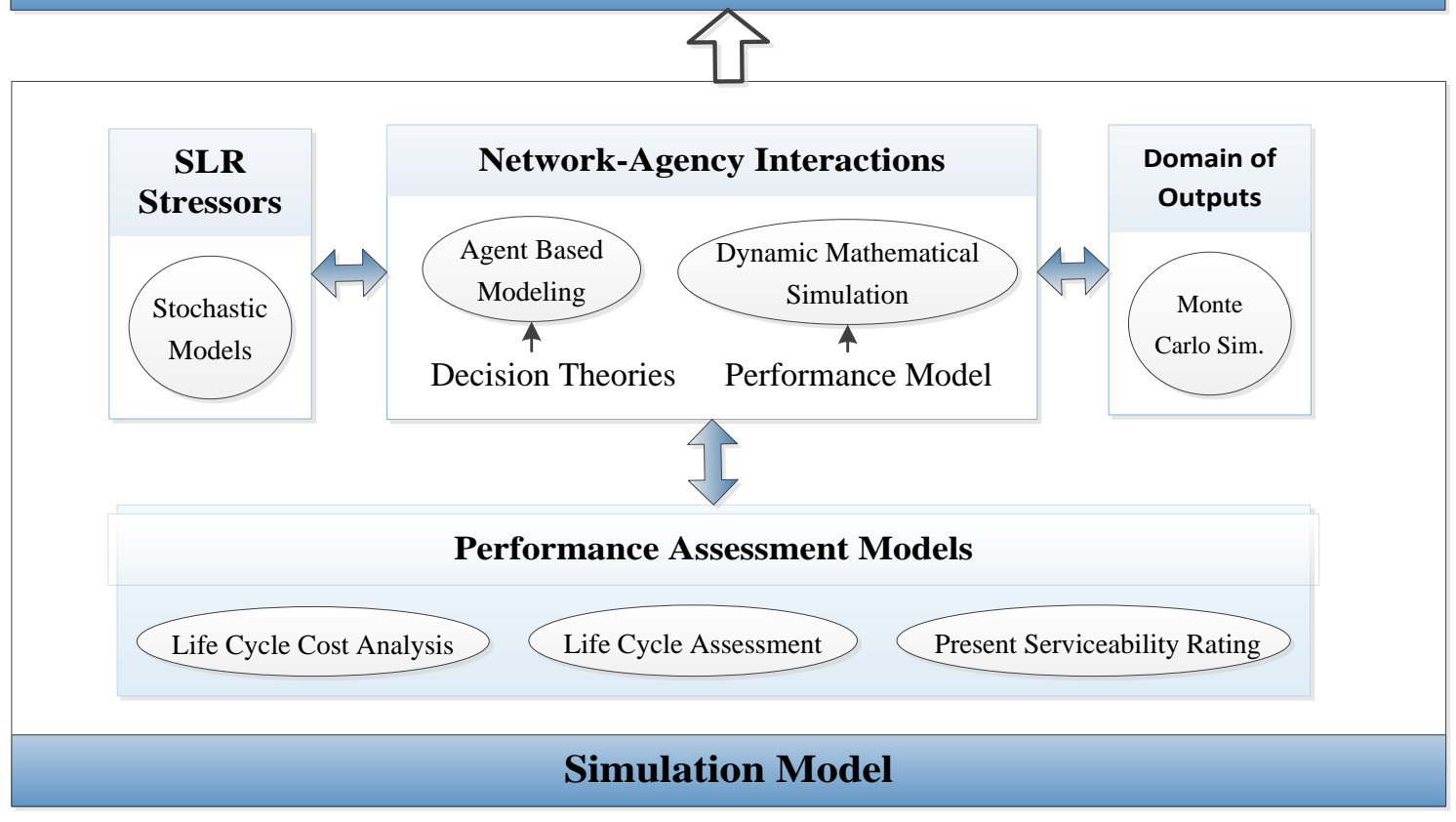

Figure 1-4: Overview of the research study 
The simulation model was used to conduct simulation experiments related to a number of exploratory variables including sea-level rise, perception, risk attitude, performance target, and adaptation planning interval. The outcomes of the simulation experimentations were analyzed using Classification and Regression Tree (CART) analysis to enable testing the research hypotheses and building theoretical constructs of this research.

\subsection{Research Tasks}

This study included six tasks as shown in Figure 1-5. First, the behaviors of the problem system were abstracted. Second, data related to a case study of a roadway network threatened by the impacts of SLR were collected. A sub set of the road network in the city of Miami Beach was selected for this study due to the significance of SLR impacts in the area. Third, a simulation model was created based on the abstracted system behaviors and data collected from the city of Miami Beach. Fourth, the data, conceptual framework, and the simulation model were validated using several validation and verification techniques. Fifth, simulation experimentation was conducted and the outcomes were analyzed using CART analysis. Finally, the research hypotheses were tested and the theoretical constructs of this research were built.

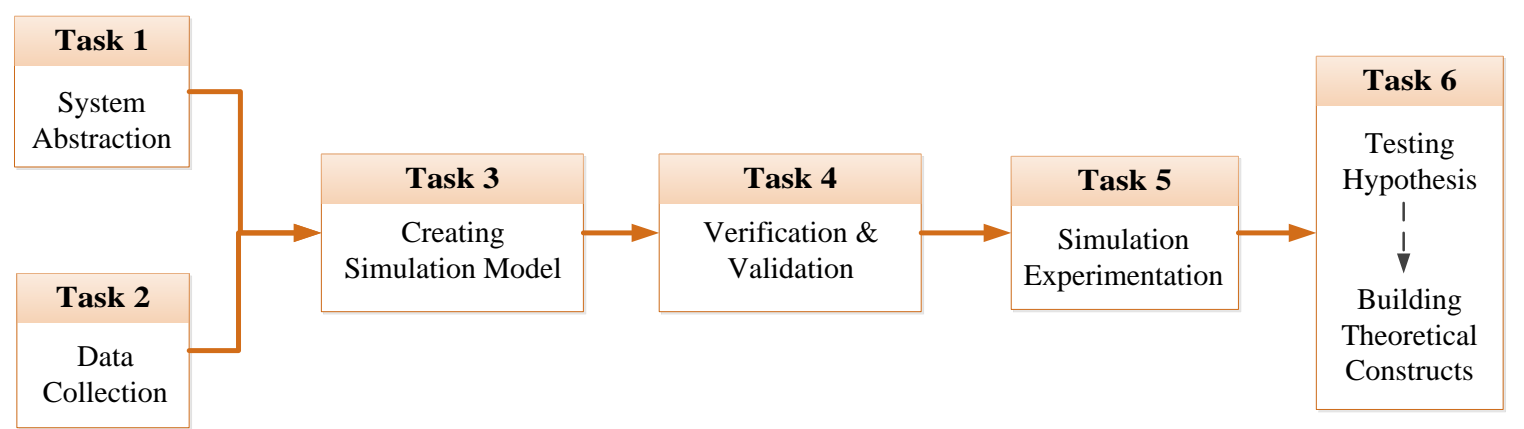

Figure 1-5: Research Tasks 


\subsection{Organization of the Dissertation Document}

This dissertation includes six chapters, from which chapters 2-5 are self-sufficient papers that are published, submitted or planned to be published in peer reviewed journals. Table XX summarizes the content and focus of different chapters. The present chapter, provided a background of the problem and the point of departure, discussed the links between research methods, hypothesis, research questions, and the research objective, and presented an overview of the research process and undertakings. In Chapters 2 and 3, it is first discussed that the existing life cycle cost analysis (LCC) and life cycle assessment (LCA) methodologies have several limitations for assessing long-term cost and environmental impacts of infrastructure systems. Then, methodological improvements in LCC and LCA are proposed and tested. In Chapter 4 a system of systems framework for assessing the long-term impacts of SLR and SLR adaptation is created. Chapter 5 presents a case study of a subset of the roadway network in the city of Miami Beach; and demonstrates the theoretical constructs developed from conducting simulation experiments and analyzing the results of the case study. Chapter 6 summarizes the findings, contributions, limitations and future work directions of this research. 
Table 1-2: Overview of the dissertation document

\begin{tabular}{|c|c|l|}
\hline Chapter & Focus & Content \\
\hline 1 & Introduction & $\begin{array}{l}\text { Research background and point of departure, } \\
\text { problem statement, research questions, objective, } \\
\text { and hypotheses, overview of the research and the } \\
\text { dissertation document }\end{array}$ \\
\hline 2 & $\begin{array}{c}\text { Development of } \\
\text { Underlying } \\
\text { Methodology }\end{array}$ & $\begin{array}{l}\text { Development of a methodology for assessing life } \\
\text { cycle costs of infrastructure systems considering the } \\
\text { specific traits of infrastructure }\end{array}$ \\
\hline 3 & $\begin{array}{c}\text { Development of } \\
\text { Underlying } \\
\text { Methodology }\end{array}$ & $\begin{array}{l}\text { Development of a methodology for assessing life } \\
\text { cycle environmental impacts of infrastructure } \\
\text { systems considering the specific traits of } \\
\text { infrastructure }\end{array}$ \\
\hline 4 & $\begin{array}{c}\text { Creating Conceptual } \\
\text { Framework and } \\
\text { Computational Model }\end{array}$ & $\begin{array}{l}\text { Creating a system of systems framework and a } \\
\text { simulation based computational model to investigate } \\
\text { the transformation of roadway infrastructure } \\
\text { systems under the impacts of SLR }\end{array}$ \\
\hline 5 & $\begin{array}{c}\text { Conducting Case } \\
\text { Study and building } \\
\text { Theoretical Constructs }\end{array}$ & $\begin{array}{l}\text { Building theoretical constructs from conducting } \\
\text { simulation experiments and result analysis in a case } \\
\text { study }\end{array}$ \\
\hline 6 & Conclusion & $\begin{array}{l}\text { Summary of the findings, contributions, limitations } \\
\text { and future work }\end{array}$ \\
\hline
\end{tabular}




\section{A SIMULATION FRAMEWORK FOR NETWORK LEVEL COST ANALYSIS IN INFRASTRUCTURE SYSTEMS}

\section{ABSTRACT}

The rapid deterioration of infrastructure systems along with the shrinkage of funding resources necessitates cost-effective management of infrastructure networks. The existing methods for cost analysis of infrastructure networks are based on optimizing network costs for a limited period, and hence, are prone to: (i) shifting the cost burdens, (ii) not considering the service life of assets in a network beyond the planning horizon and (iii) not considering uncertainty in factors such as future preservation funding as well as timing and cost of preservation activities. In this paper, we propose a simulation framework to address these limitations in network-level cost analysis. The proposed framework is based on the premise that a sustainable practice is the one that provides the longest service life at the lowest cost in infrastructure networks. The proposed framework determines the network-level costs considering the dynamic network-agency-user interactions and uncertainties. The application of the proposed framework is demonstrated using a case study pertaining to a pavement network. The results show the capability of the proposed framework in evaluating and identifying sustainable strategies leading to the longest service life for the assets at the minimum network-level costs. 


\subsection{INTRODUCTION}

The ever-growing gap between available funds and necessary expenditures to keep pace with the accelerating deterioration of U.S. infrastructure calls for sustainable strategies for cost effective management of the nation's civil systems. In particular, decision-makers are increasingly interested in identifying efficacious strategies that can provide long-term benefits for infrastructure networks (Rangaraju et al., 2008). To achieve this goal life-cycle cost analysis (LCCA) has become a key component of asset management in some governmental agencies. LCCA enables the direct economic comparison between competing alternative investments in order to identify the best value investment, which is the lowest long-term cost that satisfies performance objectives (Keoleian and Spitzley, 2006; Santos and Ferreira, 2013; Walls and Smith, 1998). However, the existing LCCA approaches (e.g., Zhang et al., 2013) have certain limitations for network-level cost analysis. First, they assume that the timing, type and amount of future costs are deterministic, fixed values. However, infrastructure networks include dynamic and uncertain interactions between the environmental conditions, availability of funding, deterioration of assets, user behaviors, and agency's decision processes and priorities, all of which affect the likelihood, timing, and amount of future costs (Batouli and Mostafavi, 2014). Second, in the existing optimization-based cost analysis methodologies, costs are only taken into consideration if they occur within the planning horizon. In reality, however, this assumption is inconsistent with the continuous nature of service in infrastructure networks; hence, using the existing optimization-based methods will lead to shifting cost burdens beyond the planning horizon, defying the principles of 
sustainability (Batouli and Zhu, 2014). For instance, in the example shown in Figure 2.1, preservation activity $\mathrm{A}_{M 4}$ is scheduled to be implemented during the final years of the planning horizon. If the preservation activity is deferred, it will lead to cost reduction over the planning horizon. However, this practice is not consistent with the principles of sustainability. In order to resolve the cost-deferring tendency of the existing optimizationbased approaches, all life cycle costs of individual assets, even those that fall beyond the planning horizon, should be taken into consideration. To this end, an appropriate methodology for cost analysis in networks of infrastructure should be capable of modeling the long-term costs beyond the planning horizon by considering the dynamic interactions and uncertainties. This study proposes a simulation framework for this purpose.

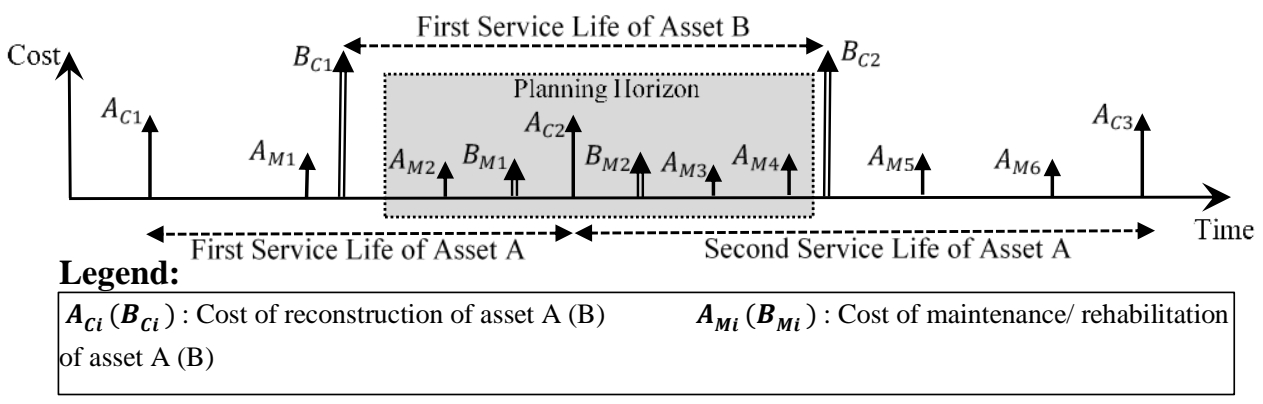

Figure 2-1. Discrepancy between service lives of individual assets and continuous service life of an infrastructure network.

\subsection{METHODOLOGY}

We propose a simulation framework for network-level costs analysis in infrastructure systems. We first present an overview of the steps in the proposed framework, and then demonstrate the implementation of the framework in a case study. The proposed framework includes four steps as shown in Figure 2.2: First, the interactions between user, agency and assets are modeled. Users' behaviors affect the level of demand on assets, while at the same time, the assets' quality and level of service influences the users' behaviors. 
The condition of an asset depends on the level of demand as well as the preservation/expansion actions taken by the administrative agency. The administrative agencies determine their management strategies based on the conditions of assets, expectations of users, and availability of resources. These dynamic interactions can be abstracted and simulated using appropriate methods such as agent-based modeling and dynamic mathematical modeling (Mostafavi et al. 2013).Second, using the simulation model created, the amount and timing of cost cash flows are modeled. Then, the costs for all asset life cycles that fully or partially overlap with the planning horizon are determined. A "life-cycle" for an asset is defined as the time between two consecutive reconstruction activities for the asset. For example, if the planning horizon is 40 years and the next reconstruction for asset A will occur in year 50, the analysis will consider all costs up to year 50 (i.e., end of the current service life for asset A).
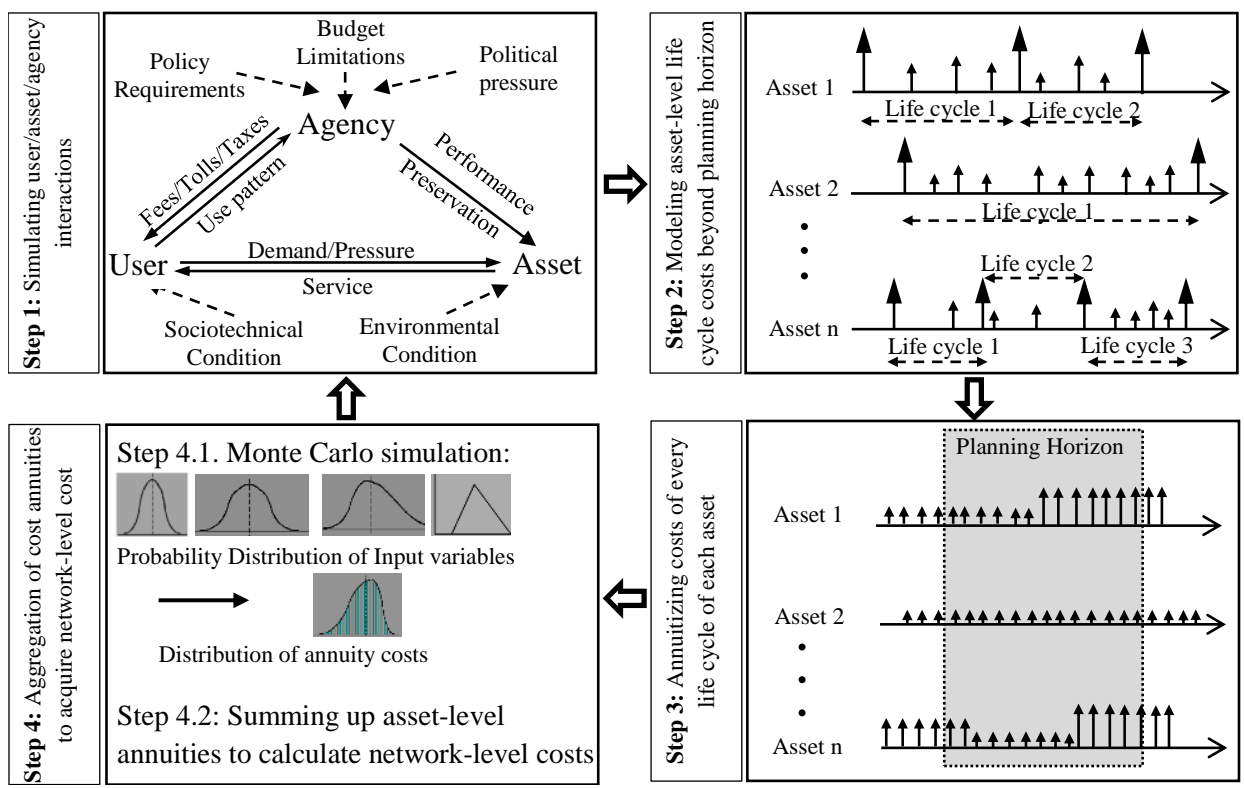
Figure 2-2. The proposed framework for calculating network-level costs.

Third, the cash flows related to individual asset costs are converted into their equivalent annual worth (i.e., annuity). This is because individual assets have different life cycles from each other and from the planning horizon. Hence, using annual worth conversion, the annual equivalent costs of each asset are determined and aggregated to determine the network level annual equivalent costs over the planning horizon (Newman 2004). Fourth, the variables and parameters affecting the agent-network-user interactions are inherently uncertain. For example, the uncertainty related to the level of funding, deterioration of assets, and the future preservation costs affect the uncertainty in the cost cash flows, and hence, annual network-level costs. In step 4, Monte-Carlo simulation is used to determine the mean and variance of network-level costs. This will enable selecting strategies that lead to lowest network costs with the greatest likelihood.

\subsection{Numerical example}

Twelve sections of a road network provided in The ICMPA7 Investment Analysis and Communication Challenge for Road Assets (Hass, 2008) were used to demonstrate the application of the proposed framework. The roads in the network are of different types, ages and conditions, as shown in Table 1. The scope of this numerical case study is limited to the costs incurred to the agency; hence, the user costs and the influencing user behaviors are excluded from the analysis in this case study. 
Table 2-1. Characteristics of the Case Network

\begin{tabular}{|c|c|c|c|c|c|c|c|c|c|}
\hline \multirow{2}{*}{$\begin{array}{l}\text { Road } \\
\text { Name }\end{array}$} & \multirow{2}{*}{$\begin{array}{l}\text { Road } \\
\text { Type }\end{array}$} & \multirow{2}{*}{$\begin{array}{c}\text { Length } \\
\text { (miles) }\end{array}$} & \multirow{2}{*}{ Lanes } & \multirow{2}{*}{$\begin{array}{c}\text { ESAL/ } \\
\text { Day }\end{array}$} & \multicolumn{5}{|c|}{$\begin{array}{c}\text { Cost distribution } \\
\text { (Normal (Mean, Sigma) in thousand dollars/lane-mile) }\end{array}$} \\
\hline & & & & & Construction & \begin{tabular}{|c|} 
Routine \\
Maintenance
\end{tabular} & $\begin{array}{c}\text { Surface } \\
\text { Treatment }\end{array}$ & Overlay & Rehabilitation \\
\hline $\mathrm{A}$ & $\mathrm{R}$ & 1.55 & 4 & 224 & $(141.2,24.9)$ & $(3.7,0.9)$ & $(15.5,4.3)$ & $(46.9,11.9)$ & $(79.9,7.9)$ \\
\hline B & I & 0.50 & 4 & 1185 & $(341.5,48.6)$ & $(4.7,1.2)$ & $(21.4,5.8)$ & $(70.8,14.9)$ & $(116.1,10.8)$ \\
\hline $\mathrm{C}$ & I & 0.68 & 4 & 1645 & $(228.8,36.3)$ & $(4.8,1.2)$ & $(21,5.6)$ & $(72.1,15.2)$ & $(117.3,10.5)$ \\
\hline $\mathrm{D}$ & $\mathrm{I}$ & 0.19 & 4 & 1756 & $(416.9,60.9)$ & $(5.6,1.4)$ & $(27.3,7.6)$ & $(82.7,17.1)$ & $(140.4,14.3)$ \\
\hline E & $\mathrm{R}$ & 0.43 & 4 & 864 & $(278.1,45.3)$ & $(5.4,1.4)$ & $(24.4,6.6)$ & $(80.2,16.9)$ & $(132.5,13.1)$ \\
\hline $\mathrm{F}$ & $\mathrm{R}$ & 2.73 & 4 & 688 & $(260.4,54)$ & $(3.1,2.1)$ & $(10.6,2.7)$ & & $(58.7,15)$ \\
\hline $\bar{G}$ & $\mathrm{I}$ & 0.62 & 4 & 1142 & $(533.8,110)$ & $(5,3.3)$ & $(18,4.7)$ & & $(101,26.8)$ \\
\hline $\mathrm{H}$ & $\mathrm{R}$ & 1.06 & 6 & 1785 & $(376.1,67.2)$ & $(3.3,2.3)$ & $(11.3,3)$ & & $(63.6,16.3)$ \\
\hline I & $\mathrm{R}$ & 2.80 & 4 & 1785 & $(289.9,60.1)$ & $(2.9,1.9)$ & $(10.1,2.6)$ & & $(55.9,14.2)$ \\
\hline $\mathrm{J}$ & I & 1.37 & 4 & 1185 & $(312.2,44.3)$ & $(4.2,1.1)$ & $(17.6,4.9)$ & $(65.1,14)$ & $(102.1,8.8)$ \\
\hline $\mathrm{K}$ & I & 1.68 & 4 & 1479 & $(247.5,34.8)$ & $(3.9,1)$ & $(16.1,4.3)$ & $(60.3,12.7)$ & $(94.7,8.2)$ \\
\hline $\mathrm{L}$ & I & 0.62 & 6 & 1756 & $(33.1,48)$ & $(4.1,1.1)$ & $(17.9,4.9)$ & $(61.9,12.8)$ & $(100.3,9.1)$ \\
\hline
\end{tabular}

\subsubsection{Simulating agency/asset/user interactions}

A simulation model was created to abstract and model agency/asset/user interactions. The performance of asset networks is a function of the timing and type of preservation activities, availability of M\&R funding, the agency's decision processes for prioritization of projects, and the life cycle cost and condition of individual roads. In this example Present Serviceability Rating (PSR) was used as an indicator of pavement performance. A simplified prediction model proposed by Lee et al. (1993) was utilized to model the deterioration behavior of pavement assets. The model predicts the long-term performance of a pavement given the initial conditions, traffic load, structure of the pavement, and weather conditions (Eq. 1):

$\mathrm{PSR}=\mathrm{PSR}_{\mathrm{i}}-\mathrm{A} . \mathrm{F} . * \mathrm{a} * \mathrm{STR}^{\mathrm{b}} * \mathrm{Age}^{\mathrm{c}} * \mathrm{CESAL}^{\mathrm{d}}$ 
In Eq. $1, \mathrm{PSR}_{\mathrm{i}}$ denotes the initial value of PSR for a given link right after construction. This value is 4.5 according to Chootinan et al. (2006) and Lee et al. (1993). Cumulative Equivalent Single Axle Loads per day (CESAL) and STR (existing structure of pavement) capture the impact of traffic load and structural design of the pavement, respectively. An adjustment factor (A.F.) was used to capture the effect of climate conditions. Finally, $a, b, c$ and $d$ are empirically-based coefficients whose values depend on the type of pavement (Lee et al. 1993).

The performance of pavement assets is also affected by the M\&R activities. Four types of M\&R activities were considered in this case study: routine maintenance, surface treatment, overlay, and rehabilitation. Each of these activities leads to a certain level of improvement in performance depending on the age of the pavement (Chootinan et al., 2006). The timing and type $M \& R$ activities depend upon the decision-making processes of the administrative agency that modeled using agent-based modeling. The main variables in the agent-based model include the performance conditions of assets and the level of funding. The decision rules of the administrative agency follow a "worst-first" strategy in which the roads with lowest performance are prioritized for allocation of M\&R funding. A maintenance and rehabilitation (M\&R) activity is implemented if it can restore the pavement to an excellent condition; otherwise, if an adequate funding is not available for the required M\&R, repair activities are deferred to the next period. The details related to the agent-based modeling of the agency decision processes and user behaviors can be found in Batouli and Mostafavi (2014). The outcomes of this simulation model determine the performance conditions of pavement assets, the service life of each assets, and the type and timing of M\&R activities. Figure 2.3 depicts the simulated performance condition of the 
pavement assets in the network. The service lives of pavement assets are determined based on the threshold values of PSR to determine the need for reconstruction. These threshold values were considered to be 2.2 and 2 for urban and rural roads, respectively (Elkins et el. 2013). Once a road reaches this threshold PSR value, it is considered to be irremediable by maintenance activities, and hence, it should be reconstructed.

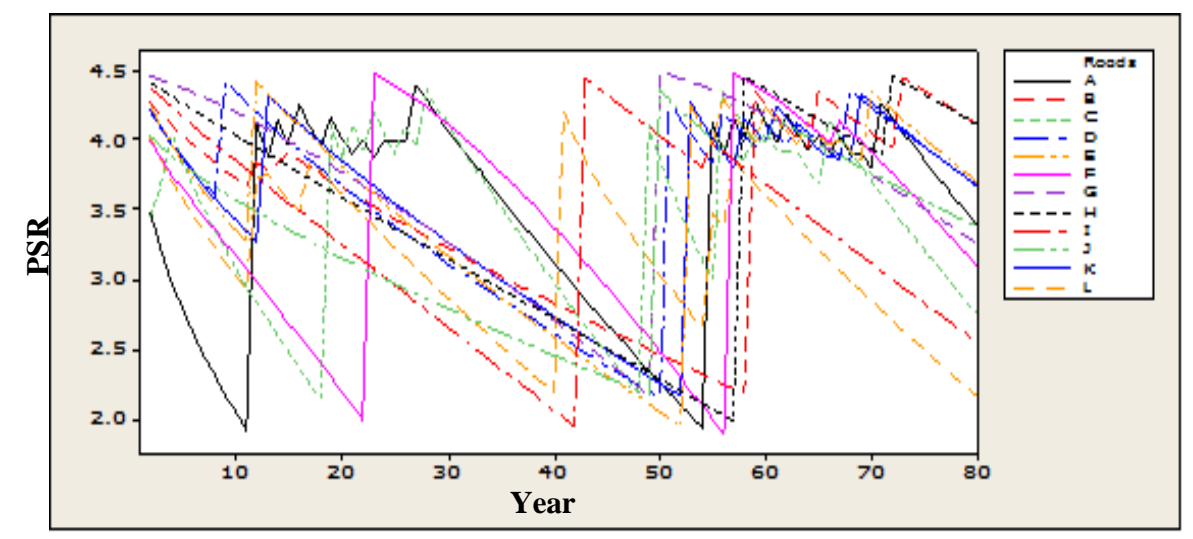

Figure 2-3. Simulated performance condition of pavement assets.

\subsubsection{Calculation of asset-level life cycle costs}

Using the outcomes of the previous step, a probabilistic life-cycle cost for each road in the network was estimated consistent with Federal Highway Administration (FHWA) guidance considering initial cost variation. Although other sources of variation exist (e.g., future material prices, quantity of inputs, or maintenance schedule), they are of secondary importance relative to initial cost variation (Swei et al., 2013). Initial cost variation was taken into consideration through the same methodology implemented by Swei et al. (2013); that is, economic theory postulates the average cost of production decreases as production increases (e.g., economies of scale). Making use of significant bid data available through Oman Bid Systems, a univariate regression model for each relevant paving activity was 
developed where average unit-cost is a function of bid volume. Given that the regression model will not capture all of the variation which may exist, the standard error of that regression is used in order to form a probability distribution for unit-cost. The current model assumes routine maintenance requires a small amount of patching $(0.5 \%)$ as well as joint sealing for concrete pavements, surface maintenance involves fog seal cracking or diamond grinding, and rehabilitation requires a mill and fill along with significant patching for asphalt pavements, or diamond grinding, sealing of joints, and significant patching for concrete pavements. The cost distributions related to construction and maintenance activities are given in Table 1. The outcome of this step determine the cash flows related to the life cycle costs of each asset in the network.

\subsubsection{Annuitizing costs related to every life cycle of each asset}

After the service life and life cycle costs of each asset were calculated, the annual equivalent costs for each pavement asset were calculated using annual equivalent worth analysis. A real discount rate of $4 \%$ was used in the annual equivalent worth analysis,

consistent with FHWA guidance and current practice for many DOTs (Walls and Smith, 1998) to calculate the annual equivalent cost values for each pavement asset. The outcome of this step determines the annual equivalent costs of each pavement asset calculated in dollar per lane-mile-year.

\subsubsection{Aggregation of cost annuities to acquire network-level cost}

In this step, the annual equivalent costs of each asset were aggregated to determine the annual network costs based on several Monte-Carlo simulations. One example for 
application of the framework proposed in this paper is to evaluate the impacts of M\&R funding on the network-level costs. Different levels of funding between $\$ 10,000$ and $\$ 1,200,000$ were considered with the result of the analysis shown in Figure 2.4. It is clear that an increase in the availability of $M \& R$ funding from zero up to about $\$ 110,000$ reduces the \$/lane-mile-year at the network-level. Although a maintenance funding less than about \$110k is not adequate for most corrective M\&R activities, it enables conducting other less costly preventative maintenance activities. Thus, it leads to an increase in the service lives of the pavements, which improves the \$/lane-mile-year of the network. On the other hand, when the M\&R budget increases beyond $\$ 110,000$, the $\$ /$ lane-mile-year at the network level increases due to sub-optimal use of more expensive $M \& R$ activities while they might not be necessarily needed. This implies that for a network with specific characteristics (pavement type, age, length, etc.), there is a budget level that leads to a minimum $\$ /$ lanemile-year across the analysis horizon. Identifying this budget level is a critical step in sustainable management of a network. For the case study network, a sustainable level of M\&R budget is about $\$ 110,000$. A budget amount greater and less than $\$ 110,000$ could reduce the sustainability of the road network. Identifying this funding level is critical in sustainable management of a network.

The level of M\&R funding also affects the overall performance of the network (as measured by the average PSR values of the roads). A greater investment on M\&R activities leads to a greater performance of the network. However, as shown in Figure 2. 4.b, there is not a linear relation between the rate of increase in the level of performance and the availability of M\&R funding. Beyond a certain level of funding, the rate of improvement in the performance of the network decreases. In the case study network, the funding levels 
greater than $\$ 200,000$ do not lead to significant improvement in the overall performance of the network. Based on the previous results, the sustainable level of M\&R funding leading to the minimum $\$$ /lane-mile-year at the network level is $\$ 110,000$ in the case study. This M\&R funding amount leads to an average performance of 3.37 at the network level over the 40-year planning horizon.

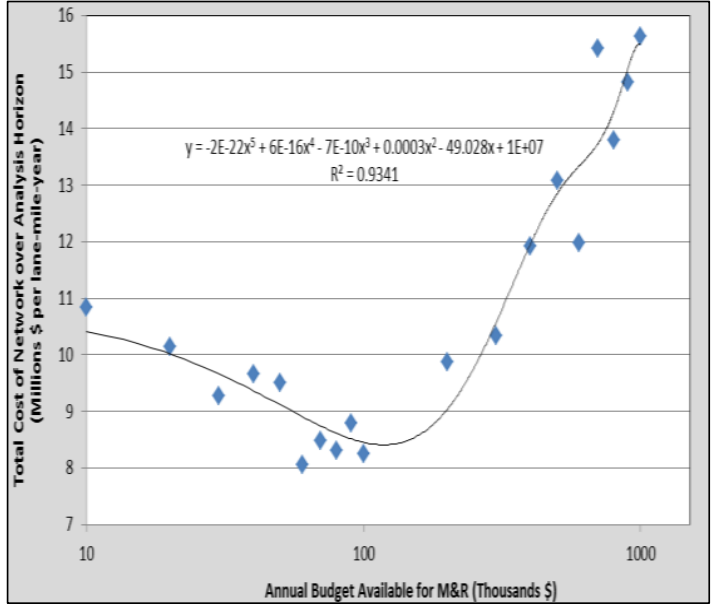

a. Network-Level Cost

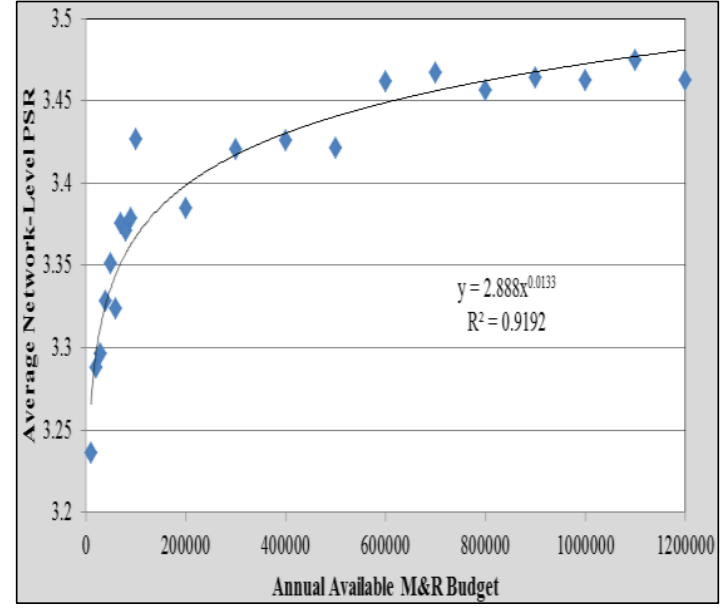

h Network-I evel

Figure 2-4: Impacts of availability of $M \& R$ funding on the network

\subsection{CONCLUSION}

In this paper we proposed a simulation framework for assessment of life-cycle costs of infrastructure networks. Unlike traditional cost analysis models, which are based on lumpsum static assessment of costs, the proposed framework captures the inherent uncertainties in timing and amount of future costs based on modeling the complex dynamic interactions between the condition of infrastructure assets, the behavior of users and the decision 
making processes in the administrating agency. The application of the proposed framework was shown using a numerical case study. In the case study, the proposed framework was used to determine the level of M\&R funding that leads to the lowest $\$$ lane-mile-year values at the network level. The value of \$/lane-mile-year can be a measure of sustainability since a sustainable practice is the one that provides the longest service life for the network at the lowest costs. Hence, the results of the case study highlighted the capability of the proposed framework in evaluating different alternatives and strategies for improving the sustainability of road networks. Infrastructure agencies could adopt the framework presented in this paper to evaluate the sustainability of different strategies (e.g., funding prioritization, material selection, design, and maintenance/rehabilitation strategies) in management of their infrastructure networks. From a theoretical perspective, the framework proposed in this study is a preliminary step toward integrating the traditional infrastructure management principles with the theoretical underpinnings of complex adaptive systems for identifying sustainable strategies in infrastructure networks based on capturing the dynamic behaviors and uncertainty at the interface of agency/asset/user interactions.

\section{Service and Performance Adjusted Life Cycle Assessment: A Methodology for Dynamic Assessment of Environmental Impacts in Infrastructure Systems}

\subsection{Abstract}

Infrastructure systems are at the core of the sustainability challenge. Currently life cycle assessment (LCA) is widely used for assessing environmental sustainability of infrastructure systems. However, infrastructure systems have specific traits that are incompatible with the requirements of LCA. In particular, infrastructure systems do not 
have definite "life cycle" as a basis of LCA. In addition, environmental performance of infrastructure systems depends on the dynamic changes in the level of service and performance of infrastructure normally not captured in existing LCA approaches. The objective of the research presented in this paper attempts to address the limitations of existing LCA approaches by creating a service and performance adjusted LCA (SPA-LCA) methodology, one which is specifically tailored for the requirements of environmental assessment of infrastructure systems. Among other improvements, the created methodology introduces a dynamic conception of life cycle inventory analysis and a service-based environmental accounting for the impact assessment phase of LCA. A simulation-based computational model is created to enable implementation of the SPALCA methodology. The SPA-LCA method and the created computational model are tested in a case study related to assessing the environmental impacts of a pavement network. Results include assessing impacts of different budget and demand scenarios on the environmental performance of the case study network. The results indicate capabilities of SPA-LCA methodology in addressing the limitations of existing LCA approaches for assessing environmental impacts of infrastructure systems.

\subsection{Introduction}

Substantial environmental impacts are generated during the process of construction, operation, maintenance, and disposal of civil infrastructure (Hendrickson and Horvath 2000). With the growing awareness of and urgency in protecting our natural environment, decision makers are increasingly interested in accurate assessment of the environmental impacts related to networks of infrastructure. On the other hand, lack of environmental assessment methodologies specific to infrastructure systems has compelled the research 
community to use existing alternatives (Reza et al. 2014). In particular, a growing number of studies have adopted LCA for appraising environmental impacts of infrastructure systems. In the past decade LCA has been used for assessing the environmental footprint of infrastructure systems such as roadway networks (e.g. Stripple 2001, Labi and Sinha 2005, Zhang et. al. 2012, Sathaye et. al. 2010), water and sewer systems (e.g. Lassaux 2007, Lundin et. al 2000, Foley et. al. 2010), and electrical grids and energy transmission lines (Weber et. al. 2010). However, LCA's primary application is intended for assessing environmental impacts of manufactured products rather than infrastructure systems (ISO 14040 2006; ISO 14044 2006). On the other hand, infrastructure systems have distinctive traits that make them different from manufactured products and services. Hence, the use of LCA for infrastructure systems has led to various methodological and conceptual limitations related to the compatibility of the approach to the traits of infrastructure systems. Despite the important role of LCA for environmental assessment of infrastructure, less attention has been paid to modifying LCA for the specific traits of infrastructure systems. To address this gap in the existing body of knowledge, the objective of the research presented in this paper is to create an LCA-based environmental assessment methodology that is tailored for the specific traits of infrastructure systems.

The paper is developed as follows. First, the limitations of existing LCA approach for assessing environmental impacts of infrastructure systems are enumerated. A discussion of the LCA limitations is presented to show that most of these limitations are rooted in lack of consideration of the dynamic evolution of service and performance in infrastructure systems. Second, a service and performance adjusted LCA framework, the SPA-LCA, is introduced. The SPA-LCA framework is explained to illustrate how different 
phases of LCA are adjusted to suite the requirements of environmental assessment in infrastructure systems. Third, the application of the proposed framework is shown in a numerical case study related to a pavement network. Finally, the findings of the case study are discussed in conjunction with the contributions of the present research.

\subsection{Limitations of LCA for Environmental Assessment of Infrastructure Systems}

The concept of LCA is based on the premise that compilation and aggregation of environmental impacts associated with all stages of a product's life eliminates possibility of shifting environmental burdens from one stage of life cycle to another (ISO 14040 2006; ISO 14044 2006). The LCA framework includes four distinct though interdependent phases: goal and scope definition, inventory analysis, impact assessment, and interpretation. However, in all four phases there are important limitations for assessing environmental impacts of infrastructure systems. These limitations are summarized in Table 1 and will be explained in detail in the rest of this section.

Table 3-1: Limitations of LCA for assessing environmental impacts of infrastructure systems

\begin{tabular}{|c|c|c|}
\hline Phase & Feature of LCA & $\begin{array}{c}\text { Limitation for assessing infrastructure } \\
\text { systems }\end{array}$ \\
\hline $\begin{array}{l}\text { Goal and } \\
\text { Scope } \\
\text { Definition }\end{array}$ & $\begin{array}{l}\text { - Defining a lifetime for the system } \\
\text { being studied } \\
\text { - Defining a fixed functional unit }\end{array}$ & $\begin{array}{c}\text { - Infrastructure systems do not have a } \\
\text { definite lifetime } \\
\text { - } \quad \text { The function of infrastructure is } \\
\text { sensitive to the level of service and } \\
\text { performance }\end{array}$ \\
\hline $\begin{array}{l}\text { Inventory } \\
\text { Analysis }\end{array}$ & $\begin{array}{l}\text { - Static compilation of material, } \\
\text { energy, and emission flows related } \\
\text { to fixed unit processes }\end{array}$ & $\begin{array}{l}\text { - The timing and type of unit } \\
\text { processes dynamically change due to } \\
\text { fluctuations in the level of service and } \\
\text { performance }\end{array}$ \\
\hline $\begin{array}{c}\text { Impact } \\
\text { Assessment }\end{array}$ & $\begin{array}{l}\text { - Lump sum assessment of } \\
\text { the environmental impacts }\end{array}$ & $\begin{array}{l}\text { - Need for decision making in } \\
\text { different time horizons (short-term to } \\
\text { long-term) }\end{array}$ \\
\hline
\end{tabular}




\begin{tabular}{|l|l|l|}
\hline Interpretation & $\begin{array}{l}- \text { Assess the impacts for a } \\
\text { presumed scenario of use and } \\
\text { maintenance }\end{array}$ & $\begin{array}{l}- \text { Need for policy analysis } \\
\text { considering the uncertain scenarios of } \\
\text { budget and demand }\end{array}$ \\
\hline
\end{tabular}

\subsubsection{Goal and scope definition}

Infrastructure systems have distinguishing attributes that the current goal and scope definition requirements do not capture. These are described as follows:

(i) A primary feature of the goal and scope definition is to define a "life cycle" for the system being studied. Life cycle of a product includes all stages of the product's life from raw material extraction to disposal or recycling (ISO 14040). However, unlike manufactured products, infrastructure systems do not have a definite life cycle. Instead, systems evolve over time as new assets are constructed and old assets are rehabilitated. In other words, different assets in a network have dissimilar start and end of life. Hence, no finite time horizon may encompass the entire life cycles of all assets in an infrastructure system. Lack of consideration of the cradle-to-grave impacts of all assets makes networklevel LCA studies prone to shifting environmental burdens from one stage of asset life cycle to another. In order to overcome the lack of a well definite life-cycle of infrastructure systems, some studies have suggested the use of unbounded analysis horizon for studying the cost or environmental impacts of infrastructure (e.g. (Bakker et al. 1999; Van Noortwijk 1998)). In these approaches the service life of infrastructure is modelled as a "discrete renewal process" in which each reconstruction is considered to be a maintenance activity that restores the original condition of an asset and the process of asset renewals continues infinitely (van Noortwijk and Frangopol 2004). This approach eliminates the inconsistency in the start and end of life cycle of different assets. However, its accuracy is contingent 
upon continuation of the same life cycle processes for a very long time. Nonetheless, in real world, infrastructure systems evolve over time due to changes in the level of service and performance of assets (Markard et al. 2012). On the other hand, the environmental impacts of infrastructure systems heavily depend on the way in which they evolve (Nikolic and Dijkema 2010). Therefore, while consideration of unbounded analysis horizon resolves the burden shifting problem for network-level LCA of infrastructure, it may affect accuracy of the assessment.

(ii) Another essential feature of the goal and scope definition is defining a functional unit, a reference to which the inflows and outflows of a system are related (ISO 14040). A classic example of a functional unit is the mass of paper required for the single drying of a pair of hands (ISO 14040). A typical LCA of paper towels compiles the amount of material and energy required for making and disposal of one functional unit of paper towel. Manufactured products such as paper towels usually have uniform functions (e.g. the function of paper towel remains the same for the entire roll of paper and across different rolls or different brands of paper towel). In contrast, the function (and hence environmental impacts) of infrastructure changes over time due to evolving levels of service and performance. The issue related to the unsteady function of infrastructure has been previously noticed in some life cycle cost analysis studies. For example, Frangopol et al. (1997) addressed this issue by considering thresholds for minimum acceptable structural reliability of assets. Setting constraint on minimum condition of assets reduces the range of fluctuations in functionality of infrastructure. However, even with most rigorous constraints, there still will be some dynamic changes in functionality of infrastructure. For example, a recently paved roadway has a smooth surface that leads to lower fuel 
consumption of vehicles. As the road ages, its surface gradually degrades causing more fuel consumption and higher environmental impacts (Barnes and Langworthy 2003). No static functional unit is able to capture the dynamic changes in functionality of infrastructure throughout their life cycle. For example, functional units such as pavement length (e.g. kilometers of pavement), pavement surface area (e.g. square meters of pavement), and structural capacity of pavements, which are frequently used in pavement LCA studies (e.g. Noshadravan et. al. 2013; Xu et. al. 2015), are unable to capture the dynamism of functionality in pavement assets because they do not differentiate between pavements with higher and lower level of performance (Santero et al. 2011). Inability to accurately relate functional unit to the real time functionality of infrastructure decreases the reliability of LCA results for infrastructure systems (Reap et al. 2008).

\subsubsection{Inventory analysis}

The second phase of LCA is inventory analysis. In this phase the input and output data pertaining to the system being studied are collected and compiled (ISO 14040 2006). The inventory data includes the accounts of energy, material, and waste consumed or released during different unit processes throughout the life cycle of a product. LCA takes a static approach toward modeling the inventory data, which means in the existing LCA method unit processes are assumed to be definite. For example, in a majority of the existing pavement LCA studies the assumption that the pavement life cycle is comprised of a series

of fixed processes, including a predefined construction method and a definite number of 
maintenance treatments applied within a certain life cycle (Santero et al. 2011). However, in the real world, both timing and type of unit processes related to the life cycle of infrastructure assets dynamically change due to the fluctuations in the level of service and performance. For example, the frequency and type of maintenance treatments that a pavement asset receives during its service life varies due to uncertainty in the future level of traffic and deterioration of the physical condition of the pavement assets (Santero et al. 2011; Batouli et. al. 2015). The inflows and outflows of material, energy, and emissions are evidently affected by the number and type of unit processes. Thus the lack of consideration of the dynamic development of infrastructure systems is a major limitation of LCA in creating life cycle inventories that accurately reflect environmental impacts of infrastructure systems (Miller et al. 2013).

\subsubsection{Impact assessment}

The third phase of LCA is impact assessment. In this phase the inventory data related to different stages of life cycle are aggregated into lump sum values corresponding to different impact categories (ISO 14040 2006; ISO 14044 2006). This means that for every impact category the life cycle inventories related to each decision alternative are aggregated into a single figure that is independent of the timing of the impacts. Initially, lack of consideration of the time characteristics of environmental processes may not create fundamental problems for environmental assessment of manufactured products, for which decision making is usually a single task done during the design or procurement of the 
product. However, the inherent problem can create a significant limitation for assessing environmental impacts in infrastructure networks in which decision making is an ongoing process and decision makers are more interested in assessing the environmental impacts over varying network planning horizons (i.e. short-term operational, mid-term tactical, and long-term strategic planning horizons) (Vanier 2001).

\subsubsection{Interpretation}

The final phase of LCA is interpretation. This is the stage in which one draws conclusions and makes recommendations based on the findings of the inventory analysis and impact assessment (ISO 14040 2006; ISO 14044 2006). As an environmental assessment method, LCA has greatest impact if the outcomes of interpretation can be used for policy analysis and management of systems that are not fully developed (Nikolic and Dijkema 2010). However, the interpretation of LCA results put a major limitation for policy analysis and management of infrastructure systems. LCA studies assess the environmental performance of infrastructure for a presumed scenario of maintenance and use (Santero et al. 2011). For example, typical pavement LCA studies compare the environmental performance of rigid and flexible pavements for a certain scenario related to the level of traffic and maintenance of the pavement (Inyim et. al. 2016). Hence, interpretation of LCA results is limited to the specific scenario presumed for the maintenance and use of infrastructure. However, the environmental impacts related to use and maintenance of infrastructure are prone to a great deal of uncertainty pertaining to future levels of budget and service demand. LCA does not capture the complex effects of budget and demand on environmental impacts of infrastructure systems (Miller et. al. 
2013). Hence, it provides limited capacity for policy analysis pertaining to preservation and use of infrastructure systems (Pope et al. 2004; Kharrazi et al. 2014; Reap et al. 2008b).

\subsection{SPA-LCA Framework}

To address the existing limitations of LCA, this study created a methodology for assessing environmental impacts of infrastructure systems considering the evolutionary changes in the level of service and performance of infrastructure. The method is hence called "Service and Performance Adjusted Life Cycle Assessment" or SPA-LCA. The created methodology is shown in Figure 3.1. The levels of service and performance of infrastructure evolve over time due to complex interactions between the conditions of physical network, and the decision making behaviors of the individuals and institutions involved in management and use of the network (throughout this paper these decision makers are referred to as "agency") (Batouli and Mostafavi 2014) (Mostafavi et al. 2013; Markard et al. 2012). Hence, in the proposed methodology, first the level of service and

performance of infrastructure system are simulated using the interrelated modules of agency decision making and network conditions. Then, the simulated values of service and performance are used in the module of modified LCA to identify service and performance adjusted environmental impacts of the network. 


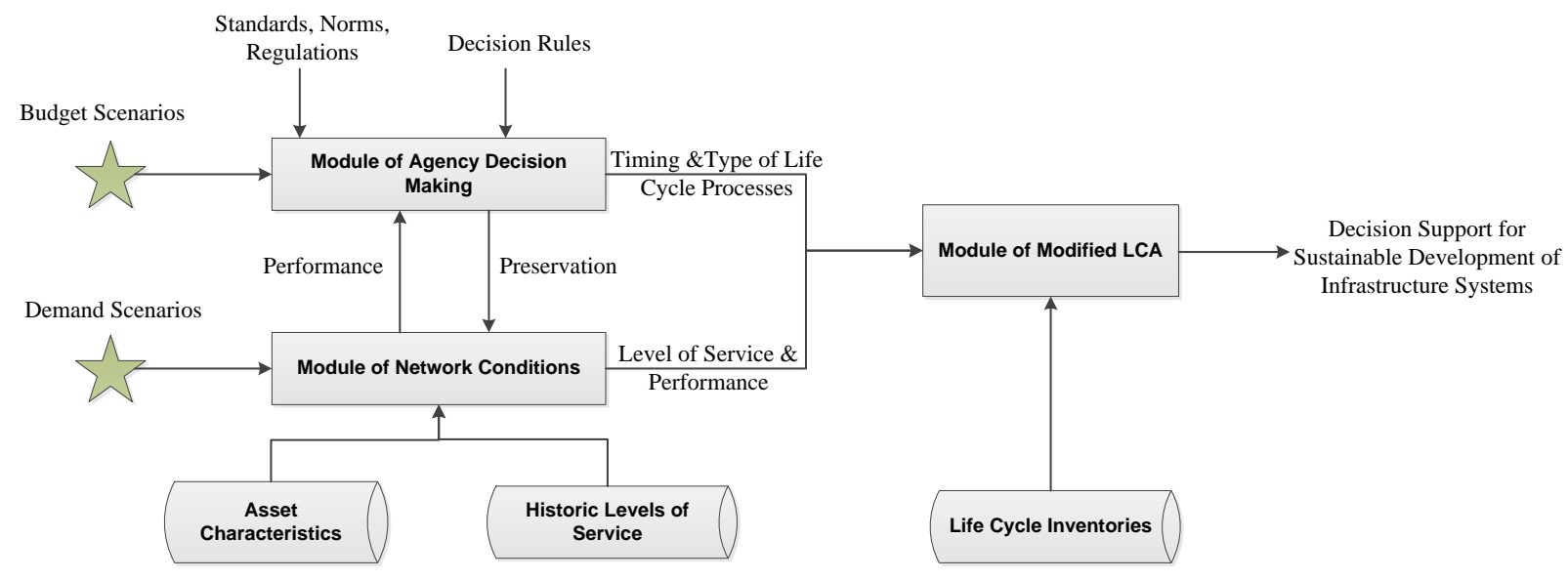

Figure 3-1: Framework for Service and Performance Adjusted Life Cycle Assessment of Infrastructure Systems

The module of Agency Decision Making captures the micro behaviors of the agency regarding maintenance, rehabilitation, and reconstruction of the infrastructure system. The behaviors of the agency are affected by the performance conditions of infrastructure assets, existing norms, standards and regulations, the decision rules behind agency actions, and the availability of required resources such as maintenance and rehabilitation $(M \& R)$ budget. On the other hand, the performance conditions of the assets depend on factors such as their characteristics (age, service capacity, structural design, etc), historic and expected future levels of service, and the improvements in the physical conditions due to $M \& R$ treatments.

The outcomes of the modules of agency decision making and network conditions include timing and type of life cycle events (e.g. maintenance, rehabilitation treatments), as well as the level of service and performance of infrastructure assets. These variables are used in the module of modified LCA to provide decision support for low impact and sustainable development of infrastructure systems. The module of modified LCA includes 
the same four phases of LCA: goal and scope definition, inventory analysis, impact assessment, and interpretation. However, in each of the four phases modifications are made to the original LCA methodology in order to make the method appropriate for assessing environmental impacts of infrastructure systems. Distinctive characteristics of SPA-LCA in each of these four phases are summarized in Figure 3.2 and will be discussed in the remainder of this section.

\begin{tabular}{|c|c|c|}
\hline Goal and Scope Definition & \multirow[b]{2}{*}{$\longleftrightarrow$} & \multirow[b]{2}{*}{$\begin{array}{l}\text { - Consider uncertainty } \\
\text { in the impacts related } \\
\text { to maintenance, } \\
\text { rehabilitation and use }\end{array}$} \\
\hline $\begin{array}{l}\text { - Define life cycle and functional unit at asset level and define the } \\
\text { system boundary at network level. } \\
\text { Adjust the functional unit at each year of life cycle based on the level } \\
\text { of service and performance }\end{array}$ & & \\
\hline Inventory Analysis & \multirow[b]{2}{*}{$\longleftrightarrow$} & \multirow{4}{*}{ 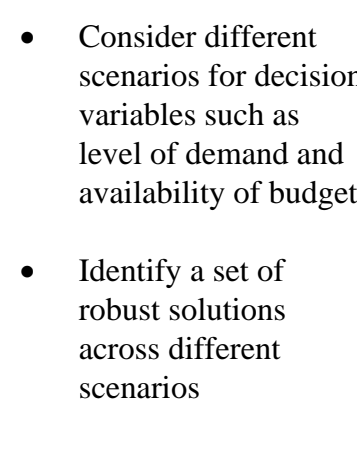 } \\
\hline $\begin{array}{l}\text { - Consider the dynamic changes in the maintenance and use impacts } \\
\text { caused by adaptive behavior of decision makers, as well as budget and } \\
\text { demand uncertainty }\end{array}$ & & \\
\hline Impact Assessment & & \\
\hline $\begin{array}{l}\text { - Attribute impacts to each year of life cycle based on the level of service } \\
\text { and performance } \\
\text { - Aggregate impacts at network-level }\end{array}$ & $\longleftrightarrow$ & \\
\hline
\end{tabular}

Figure 3-2: The four phases of SPA-LCA methodology

\section{Goal and scope definition}

To address the limitations of LCA at the goal and scope definition phase, the present study adopts a two-step approach. In the first step the life cycle, functional unit, and system boundary are defined. Then, in the second step, the impacts are adjusted based on the annual level of service and performance of each asset. Figure 3.3 illustrates the two steps of goal and scope definition in SPA-LCA method. The two steps are explained below. 


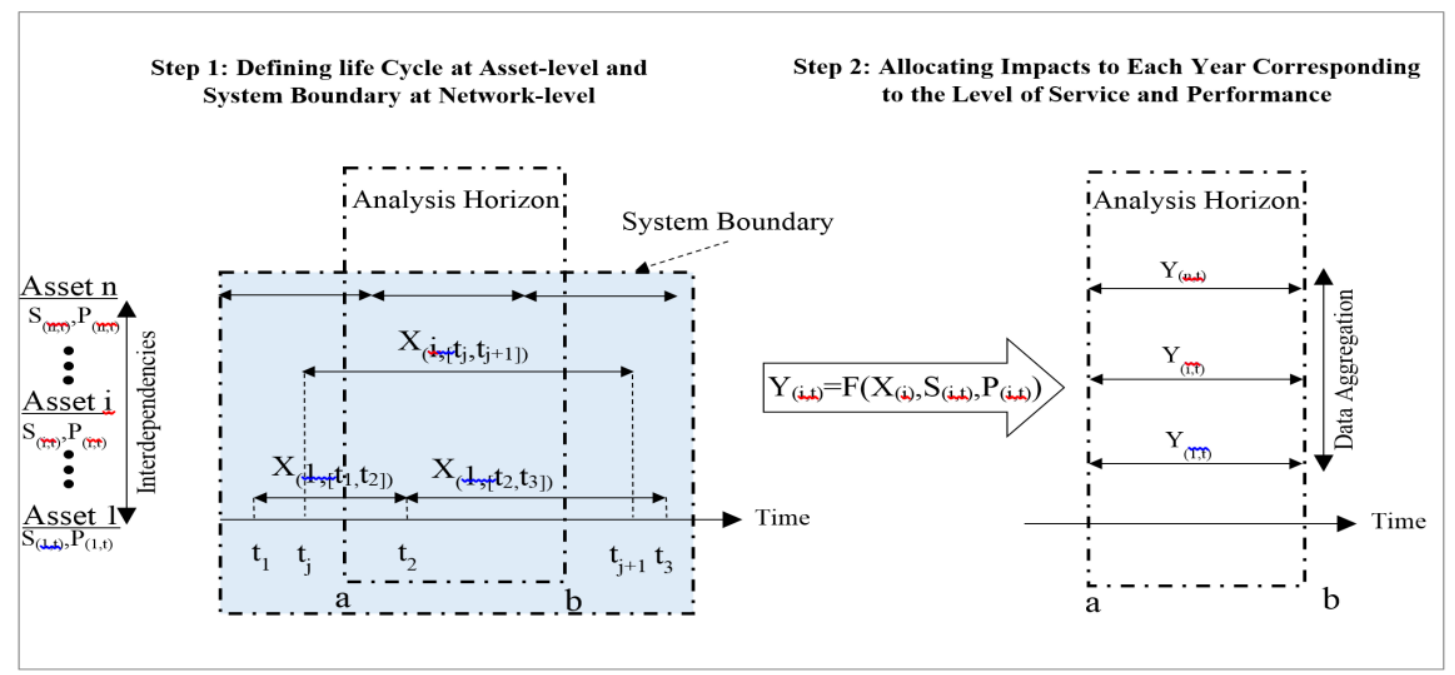

Figure 3-3: The two steps of SPA-LCA for addressing limitations of goal and scope definition

(1) In the first step, the life cycle and the system boundary are defined at the asset and network level, respectively. Asset-level definition of life cycle means that the life cycle is defined separately for each asset rather than defining one life cycle for the whole system. The life cycle of an individual asset is the time interval between the construction and the demolition or reconstruction of the asset. For example, in Figure 3.3, two different life cycles of asset 1 (one between $t_{1}$ and $t_{2}$ and the other between $t_{2}$ and $t_{3}$ ) overlap with the analysis horizon, which means this asset is reconstructed at $t_{2}$. Defining the life cycles at asset level eliminates the need for universal definition of life cycle for the system and hence resolves the first methodological limitation of LCA. On the other hand, the network-level definition of system boundary ensures that in calculation of the life cycle impacts of each asset the interrelationships of the asset with the rest of the network are taken into consideration. The interrelationships among different assets include the functional and budgetary interdepencies in an infrastructure system. For example, spending limited maintenance funding on one asset leaves less funding available for maintenance activities 
on other assets in the network, and thus affects the environmental performance of other assets. Expanding the system boundary to incorporate the entire infrastructure system enables simultaneous assessment of impacts at the network-level, hence eliminating the possibility of shifting environmental burdens from one asset to another.

(2) In the second step, the life cycle impacts of every asset are attributed to each year of service life according to the annual level of service and performance of the asset. Let $\mathrm{X}_{(\mathrm{i},[\mathrm{t}, \mathrm{j}+\mathrm{j}+1])}$ be the lump sum life cycle impacts of asset $\mathrm{i}$ (e.g. total global warming potential created during material extraction, transportation, construction, maintenance, use, and end of life of the asset) related to a service life of the asset started at $t_{j}$ and ended at $t_{j+1}$ (Figure 3.3). Also, let a and $b$ denote the start and end of the analysis horizon. Then, the impacts of asset $\mathrm{i}$ at any time $\mathrm{t}$ (where $\mathrm{t} \in[a, b] \cap[\mathrm{tj}, \mathrm{tj}+1]$ ) is a function of the level of service and performance of the asset at year $t$ and the total life cycle impacts of the asset $\mathrm{X}_{(\mathrm{i},[\mathrm{t}, \mathrm{t} j+1]) .}$ In mathematical terms:

$\left.Y_{(i, t)}=F\left(X_{(i,[t j, t j+1]}\right), S_{(i, t)}, P_{(i, t)}\right)$

Equation (1)

In Equation 1, $\mathrm{S}_{(\mathrm{i}, \mathrm{t})}$ and $\mathrm{P}_{(\mathrm{i}, \mathrm{t})}$ denote the level of service and performance of asset $\mathrm{i}$ in year $\mathrm{t}$, respectively.

Adjustments of the impacts based on the annual level of service and performance, addresses the limitation of LCA pertaining to insensitivity of the functional unit to the varying levels of service and performance. In addition, converting the lump sum life cycle impacts into annual impacts enables aggregation of the impacts at the network-level by resolving the mismatch between the start and finish dates of life cycles of different assets. 
Details pertaining to adjustment of impacts based on the annual level of service and performance will be provided in the following sections.

\section{Inventory analysis}

Similar to traditional LCI, the life cycle inventory analysis of SPA-LCA (SPA-LCI) includes quantification of energy, material, and waste flows related to the entire life cycle of an infrastructure, including construction, use, Maintenance and Rehabilitation (M\&R), and end of life. However, in order to resolve the limitation of LCA in the inventory analysis phase, the uncertainty in timing and type of the unit processes is captured in SPA-LCI. To this end, two different types of processes in the life cycle of infrastructure assets are differentiated (Figure 3.4):

1) The processes whose impacts are not sensitive to the level of service and performance of infrastructure. This includes the material acquisition and transportation, construction, and end of life impacts. For this type of event SPA-LCA uses the same inventory analysis approach as traditional LCI. For clarity of presentation, the inventory data related to material acquisition and transportation are considered as impacts embodied in the construction phase.

2) The processes whose type, frequency of occurrence, and magnitude of impacts depend on the dynamic changes in the level of service and performance of infrastructure. The processes related to maintenance and rehabilitation (M\&R) and use phase fall into this category. For this type of event, first the timing and type and of life cycle processes (such as maintenance treatments and extent of use) are simulated. Then the total flows are dynamically calculated based on the cumulative flows of all processes 
occurred within the life cycle of an asset. At this step the flows related to use phase are also adjusted based on the dynamic level of performance.

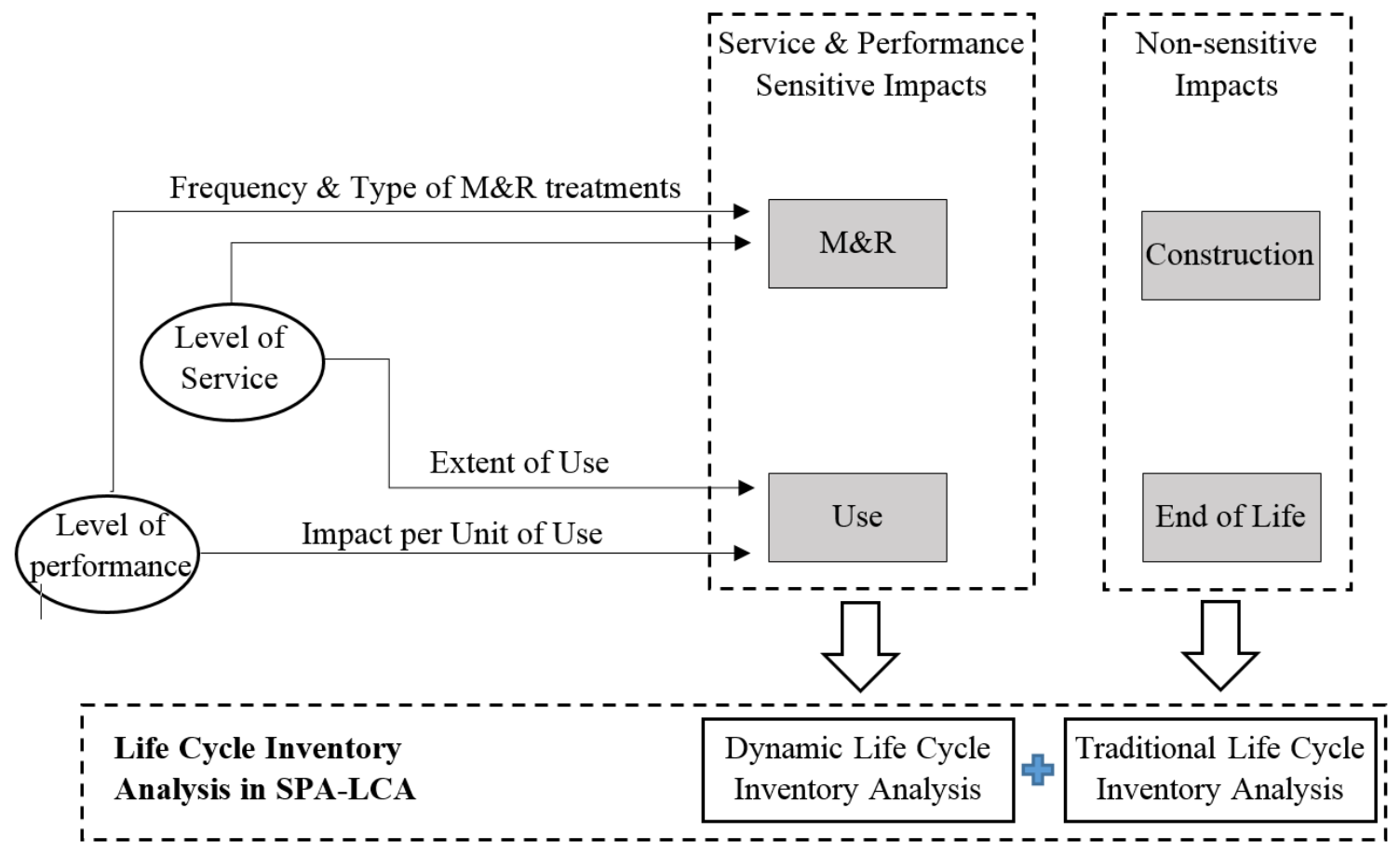

Figure 3-4: The Life Cycle Inventory Analysis phases of SPA-LCA methodology

Dynamic calculation of the life cycle impacts in SPA-LCA has two important advantages. First, SPA-LCI is inherently an LCA approach that takes all direct and indirect flows of energy, material, and pollutants related to the entire service life of assets into consideration. Thus, the SPA-LCI is not prone to the burden shifting problem of traditional network-level LCA approaches. Second, unlike LCA, which is a static method, the dynamic LCA (DLCI) approach of SPA-LCI enables the consideration of dynamic changes in the level of service and performance of infrastructure assets and their effects on the environmental performance of an infrastructure system. 


\section{Impact assessment}

To enable assessment of environmental impacts at varying analysis horizons, a new approach for environmental accounting is proposed for the impact assessment phase of SPA-LCA. The change of the accounting method is motivated by an analogy between the environmental accounting and financial accounting. In business and finance literature, two distinctive types of financial accounting are used (Kwon 1990): i) cash-based accounting in which revenues and expenses are recorded when the cash is transferred; and ii) accrual accounting in which economic events are recognized at the time of transaction rather than when a payment is made (or received). Table 2 summarizes the characteristics of the two financial accounting methods and their equivalent environmental accounting approaches. The impact assessment phase of LCA recognizes environmental burdens when emission occurs or natural resources are depleted, and is therefore similar to cash-based financial accounting where the release of pollutants or consumption of resources are analogous to the exchange of cash flows. Throughout the present paper, this environmental accounting approach is referred to as emission-based environmental accounting.

Table 3-2: The proposed service-based accounting is analogues to accrual accounting.

\begin{tabular}{|c|c|c|c|}
\hline \multicolumn{2}{|c|}{ Financial Accounting } & \multicolumn{2}{|c|}{ Environmental Accounting } \\
\hline $\begin{array}{l}\text { Cash based } \\
\text { Accounting }\end{array}$ & $\begin{array}{l}\text { Events are recognized at } \\
\text { the time of payment. }\end{array}$ & $\begin{array}{c}\text { Emission based } \\
\text { Accounting }\end{array}$ & $\begin{array}{l}\text { Events are recognized } \\
\text { at the time of emission. }\end{array}$ \\
\hline $\begin{array}{c}\text { Accrual } \\
\text { Accounting }\end{array}$ & $\begin{array}{l}\text { Events are recognized at } \\
\text { the time of transaction. }\end{array}$ & $\begin{array}{l}\text { Service Based } \\
\text { Accounting }\end{array}$ & $\begin{array}{l}\text { Events are recognized } \\
\text { at the time of service. }\end{array}$ \\
\hline
\end{tabular}


The emission-based accounting principle only considers direct flows of energy, material, and pollutants and does not take the flows that fall beyond the analysis horizon into consideration. For example, with the emission-based accounting approach, the future impacts of postponing required maintenance (e.g. by creating the need for earlier reconstruction of the asset) are not taken into consideration. Hence, the method may amplify and shift the burdens beyond the analysis horizon. This drawback of emissionbased environmental accounting is similar to the long known limitation of cash-based financial accounting. The cash-based accounting approach only considers direct cash inflows/outflows and does not take into account the long term financial impacts related to future streams of revenue (or liability) generated by selling on credit or capital investments. Because of this limitation of cash-based accounting, a growing number of organizations all around the world are moving away from this method and are adopting accrual basis of accounting for budgeting and financial purposes (Peter Van Der Hoek, M 2005). The advantage of accrual accounting over cash-based accounting is that it takes both current and expected future cash flows into consideration and is hence more reflective of the impacts of managerial decisions on the long term financial conditions of organizations (Kwon 1990; Carlin 2005). Successful application of accrual accounting in financial management inspired the present study to propose a similar approach for environmental accounting. The environmental accounting approach proposed in this paper is called service-based environmental accounting. In service-based environmental accounting the impacts are recognized when the service is provided rather than when pollutants are released to the environment. In other words, the service-based accounting attributes life cycle environmental impacts of an asset to each year of its service life based on the 
proportion of total expected service offered in that year rather than the direct emissions made. By calculating the environmental impacts of an asset in each year of its service life one can create a life cycle environmental impacts (EI) profile of the asset. Figure 3.5 visualizes the process of calculating life cycle impacts profile in SPA-LCA framework.

This novel approach enables consideration of both current and future environmental flows. For example, in assessing the environmental impacts of a roadway in a certain year, not only the direct emissions of vehicles traveling on the road are recognized, but also the indirect impacts related to creating the need for future maintenance and rehabilitation of the road are accounted for.

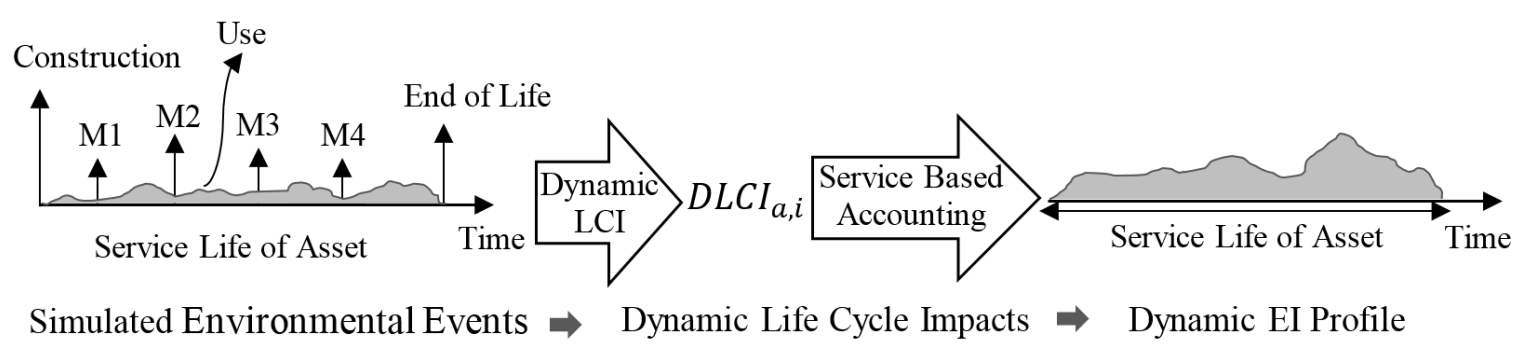

Figure 3-5: From simulated environmental events to dynamic environmental impacts profile

\section{Interpretation}

The interpretation phase of SPA-LCA has two advantages over the life cycle interpretation of traditional LCA:

(i) The proposed SPA-LCA method allows for interpretation of results at any desired time horizon. The flexibility in time interval of interpretation has been enabled due to the annual basis of impact assessment in SPA-LCA compared to the lump-sum impact assessment of LCA. The budgetary and functional interdependencies of different assets are taken into 
consideration when the annual impacts of each asset are calculated. Therefore, aggregation of the annual impacts of all assets at any point of time provides a true indicator of networklevel environmental performance. Having the network-level impacts on a yearly basis allows for interpretation of results at any desired analysis horizon. Figure 3.6 illustrates the aggregation and interpretation of impacts in SPA-LCA for a desired time horizon.

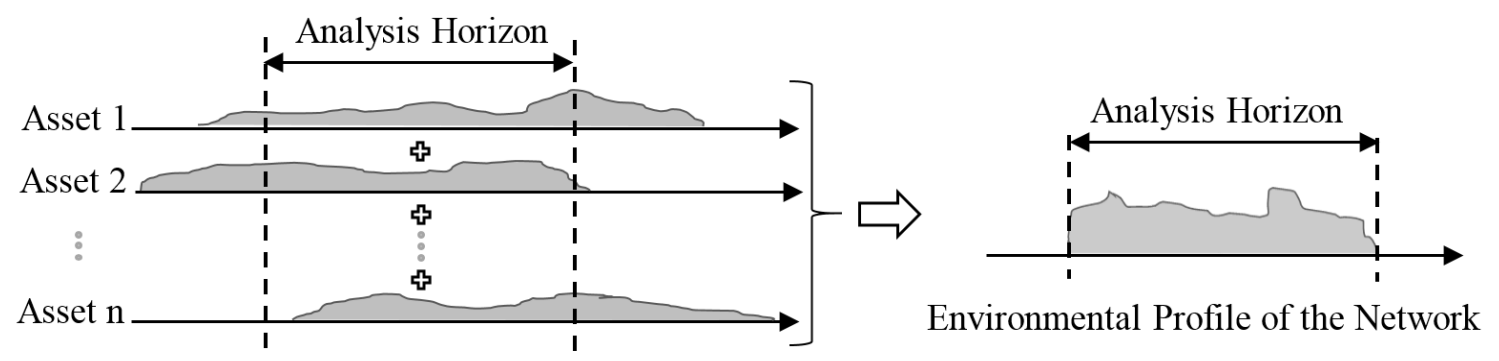

Figure 3-6: Aggregation of impacts into environmental profile of the network (ii) While LCA results can only be used to identify the best solution for a specific scenario of budget and demand, the dynamic impact assessment in SPA-LCA enables identification of a set of robust solutions under various uncertain demand and budget scenarios. Figure 3.7 illustrates this difference in interpretation of LCA and SPA-LCA results. 


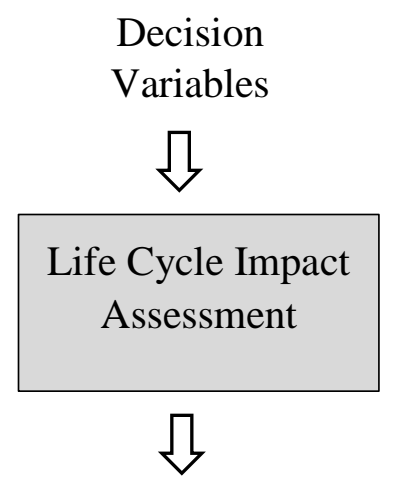

Best Solution for Specific Scenario
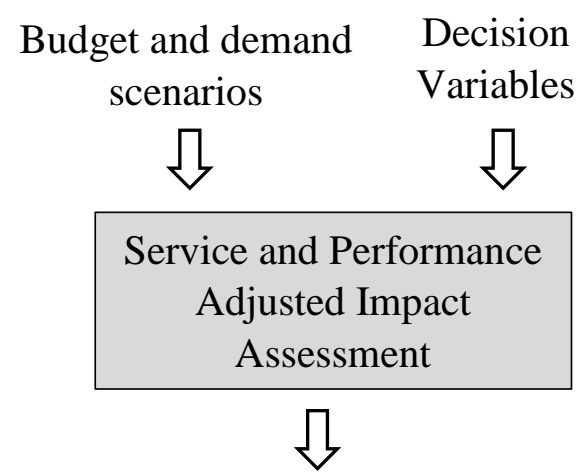

Set of Robust Solutions across Different Scenarios
a. LCA
b. SPA-LCA

Figure 3-7: Interpretation in LCA and SPA-LCA

\subsection{Computational Model}

In order to implement the proposed methodology an agent based simulation model was developed for assessing environmental impacts of infrastructure systems. To this end, the three modules of the proposed framework are computationally modeled in a java-based object-oriented programming platform (i.e., AnyLogic 7.0). The created computational simulation model is comprised of four classes of objects as shown in class diagram in Figure 3.8. The Main class is where the simulation environment and the other three classes of objects are defined. The main class also controls the time steps of the simulation model. The other three classes of objects (i.e. Agency, Physical Network and Modified LCA) are modelled as agents. The following sections explain the attributes and operations of each agent. 


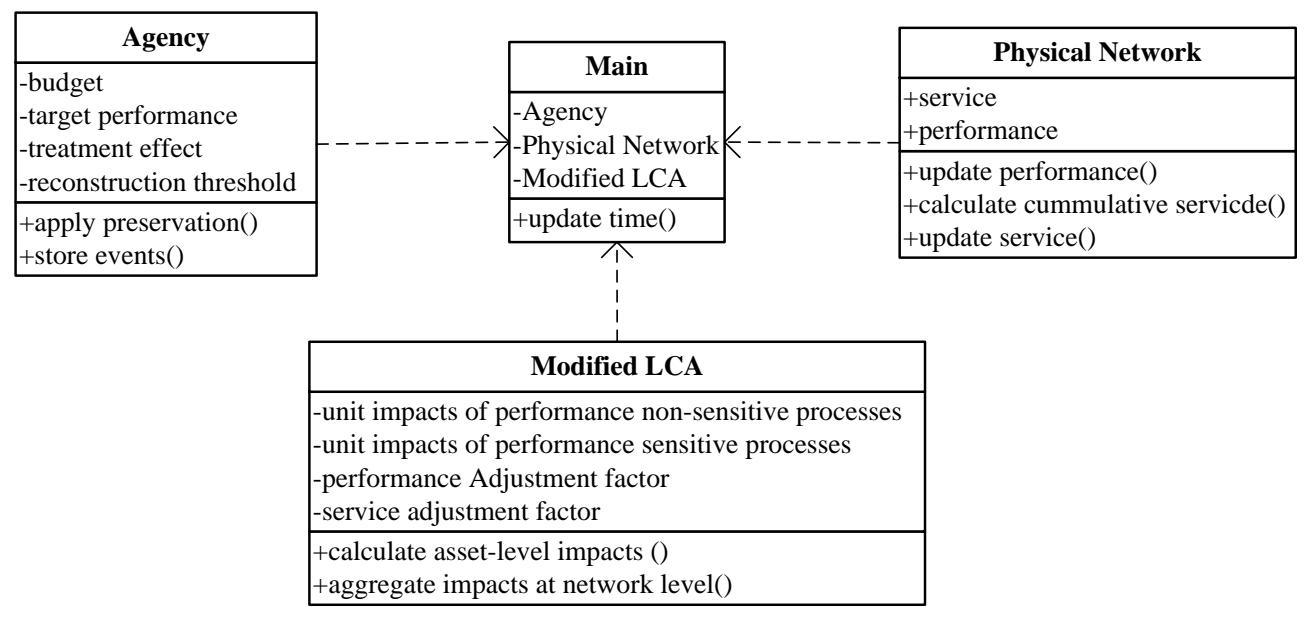

Figure 3-8: Class diagram of the simulation model

\subsubsection{Physical Network}

The dynamic service and performances of the infrastructure assets are captured in the Physical Network object. Each asset "a" is an instance object of type Physical Network.

The physical network agent obtains from an external database the forecasted service level of asset a at time $\mathrm{t}$ (denoted by $S_{a, t}$ ). Then calculates the cumulative service level of the asset since its start of life (i.e. construction or reconstruction of the asset) from Equation 2:

$C S_{a, t}=C S_{a, t-1}+S_{a, t}$ Equation (2)

Where $C S_{a, t-1}$ is the cumulative service of asset a at previous simulation time step (t-1). When an asset reaches its end of life, the Physical Network agent stores its total cumulative service and repeats the process for the new life cycle.

The performance conditions of the assets are assessed based on empirical performance prediction models (Kong and Frangopol 2003). Hence, performance 
prediction models are specific to different infrastructure sectors and study objectives. In general, performance models quantify the performance conditions of an infrastructure asset "a" at any given time " $t$ " based on variables such as initial conditions of the asset $\left(P_{a, i}\right)$, design characteristics of the asset $\left(D C_{a}\right)$, asset's age $\left(A g e_{a, t}\right)$, ambient climate $\left(A C_{a}\right)$, and the cumulative service load of the asset in the period ending at $t\left(C S_{a, t}\right)$ (Ben-Akiva and Gopinath 1995). Equation 3 shows the general formulation of infrastructure performance prediction models.

$P_{a, t}=F\left(P_{a, i}, D C_{a}, A g e_{a, t}, A C_{a}, C S_{a, t}\right)$ Equation (3) An example of a performance prediction model, adopted in the case study section of this paper, is the model proposed by Lee et al. (1993) to project the performance conditions of pavement assets. This model uses Present Serviceability Rating (PSR) as an indicator of pavement and quantifies it based on the empirically obtained Equation 4:

$P S R_{A, t}=P S R_{A, i}-A \cdot F * a * S T R_{A}{ }^{b} * A g e_{A, t}{ }^{c} * C E S A L_{A, t}{ }^{d}$ Equation (4)

In Equation 4, $P S R_{A, i}$ denotes the initial value of PSR for asset "A" right after construction or after a major rehabilitation. This value is assumed to be 4.5 according to Chootinan et al. (2006) and Lee et al. (1993). In Equation 4, a,b,c,d are coefficients whose values depend on the type of pavement (Lee et al. 1993).Cumulative Equivalent Single Axle Loads per day $\left(C E S A L_{A, t}\right)$ and $S T R_{A}$ (existing structure of pavement "A") capture the impact of traffic load and structural design of the pavement, respectively. An adjustment factor is shown as A.F and is used to customize the prediction based on the 
effect of climate conditions. Finally, the age of the pavement (since the initial construction or the last major activity rehabilitation or overlay) is shown as " $A g e_{A, t}$ " in Equation 4.

\subsubsection{Agency}

The dynamic behaviors pertaining to the decision-making processes of agency are captured in the Agency object using an action chart. The behavior of agency is modeled based on the predominant approach for preservation of infrastructure assets, known as Conditionbased maintenance (CBM) (Saha and Ksaibati 2015). According to CBM models, the agency monitors the actual condition of infrastructure assets to decide what maintenance needs to be done. In other words, the decision to implement a maintenance treatment is made when certain indicators of asset condition show sign of decreasing performance or risk of failure. Figure 3.9 shows the action chart used to model this behavior of the agency. At each decision point (e.g. every year) the agency assesses the performance condition of all assets. The assets with lower performance are prioritized for maintenance treatment or reconstruction. The maintenance treatment is applied if the asset does not meet the agency's target performance level but has not yet reached such low level of performance that necessitates reconstruction of the asset. The reconstruction, and maintenance treatments are implemented contingent upon availability of capital improvement and maintenance budget, respectively. When an asset is reconstructed its performance is restored to the highest possible performance level. The maintenance treatment (based on the type of treatment) makes partial improvement in performance condition of an asset. After the decisions pertaining to maintenance or reconstruction of all assets are made, the Agency object stores all events and proceeds to the next decision point. 
$\mathrm{P}_{(i, t)}=$ Performance of $\mathrm{i}^{\text {th }}$ asset at time $\mathrm{t}$

$\mathrm{P}_{(\text {target })}=$ The agency's target level of performance

$\mathrm{P}_{(\max )}=$ Performance of a newly constructed asset

$\mathrm{BCI}_{(t)}=$ Capital improvement budget at time $\mathrm{t}$

$\mathrm{BM}_{(t)}=$ Maintenance budget at time $\mathrm{t}$

$\mathrm{C}_{(\text {recon(i)) }}=$ Cost of reconstructing asset $\mathrm{i}$

$\mathrm{C}_{(\text {maint }(\mathrm{i}))}=$ Cost of maintenance treatment on asset $\mathrm{i}$

Age $_{(i, t)}=$ Age of asset $\mathrm{i}$ at time $\mathrm{t}$

$\mathrm{BCI}_{(t)}>\mathrm{C}_{(\mathrm{recon}(\mathrm{i}))}$

$\mathrm{BM}_{(t)}>\mathrm{C}_{(\text {maint(i)) }}$

$\mathrm{P}_{(\text {maint })}=$ Performance improvement due to maintenance treatment

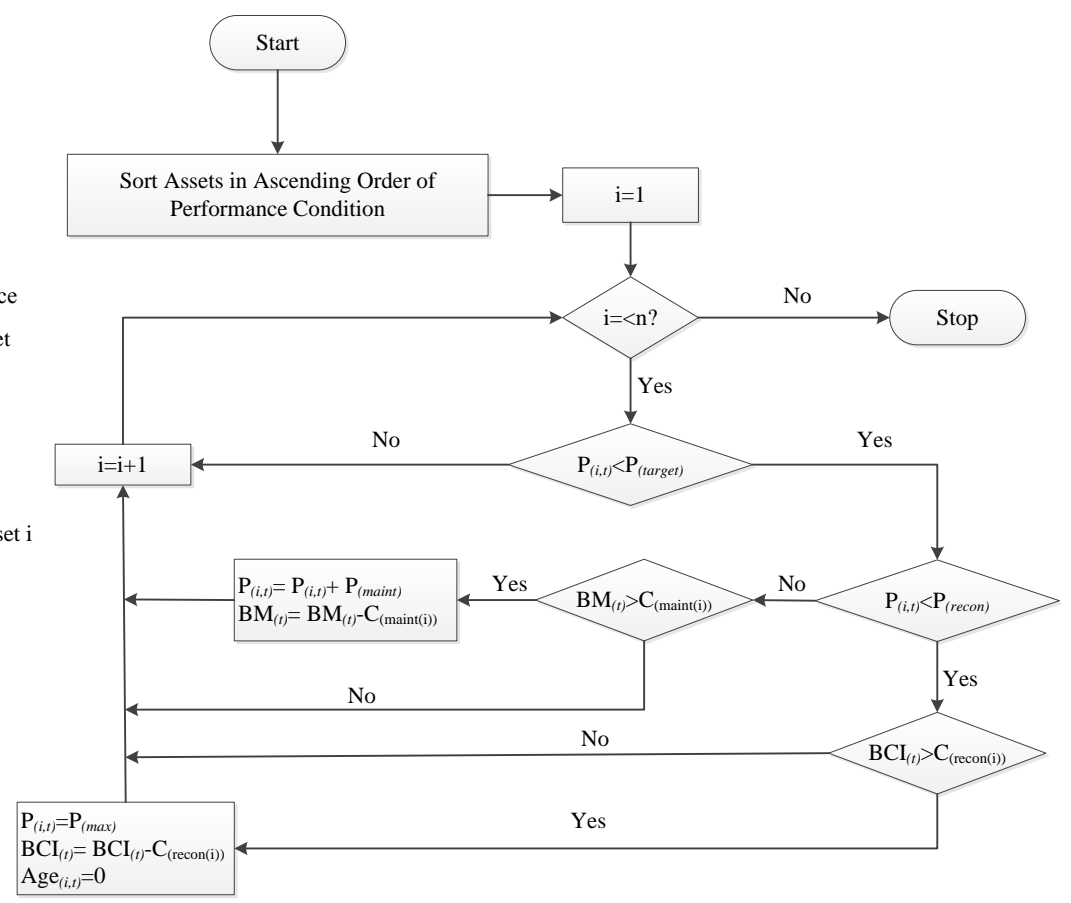

Figure 3-9: Action chart to model the condition based maintenance behavior of the agency

\subsubsection{Modified LCA}

The Modified LCA agent calculates the service and performance adjusted life cycle impacts of an infrastructure network based on the simulated life cycle processes (such as maintenance and rehabilitation actions) as well as the simulated annual values of service, and performance. To this end, first a dynamic life cycle inventory is created for each asset using Equation 5:

$D L C I_{k}=\sum_{j=1}^{n} M R_{a, j} * N_{M R_{a}, i}+\sum_{l=1}^{m} U . s t d_{a} * P A F_{a, l}$

Where:

$D_{L C I}=$ Dynamic Life Cycle Inventories of Asset $k$ 
n: Total number of $M \& R$ types

$M R_{k, j}=$ Unit flows related to applying jth type of $M \& R$ activity on asset $k$

$N_{M R_{k, j}, i}=$ Simulated Number of $j$ th type of $M \& R$ during service life of Asset $k$

$m=$ Length of service life

$U . s d_{k}=$ Annual use impact of asset $k$ under standard performance

$P A F_{k, l}$

$=$ Performance adjustment factor for year lof the service life of asset $A$

The dynamic life cycle inventories are then attributed to each year of the service life based on the proportion of total expected service offered in that year (Equation 6).

$$
E I_{k, i}=L C I_{k} * \frac{s_{k, j}}{C S_{k}}
$$

In Equation 6, $E I_{k, i}$ denotes service-based environmental impacts of asset $k$ in year i of its life cycle. $L C I_{k}$ is the total life cycle impacts of asset $k . L C I_{a}$ is calculated from the dynamic life cycle inventories using the same classification and characterization models as in traditional LCA (refer to ISO 14040 and 14044 for details on classification and characterization models). The coefficient $\frac{S_{k, i}}{C S_{k}}$ represents a service adjustment factor in which $S_{a, i}$ and $C S_{a}$ respectively denote service level of asset $\mathrm{A}$ in year i, and the cumulative service of asset A during the service life of the asset. 
Finally, the network level environmental impacts at year $i$ is calculated by summing up the environmental impacts associated with all assets in year $i$.

\subsection{Numerical Case Study}

In order to demonstrate the application of the proposed framework and computational model, the global warming potential (GWP) associated with the service life of pavements pertaining to twelve sections of a road network are analyzed. The study network is a subset of the roadway network presented in The ICMPA7 Investment Analysis and Communication Challenge for Road Assets (Haas 2008). As shown in Table 3 the network includes roads of either rural (R) or urban interstate (I) highways. The initial traffic on each road is represented by Equivalent Single Axle Load (ESAL) in Table 3. All roads include 4 lanes except for roads $\mathrm{H}$ and I, which have 6 lanes.

Table 3-3: Characteristics of the case network

\begin{tabular}{ccccccccccccc} 
& A & B & C & D & E & F & G & H & I & J & K & L \\
\hline Road Type & R & I & I & I & R & R & I & R & R & I & I & I \\
\hline Length (Km) & 2.5 & 0.8 & 1.1 & 0.3 & 0.7 & 4.4 & 1.0 & 1.7 & 4.5 & 2.2 & 2.7 & 1.0 \\
\hline Width (feet) & 36.1 & 37.4 & 41.0 & 37.4 & 42.7 & 41.3 & 46.6 & 53.8 & 39.0 & 40.7 & 38.7 & 54.5 \\
\hline No. of Lanes & 4 & 4 & 4 & 4 & 4 & 4 & 4 & 6 & 4 & 4 & 4 & 6 \\
\hline STR & 3.53 & 14.6 & 4.3 & 7.2 & 4.8 & 11 & 17.7 & 13.4 & 13.4 & 14.6 & 5.6 & 7.7 \\
\hline ESAL/ Day & 224 & 1185 & 1645 & 1756 & 864 & 688 & 1142 & 1785 & 1785 & 1185 & 1479 & 1756 \\
\hline
\end{tabular}

\section{Goal and scope definition}

The goal of the study is to assess the global warming potential associated with construction, maintenance and rehabilitation, use, and end of life of the twelve assets in the network. The study intends to identify the impacts of three demand scenarios and 11 different $M \& R$ budget levels on global warming potential of the network. The three demand scenarios include a base scenario of "no change" in the traffic load and two 
alternative scenarios of 3 and 5 percent traffic growth per year. The M\&R budget scenarios start at a low annual budget level of $\$ 100,000$ and explores levels up to $\$ 1,100,000$ at $\$ 100,000$ intervals. The base scenario considers a budget level equal to $\$ 100,000$ and no traffic growth. The impacts are assessed over a 40-year analysis horizon. The goal and scope definition phase includes two steps, in accordance with the SPA-LCA framework:

(i) The life cycle of each asset is defined as the time between two consecutive reconstructions of the asset. The relevant proportion of the impacts related to any life cycle that, fully or partially, overlaps with the analysis horizon is within the scope of the impact assessment. The main function of the roadway assets is to facilitate mobility of vehicles. Therefore, the functional unit is considered to be one lane-mile of pavement. The system boundary includes functional and budgetary interrelations among assets. All assets are dependent on the same maintenance and rehabilitation budget pool. The assets with lower performance are prioritized for the budget allocation. In addition, the demand scenarios apply universally to the entire network.

(ii) The functional unit is adjusted to the level of service. To this end, the life cycle impacts associated with one functional unit (i.e. one lane-mile of a pavement) are attributed to each year of service life. The impacts are attributed to each year, based on the proportion of traffic load in that year to the design traffic load of the pavement for its entire service life. The functional unit is also adjusted to the level of performance of the pavements in order to account for the effects of pavement roughness on environmental impacts of pavements. The roughness of the pavements is measured using the Present Serviceability Index (PSI), a five-point scale widely used for assessing pavement performance. A PSI 
value equal to 1 represents pavements with lowest performance and a PSI value of 5 indicates excellent performance conditions. According to Barnes and Langworthy (2003) when PSI value of a road is between 3 and 3.5 the fuel consumption is $5 \%$ greater than fuel consumption on pavements with excellent condition. For PSI values in the range of 2.53.0, fuel consumption increases $15 \%$. These coefficients are used to adjust the impacts of use phase based on the level of performance of the pavements.

\section{Inventory analysis}

The life cycle inventories of the network are quantified using the SPA-LCA framework. In order to account for the effects of service and performance fluctuations on the environmental impacts of the case network, the life cycle processes of pavement assets are divided into two categories of inventory items:

(i) The impacts associated with the materials production, construction, and end of life are not sensitive to the level of service and performance. The inventory data related to greenhouse gas emissions generated during these phases was obtained from Loijos et al. (2013) and is based on average conditions in the United States for different types of roadways. For example, material acquisition, construction, and end of life of the pavement in one $\mathrm{km}$ of a 4 lane rural interstate roadway generate 2603,49 , and $470 \mathrm{Mg} \mathrm{CO} 2$ eq. global warming potential, respectively (Loijos et al. 2013). Accordingly, global warming potential generated in the material acquisition, construction and end of life of road A are 
6508, 123 and $1175 \mathrm{Mg} \mathrm{CO} 2$ eq. global warming potential, respectively (i.e. 2.5 times of one $\mathrm{km}$ rural interstate roadway).

(ii) The processes, and thus environmental impacts, related to $M \& R$ and use phase are sensitive to the level of service and performance of infrastructure. The mechanism through which the M\&R and use processes are affected by the level of service and performance is a complex mechanism that depends on the dynamic behaviors and interactions between the physical infrastructure network and the institutional agency managing the infrastructure (Batouli and Mostafavi 2014). Thus, in order to capture the effects of service and performance on the magnitude and frequency of $M \& R$ and use impacts, an agent-based simulation model is created to simulate the collective behaviors of the agency and the network. Details related to the agent-based modeling of the agency/network interactions can be found in Batouli and Mostafavi (2014).

The first outcomes of the simulation model include the timing and type of M\&R activities applied on the network, the simulated annual level of service and performance of the roads, and the expected service life of each asset. This information is used to convert a traditional static life cycle inventory of the M\&R and use phases into a dynamic LCI.

For calculating the inventory data related to $M \& R$ phase, the number of occurrences of each maintenance treatment is multiplied by the unit impacts of the treatment. For example, under a base scenario of $\$ 500,000$ annual $M \& R$ budget and no traffic growth, one run of the simulation model shows that road A reaches its end of life at year 7 of the analysis horizon, and consequently it is reconstructed at year 8 . Year 8 is the beginning of a new service life for road A. This service life lasts for 41 years. During this service life, 
based on the simulated conditions and the worst-first preservation strategy, road A will receive two surface treatments, three overlays, and one rehabilitation. Each surface treatment, overlay and rehabilitation of road A create 24, 71 and $141 \mathrm{Mg}$ of CO2 eq. GWP, respectively. Therefore, during this service life (from year 8 to year 49) a total of $402 \mathrm{Mg}$ $\mathrm{CO} 2$ eq. $(2 \times 24+3 \times 71+1 \times 141=402 \mathrm{Mg} \mathrm{CO} 2$ eq. $)$ will be created due to M\&R activities.

The inventory data of the use phase is calculated by adjusting the use phase emissions for the pavement condition. For example, under excellent roughness condition, 53.75 Mg CO2 eq. GWP is created due to use of road A in each year. However, the performance of road A is not excellent in year 10 (PSI=3.36), and hence, more fuel will be consumed by driving on asset $\mathrm{A}$ in this year. To account for the additional emissions, the use impact of road A is multiplied by a PAF of 1.05 (associated with PSI of road A in year 10). Thus, the use inventory data of road A in year 10 is calculated as follows: $53.75 \times 1.05=$ 56.437 Mg CO2 eq. GWP. Similar calculation is done for every year of this life cycle of asset $\mathrm{A}$ and the total use phase inventory is calculated to be $2518.188 \mathrm{MG} \mathrm{CO} 2$ eq of GWP. A similar process is conducted for every life cycle of all assets in order to create the dynamic life cycle inventories of the assets.

\section{Impact assessment}

In the impact assessment phase, the inventory data is attributed to each year of life cycle by using the service-based environmental accounting method. To this end, the level of traffic in each year of life cycle is calculated. The level of traffic of each asset is simulated with consideration given to lane closures during maintenance, rehabilitation, and reconstruction activities. It is assumed that routine maintenance does not affect the annual 
level of traffic in a road. However, surface treatment, overlay, and rehabilitation of an asset result in $10 \%, 30 \%$, and $55 \%$ reduction in the level of service, respectively. Reconstruction of an asset leads to complete shutdown of the asset for a year. Therefore, there is no service in the reconstruction years. After traffic level in each year is calculated, the performance sensitive and performance non-sensitive impacts are quantified, with consideration given to the level of traffic in each year of service life. For performance non-sensitive items, the impact at each year is calculated using Equation 7:

$$
X_{i j}=N S_{i j} * \frac{E S A L_{i j}}{E S A L_{a v}}
$$

Where:

$X_{i j}:$ The GWP related to performance non - sensitive impacts of road $j$ in year $i$

$N S_{i j}:$ Total GWP related to performance non sensitive impacts of road $j$ during the life cycle that contains year $i$

$E S A L_{i j}:$ Total equivalent single axle traffic load on road $j$ in year $i$

$E S A L_{a v}$ :Total equivalent single axle traffic load on road $j$ during its service life

In Equation 7, the fraction $\frac{E S A L_{i j}}{E S A L_{a v}}$ is a service adjustment factor that determines what proportion of the total service of road $j$ is provided in year $i$. For distributing the impacts to each year, total impacts are multiplied by the service adjustment factor. For example, the simulation model shows that the traffic on road A in year 10 is 0.1442 ESAL. The total 
traffic load of Road A during this life cycle (i.e., year 8 to 49) is 10.70157 ESAL. Therefore $1.3 \%$ of the total service is provided in year 10. Based on the service basis accounting principle, $1.3 \%$ of the total life cycle impacts of road A (approximately $110.6 \mathrm{Mg} \mathrm{CO} 2 \mathrm{eq}$. GWP) is due to the service in year 10 .

The impacts of use phase are adjusted based on both the level of service and the level of performance so as to account for the impact of pavement roughness on the fuel consumption of the vehicles. The impacts related to use phase are calculated from Equation 8:

$Y_{i j}=T S_{j} * \frac{E S A L_{i j}}{E S A L_{a v}} * P A F$ Equation (8)

Where:

$Y_{i j}:$ The GWP related to performance sensitive impacts of road $j$ in year $i$

$T S_{j}$ : GWP related to use phase of road $j$ considering excellent road conditions

PAF: Performance Adjustment Factor

$E S A L_{i j}:$ Total equivalent single axle traffic load on road $j$ in year $i$

$E S A L_{a v}$ : Total equivalent single axle traffic load on road $j$ during its service life Finally, the total SPA-LCA impacts in each year are calculated as the sum of the performance-sensitive and performance-non-sensitive impacts. The results and interpretation of them are presented in next section. 


\subsection{Results and Interpretation}

Effective policy analysis pertaining to environmental sustainability of infrastructure systems requires an understanding of the likely environmental impacts of the network under different levels of budget and demand scenarios. To address this need, global warming potential of the case network is calculated for different demand and budget scenarios.

\subsubsection{Impact of demand growth on sustainability performance of the network}

Figure 3.10 shows the GWP of the case network over the forty-year analysis horizon under, three demand scenarios, with a base annual M\&R budget. According to the results as the demand increases the network's impacts will grow accordingly. For the base traffic scenario (i.e. no traffic growth) no significant change happens in the GWP of the network over the analysis horizon. However, under 3\% and 5\% demand growth, the GWP of the network increases $46 \%$ and $88 \%$ respectively. This result not only indicate that the environmental impacts of a network will increase over time if the demand grows, but also shows an exponential increase in the environmental impacts with growing demand. According to the results, if other variables remain constant, demand growth exacerbates the unsustainable conditions of the network over time. Therefore, management approaches for the networks that experience demand growth should be adapted based on demand growth levels. 


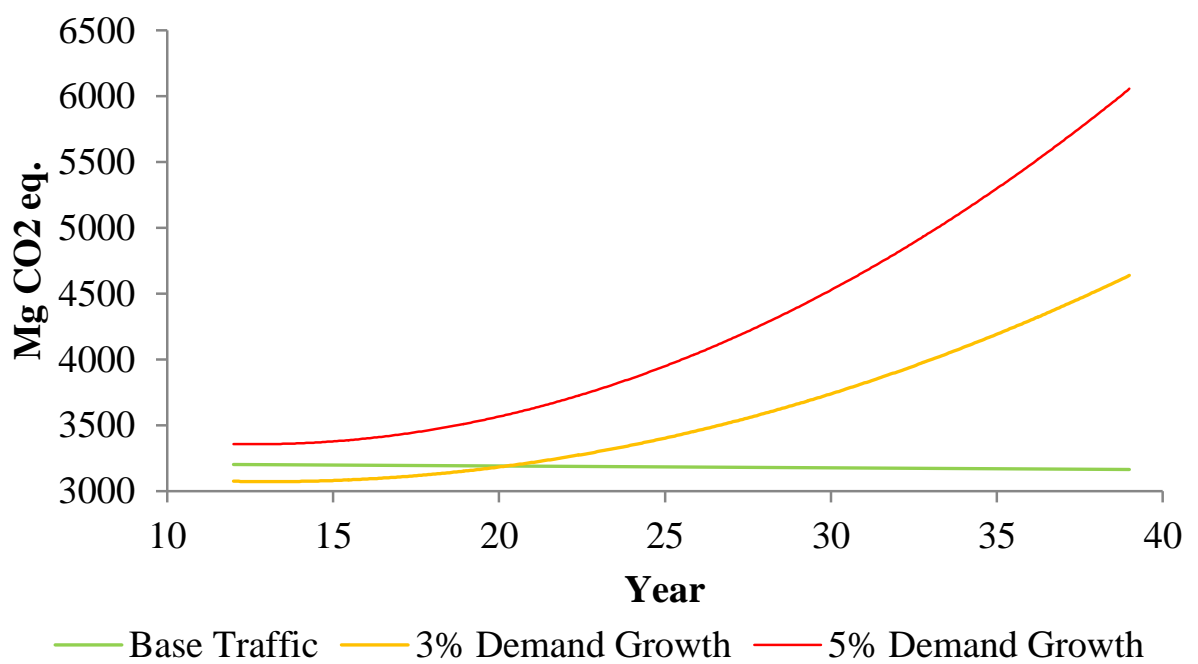

Figure 3-10: Global Warming Potential of the Network under Different Demand Scenarios

\subsubsection{Impact of $M \& R$ budget on sustainability of the network}

Figure 3.11 shows the impact of M\&R budget on performance and GWP of the network. The results show that increasing $M \& R$ budget improves the network performance and environmental impacts. However, the impact of funding increase on performance improvement and environmental impact reduction diminishes after a certain threshold. This shows that after a certain threshold increasing budget does not lead to significant improvement in network performance or environmental impacts. In addition, a tipping point behavior was observed for both performance and GWP of the network at budget level of $\$ 700 \mathrm{~K}$. This tipping point is where a small increase in the M\&R budget leads to significant improvement in network performance and environmental impacts. In the case network, this budget level changes the state of network preservation from corrective maintenance to preventive maintenance. Identifying the tipping point budget is complex because the tipping point behavior is an emergent property as a result of the dynamic 
interactions between the physical conditions of assets and decision making behavior of the agency. Identification of tipping point budget helps making informed decisions regarding the appropriate budget level for a network.
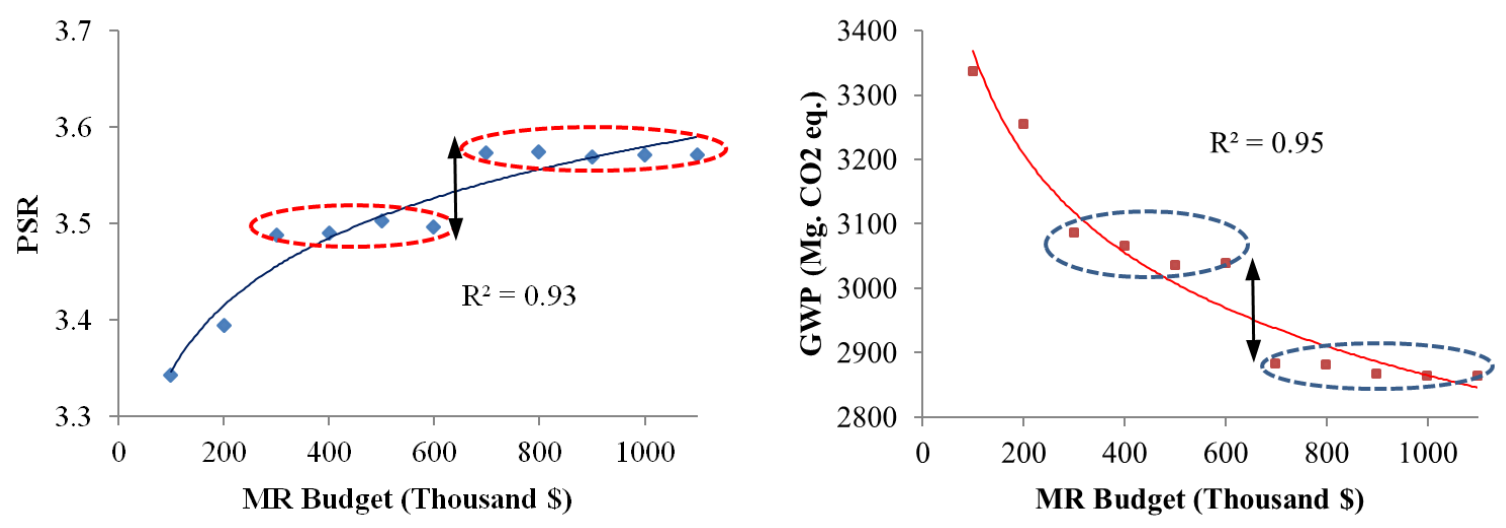

Figure 3-11: Global warming potential and PSI of the network under different budget scenarios

Observing the improvements in the sustainability performance of the network by increasing $M \& R$ budget encourages the use of funding increases as an adaptive measure to deal with the exacerbating sustainability conditions of networks with demand growth. To evaluate the effectiveness of budget increases to control the adverse impacts of growing demand on sustainability of infrastructure, the demand growth scenarios were studied in conjunction with different levels of funding. Figure 3.12 shows the network environmental performance associated with different funding levels under 0\%, 3\% and 5\% demand growth scenarios. Based on the results, funding increase improves network sustainability in all scenarios. For the no demand growth scenario, there is $14.2 \%$ reduction in the GWP by increasing the budget from $\$ 100,000$ to $\$ 1,100,000$. The reductions for 3\% and 5\% demand growth scenarios are $15.2 \%$ and $20.6 \%$ respectively. The results show that the extent of sustainability improvements is greater under the growing demand conditions. In other words, the sustainability performance of the network is more sensitive to level of 
funding at higher levels of demand. In addition, 96\%, 91\%, and 96\% of GWP reduction for the three demand scenarios respectively happen by increasing budget from the base $\$ 100,000$ to $\$ 700,000$. This shows that the sustainability performance of the network is more sensitive to level of funding at lower levels.

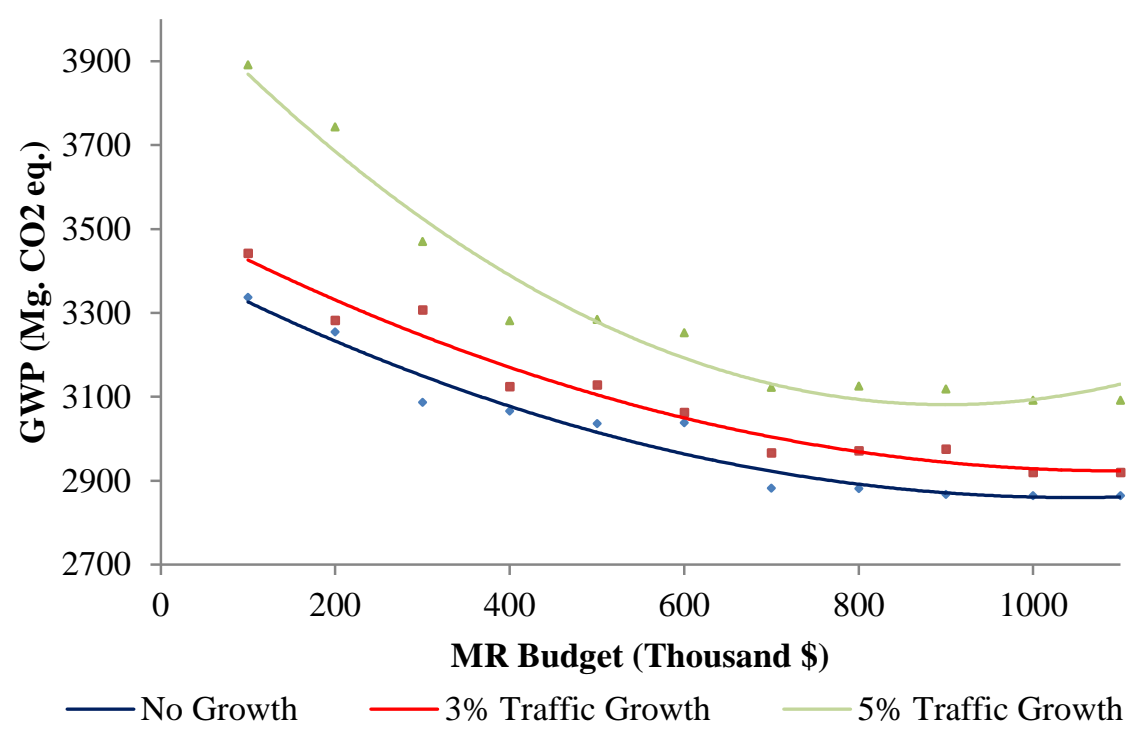

Figure 3-12: Impact of $M \& R$ budget on environmental performance of the network under different demand scenarios

\subsubsection{Impact of timing of decisions on sustainability of the network}

In addition to the amount of $M \& R$ funding, the time in which the funding is allocated also has an impact on the sustainability performance of the network. Figure 3.13 shows the value of increasing the M\&R budget in mitigating GWP of the network in different years. Based on the results both medium $(\$ 400,000)$ and high $(\$ 900,000)$ increases in the M\&R funding reduce the GWP of the network throughout the analysis horizon. However, the impact of budget increases is lower in the mid years of the analysis horizon. This implies that increasing the $M \& R$ funding in the first and last third of the analysis horizon is more 
effective for mitigating the environmental impacts in the network. Interestingly, these are the times that the network is in relatively better performance condition. As seen in Figure 3.14 , the network is in relatively good condition in the first third of the analysis horizon. Therefore, the increased $M \& R$ funding will be invested in preventive maintenance treatment. However, in the mid years of the analysis the average condition of the network deteriorates due to the aging of several assets. Higher M\&R funding in this period will lead to more spending on corrective maintenance of the assets in poor performance condition. Finally, the deteriorated assets are reconstructed and thus their performances are improved in the last third of the analysis horizon. Once again, more funding will be spent on preventative maintenance. Identifying the appropriate timing for $M \& R$ investment enables decision makers to allocate $M \& R$ funding when highest improvement in sustainability of the network can be achieved.

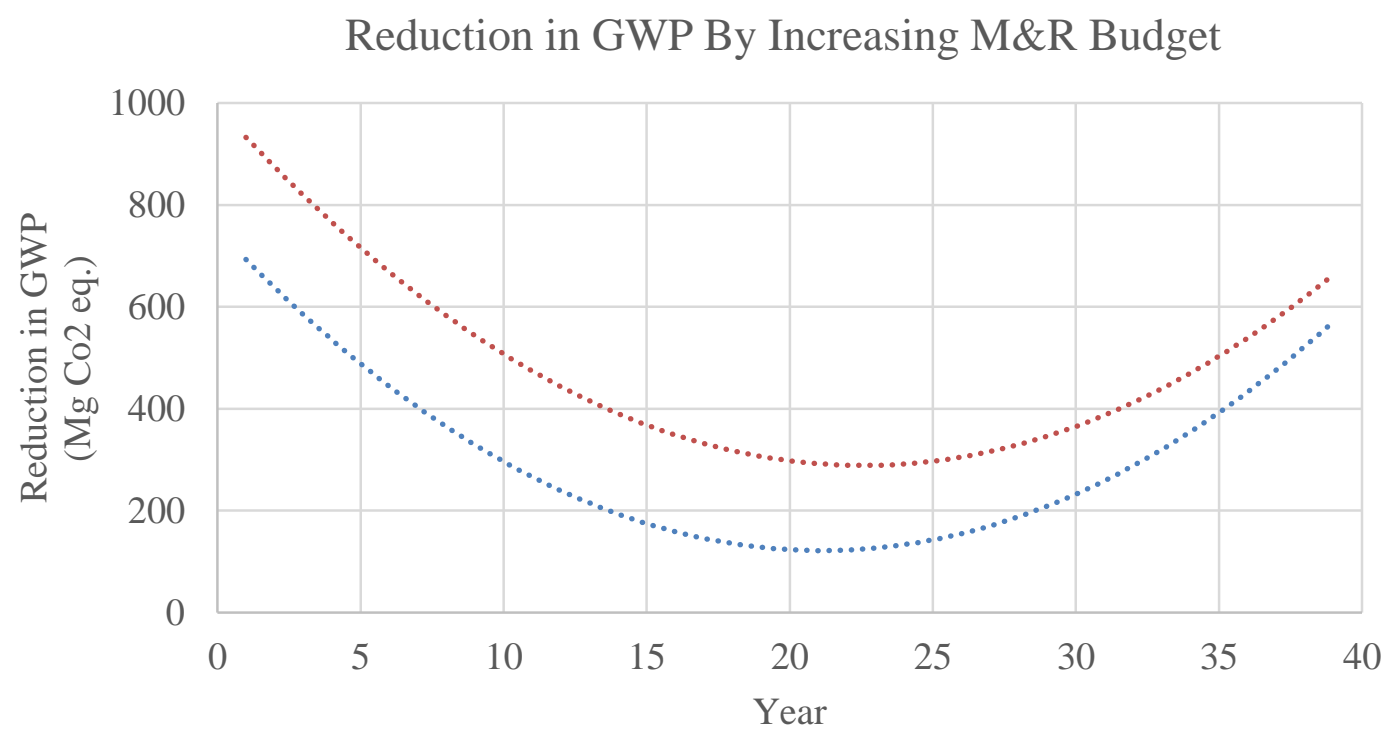

Increasing Budget by 400,000\$ Increasing Budget by $900,000 \$$

Figure 3-13: Reduction in GWP by increasing M\&R budget in different years of analysis 


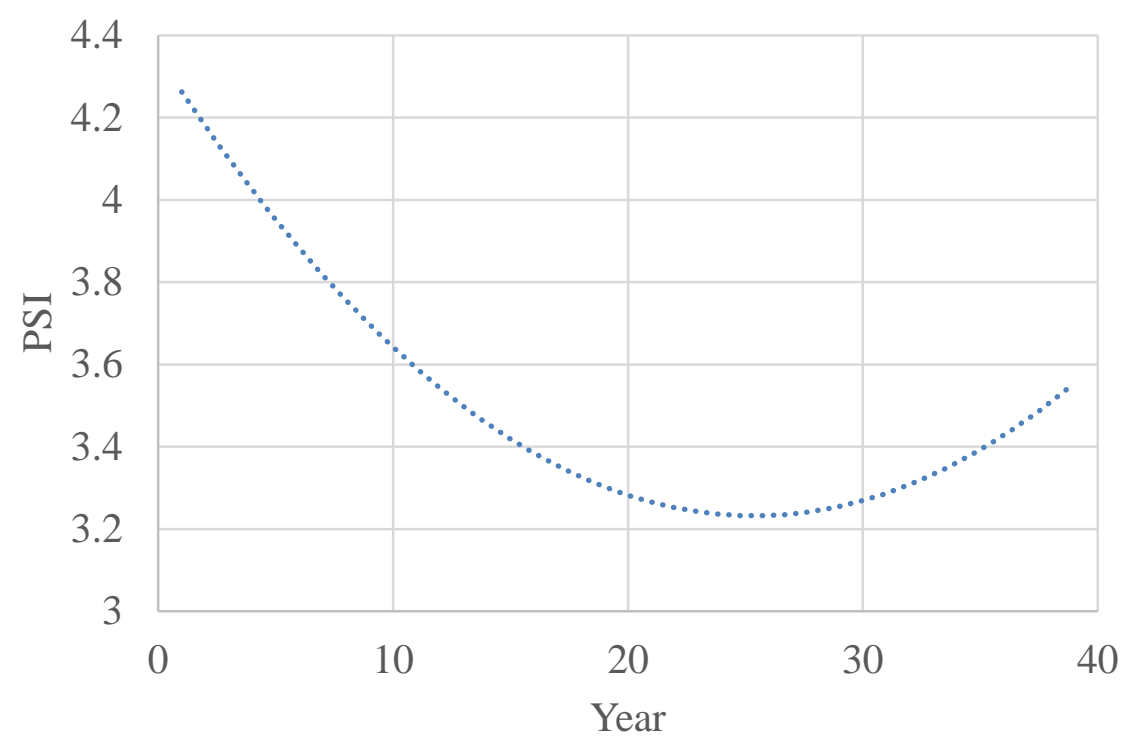

Figure 3-14: Changes in network performance over the analysis horizon

\subsubsection{Impact of Performance Condition on sustainability of the network}

Another finding of this research is that a strong negative correlation exists between GWP and PSI of the network. As depicted in Figure 3.15, the higher the performance of the network, the lower the GWP of the network. This is due to two reasons. First, the higher performance levels are achieved when the agency applies preventive maintenance on the pavements before they reach major condition problems. Applying preventive maintenance reduces the need for more intense maintenance or rehabilitation treatments in the future, thus reducing the total environmental impacts of in the network. This result highlights the importance of simple preventive maintenance treatments and encourages decision makers to put more emphasis on preservation of the assets that have not yet developed major performance problems. The SPA-LCA methodology is capable of capturing this phenomenon because it takes both direct and indirect flows into consideration. With 
emission-based environmental accounting methods the impacts of future activities are not reflected in the environmental performance in a certain year.

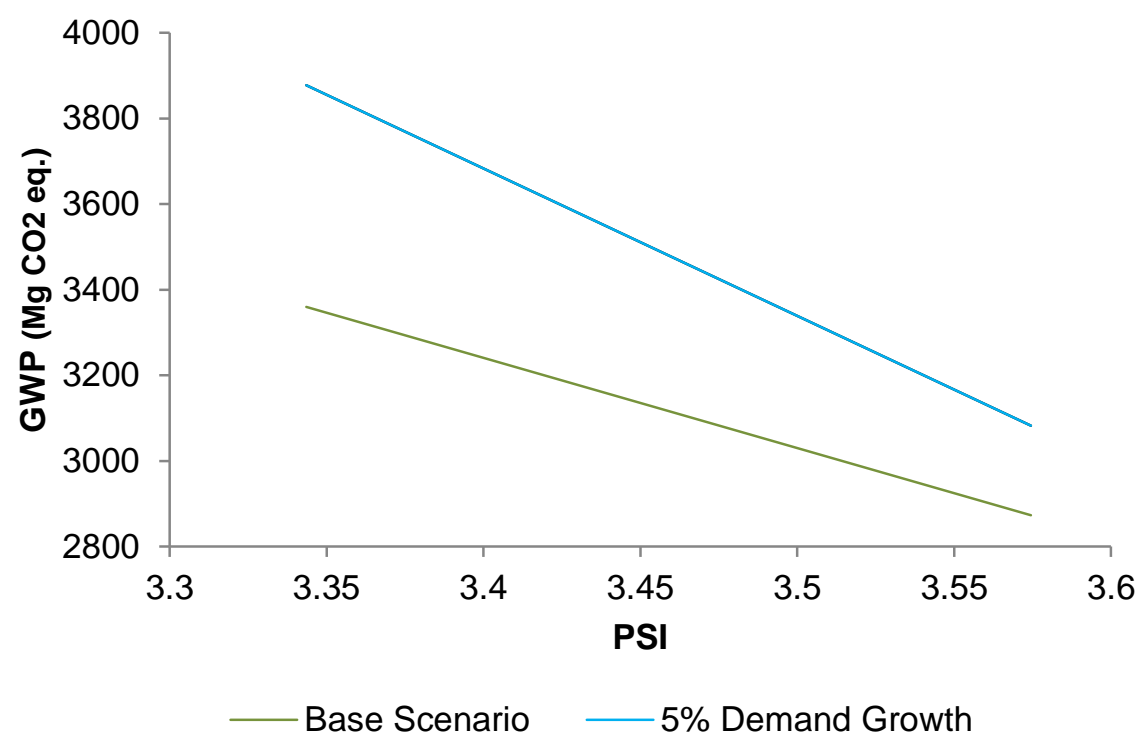

Figure 3-15: Relationship between network performance and global warming potential

Second, higher performance of pavements is associated with reduction of fuel consumption in vehicles travelling on the pavement. Thus, the use phase impacts are lower for the pavements with higher performance. This result shows that by keeping the pavement network in excellent performance condition not only will users enjoy a smoother ride, but also the environmental impacts of the network will be significantly reduced.

\subsubsection{Conclusion}

The environmental impacts associated with construction, maintenance, and use of infrastructure systems are at the core of sustainability challenge. However, the existing life cycle assessment approach was not originally created for assessing the environmental impacts of infrastructure systems, and as a result has important limitations pertaining to the 
specific traits of infrastructure systems. The research presented in this paper addressed the limitations of LCA by creating and testing a service and performance adjusted LCA (SPALCA) methodology that is tailored to the requirements of environmental assessment in infrastructure systems. The SPA-LCA method makes adjustments in all four phases of LCA. First, at the goal and scope definition the life cycle and functional unit are defined at asset-level and the system boundary is defined at network-level, thus enabling SPA-LCA to capture the interrelations between different assets without a need for defining universal life time and functional unit for the infrastructure system. Second, at the inventory analysis phase the life cycle inventories are created dynamically by using a simulation based computational model. Dynamic creation of life cycle inventories enables consideration of the effects of different development pathways of infrastructure (such as changes in timing and type of M\&R treatments and/or extent of use) caused by various budget and demand scenarios on environmental impacts in infrastructure systems. Third, at the impact assessment phase a service-based environmental accounting principle analogous to accrual accounting in finance and economic studies is introduced. The service-based accounting enables assessment of the environmental impacts of infrastructure on any desired analysis horizon without creating burden shifting problems. Finally, at the interpretation stage, SPA-LCA results support policy analysis for varying budget and demand scenarios and at different time scales.

The application of the SPA-LCA method on a pavement network has revealed important information about sustainability of infrastructure systems and so validates its importance. First, the results show that the demand growth leads to an exponential increase in the environmental impacts in a network. Of even more significance, the findings 
highlight the need for improving the current practices in management of infrastructure systems in a world where demand is growing rapidly. Second, the study found that increasing $M \& R$ funding improves network performance and environmental impacts. However, the effect of increased funding diminishes at higher levels of spending. This shows that, for a network with specific traits, improving the performance and environmental impacts beyond a certain point is unattainable solely with increasing investment. Third, a tipping point behavior was observed in the relationship between $M \& R$ funding and sustainability performance of the network. This means at a certain budget level, small increase in the amount of $M \& R$ funding leads to significant improvement in the performance and environmental impacts of the network. Identifying the tipping point of an infrastructure network enables decision makers to determine the most appropriate budget level within the limitations of their institutions. Fourth, the results showed that the extent of improvement in sustainability outcomes of a network is higher for networks that are experiencing higher demand growth. This finding reveals that budget allocation for maintenance of infrastructure should not be reactively made based on the exiting condition of the assets. Instead, the budget allocation should proactively consider the expected future level of service. Fifth, the results showed that the same increase in the level of funding leads to different levels of improvement in environmental impacts of an infrastructure network, based on the timing of the budget increase. This result clearly indicates the capability of SPA-LCA method in identifying the appropriate time for investing on maintenance and rehabilitation of infrastructure networks. Finally, the results show a negative linear relationship between the level of performance and environmental impacts 
of the network, indicating that keeping a network in better performance conditions will result in reduction of its environmental impacts.

The contributions of the present study to the body of knowledge are threefold. First, this study identified the limitations of and misconceptions about the use of LCA for environmental assessment of infrastructure systems. The results clearly demonstrated that infrastructure systems do not meet the requirements of LCA (e.g. they do not have a definite life cycle), and LCA does not meet the requirements of environmental assessment of infrastructure systems (e.g. LCA does not support policy analysis at different time scales). Second, this study proposed and tested service based environmental accounting as a basis for assessment of environmental impacts in infrastructure systems. According to the findings of this research the service-based environmental accounting can bring similar advantages to environmental assessment of infrastructure systems compared to what accrual accounting provides for financial and economic assessment. Third, this study created dynamic life cycle inventories that enable consideration of the impacts of complex changes in the level of service and performance of infrastructure systems on their environmental performance. Ultimately this study contributes to development of the theory of sustainable infrastructure by creating a methodology that is particular to assessment of the environmental impacts of infrastructure systems.

From a practical perspective, the SPA-LCA methodology and the results of the case study enable more informed decision making pertaining to sustainable construction, maintenance, and use of infrastructure systems. The SPA-LCA approach could help environmentally literate decisions at the strategic, tactical, and operational levels of 
decision making. At the strategic level, the outcomes of this study enable setting feasible and yet effective budget and performance targets for maintenance of infrastructure systems. At the tactical level, SPA-LCA facilitates identification of the appropriate timing for investment on infrastructure systems. At the operational level, the findings of this study indicate the importance of preventive maintenance treatments on reducing environmental impacts of infrastructure.

The proposed SPA-LCA methodology has certain limitations. First, it is solely focused on the environmental aspect of infrastructure sustainability. A suggested next step is to integrate SPA-LCA with methodologies for assessing economic and social dimensions of infrastructure sustainability. Second, the impacts of socio-environmental forces such as climate change on environmental performance of infrastructure systems are not considered in this study. A future research path is to use the SPA-LCA methodology for quantifying the impacts of climate change on long term environmental performance of infrastructure systems and identifying likely adaptation actions that can mitigate these impacts. 


\section{Assessment of Sea-Level Rise Adaptation in Coastal Infrastructure Systems: Robust Decision-Making under Uncertainty}

\subsection{ABSTRACT}

Sea-level rise is one of the most concerning and costly effects of climate change. Resulting sea-level rise impacts may include failure or destruction of infrastructure, immobilization due to transportation system breakdown, and catastrophic saltwater contamination of water supplies. The problem of sea-level rise adaptation is characterized by deep uncertainty that makes it complex to evaluate the economic value of adaptation investments. The key element to evaluate the effectiveness of adaptation strategies is to quantify the long-term cost of physical networks under uncertain sea-level rise scenarios. In this paper, a simulation framework is created and tested to investigate the long-term impacts of sea-level rise on infrastructure systems in order to evaluate the effectiveness of various adaptation strategies. To this end, the transformation of infrastructure systems under various scenarios of sea-level rise and adaptation strategies is modeled using the proposed simulation framework. Then, the impacts of sea-level rise are determined in terms of the life cycle costs of infrastructure networks. These estimated costs are used for evaluating the feasibility of various adaptation strategies under future uncertain sea-level rise scenarios. The application of the proposed simulation framework is shown in a case study of a road network using the sea-level rise scenarios in Southeast Florida. The results of the analysis are threefold: (1) prioritization of infrastructure assets for adaptation investment; (2) identification of the right timing of adaptation investments for different links in an infrastructure network; and (3) evaluation of the present value of adaptation 
investments for the entire network. The results enable more informed decision-making in order to implement robust adaptation under uncertain sea-level rise scenarios.

\subsection{INTRODUCTION}

The earth's surface temperature has increased significantly since late $19^{\text {th }}$ century. There is clear scientific evidence that the rising trend of the world's temperature will continue for at least a few more decades (Hartmann et al. 2013). One inevitable consequence of global warming is rising sea level due to melting of glaciers and thermal expansion of oceans. Sea-level rise can adversely affect critical infrastructure systems in coastal regions that reside $13 \%$ of the world and $39 \%$ of U.S. population. For example, sea level rise is associated with elevation of groundwater levels which could seriously damage infrastructure systems by reducing the drainage capacity of water and sewer systems, saturating the soil in sub-base and base layers of roads, and intrusion of salt water into fresh aquifers. In low lying coastal lands the ground water may breakout during the high tide periods and create seasonal flooding and, in extreme cases, can permanently inundate coastal infrastructure.

To moderate the potential impacts of sea-level rise on infrastructure systems, planning and implementation of cost effective adaptation strategies is critical. Evaluation of the effectiveness of adaptation actions is critical to avoid maladaptation in infrastructure systems. Maladaptation is poor selection of adaptation actions such that the changes in the infrastructure systems become less and less effective as time goes until the infrastructure systems on which a society depends become dysfunctional. Maladaptation may occur due to failure to anticipate the true impacts of sea-level rise and take timely actions. On the other hand, making adaptation decisions is a complex task that requires substantial 
investments under significant uncertainty. Also, making adaptation decisions would require making trade-offs between the normal condition and sea-level rise requirements over the long-term. Hence, making robust adaptation decisions is contingent upon evaluation of the long-term transformation of infrastructure systems under different adaptation strategies and sea-level rise scenarios. This important knowledge is missing in the existing body of knowledge. To address this knowledge gap, the objective of the study presented in this paper is to create and test a framework for evaluation of infrastructure adaptation under uncertainty to enable informed decision-making for optimizing adaptation investments in coastal communities.

\subsection{INFRASTRUCTURE ADAPTATION ANALYSIS FRAMEWORK}

The key element to evaluate the effectiveness of adaptation strategies is to quantify the long-term cost and performance of physical networks under various adaptation and sealevel rise scenarios. However, the long-term cost and performance of infrastructure systems are affected by condition of physical networks, vulnerability of network links to the impacts of sea-level rise, and decision-making behaviors of the institutional agencies managing physical networks. Hence, a framework for assessing adaptation strategies in infrastructure systems should capture the long-term dynamic interactions between the condition and vulnerability of a physical network as well as the decision-making behaviors of the institutional agency. To this end, an integrated framework is proposed in this study to address the requirements for the analysis of sea-level rise adaptation strategies in infrastructure systems. As shown in Figure 4.1, infrastructure systems transform over time

due to the dynamic interactions between network's vulnerability, condition of assets, and 
decision making behaviors of the agency. Vulnerability of infrastructure depends on the likelihood and extent of sea-level rise to which the infrastructure is exposed (exposure) as well as the sensitivity of the system to sea-level rise damage (sensitivity) (Lankao and Qin 2011). On the other hand, the sensitivity of the system to sea level rise damage is a function of the structural capacity of the physical networks to withstand the impacts of sea-level rise (Lankao and Qin 2011). The potential damages caused by sea-level rise lead to accelerated decay of the physical assets. To cope with the accelerated network decay the agency can interfere with either more aggressive maintenance/rehabilitation (M\&R) treatments or by investing in adaptation strategies. The adaptation action is an unconventional measure intended to reduce the vulnerability of the network to the impacts of sea-level rise. The agency makes the decision regarding ways to mitigate the impacts of sea-level rise based on the existing decision constraints (e.g., budget limitations, regulations about minimum acceptable performance, etc.) and an assessment of the risk associated with sea-level rise. However, more informed decisions about preservation of the network could be made if the real values of adaptation investments are quantified.

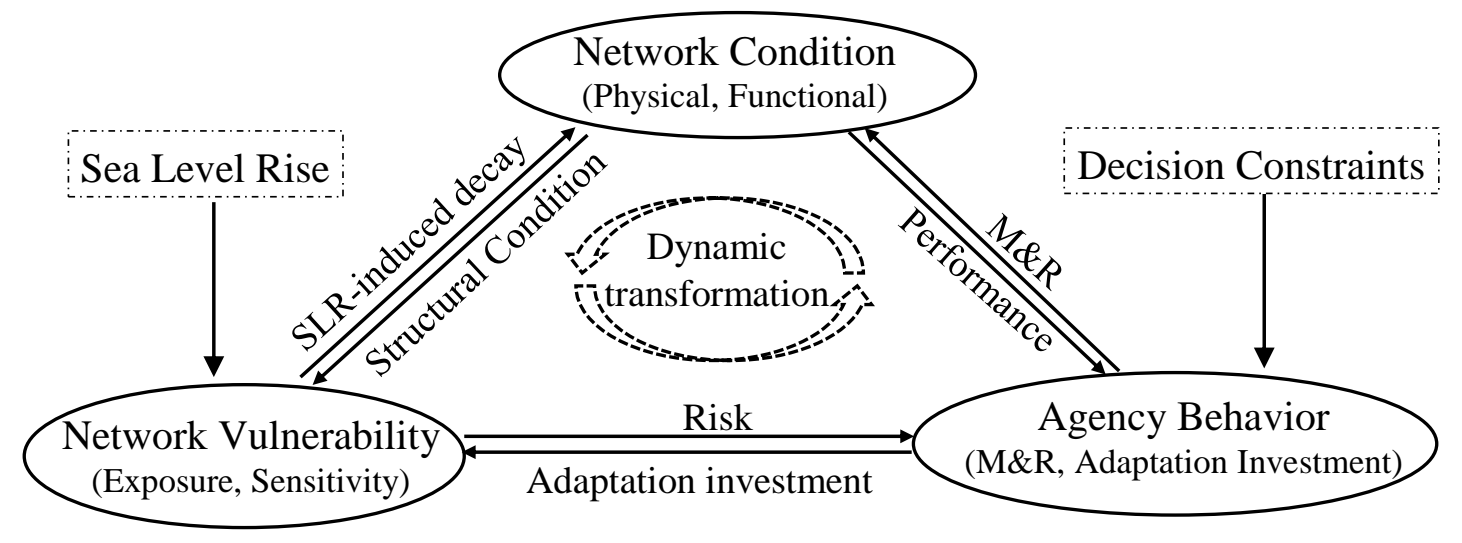

Figure 4-1: Transformation of CIS network under the impacts of sea level rise 
In order to capture the dynamic interactions affecting the long-term performance of infrastructure, a simulation framework is proposed. The simulation framework is composed of four steps as shown in Figure 4.2. The first step is to identify the likely sealevel rise projections during the analysis horizon. To this end, three sea-level rise scenarios are evaluated: slow, moderate, and fast. These scenarios are obtained from down-scaled climate studies (e.g., Compact (2011)). In the second step, different alternative adaptation strategies are evaluated based on the risk associated with sea-level rise scenarios. Each alternative strategy is evaluated in terms of its ability to reduce the vulnerability (i.e. either exposure or sensitivity) of the network to the impacts of sea-level rise. In the third step, the cash flows associated with the entire service life of all assets are simulated under two scenarios: (1) no adaptation to be implemented; and (2) a selected adaptation strategy to be implemented. The cash flows are all costs related to preservation of the network including the costs of maintenance, rehabilitation, and reconstruction of the assets. The agency decides about the maintenance and rehabilitation (M\&R), and reconstruction of assets based on the performance condition of the assets each year during the analysis horizon. The decision making processes of the agency and the performance conditions of the network are simulated using an agent-based model to determine the timing and type of cash flows associated with M\&R activities. Accordingly, the annual cost of the network during the analysis horizon is determined. In the last step, the present value of the adaptation investment is calculated based on the annual network cost difference in adaptation scenario compared to no adaptation scenario. 


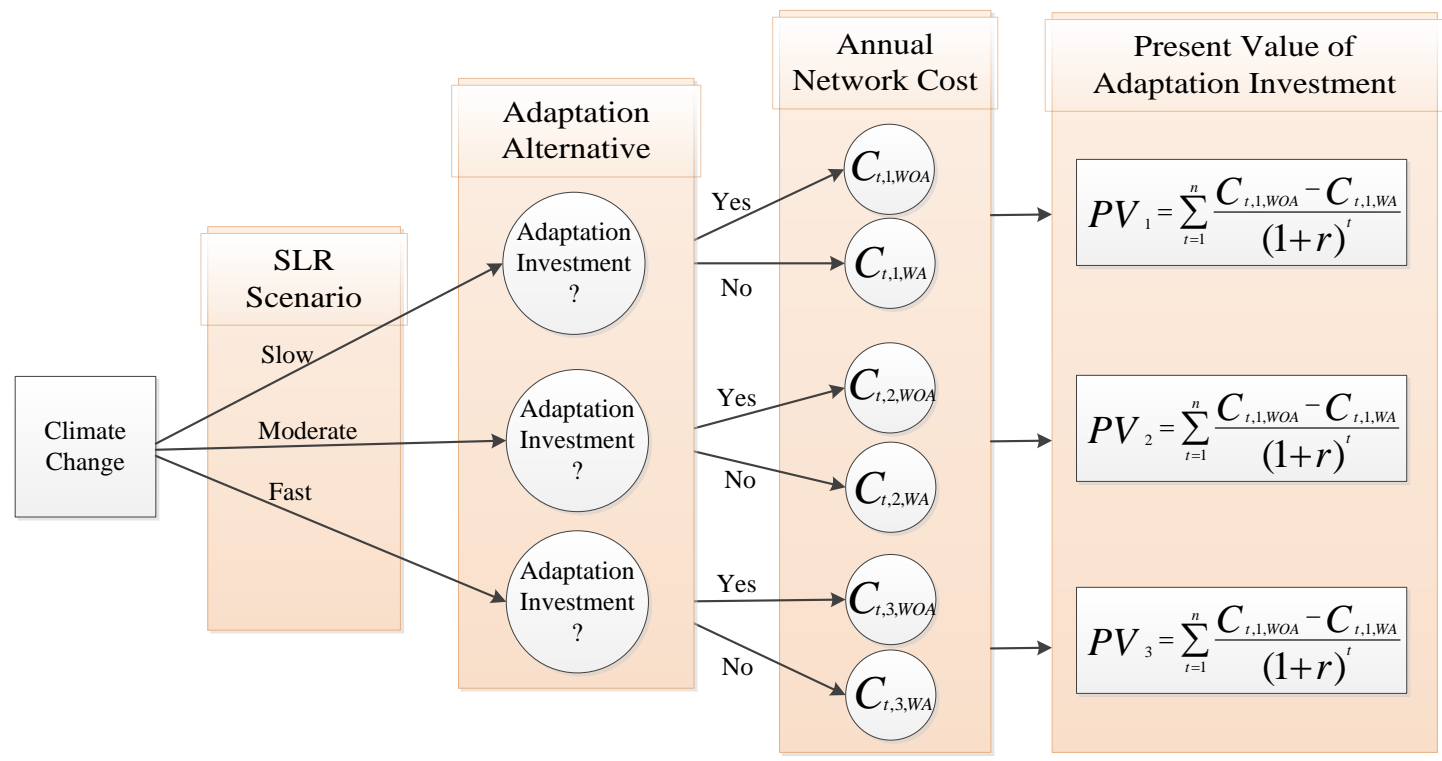

$P V_{i}$ : Present value of the adaptation alternative for ith sea level rise scenario $n$ : the analysis time

$C_{t, i, W o A}$ : Cash outflows related to cost events without adaptation investment

$C_{t, i, W A}:$ Cash outflows related to cost events with the adaptation investment alternative

$r$ : Interest rate

Figure 4-2: Simulation framework for calculating the value of adaptation

\subsection{CASE STUDY}

The application of the proposed simulation framework is illustrated in case study of a road network. Sea-level rise scenarios related to Southeast Florida, a region with one of the most vulnerable infrastructure systems in the world, was considered. The network studied in this case study is a sub-portion of a roadway network provided in Haas (2008). The network includes twelve links of either rural (R) or urban (U) type with varying dimensions (length, with, and number of lanes), structural number (STR), and traffic levels (Equivalent Single Axle Load per day or ESAL/day) as shown in Table 1. In this case study, the value of adaptation strategies to mitigate the impacts of coastal flooding induced 
by sea-level rise was investigated. Figure 4.3 shows how sea-level rise increases the likelihood of inland flooding in coastal roads. Sea-level rise elevates water table in lowlying coastal areas. The increased elevation of water table leaves less room for draining excess storm water. The loss of drainage capacity may lead to saturation of the base layer during heavy precipitation or storm surge events, and thus, cause damage to structural strength of roads (Berry et al. 2012).

Table 4-1: Characteristics of the case network

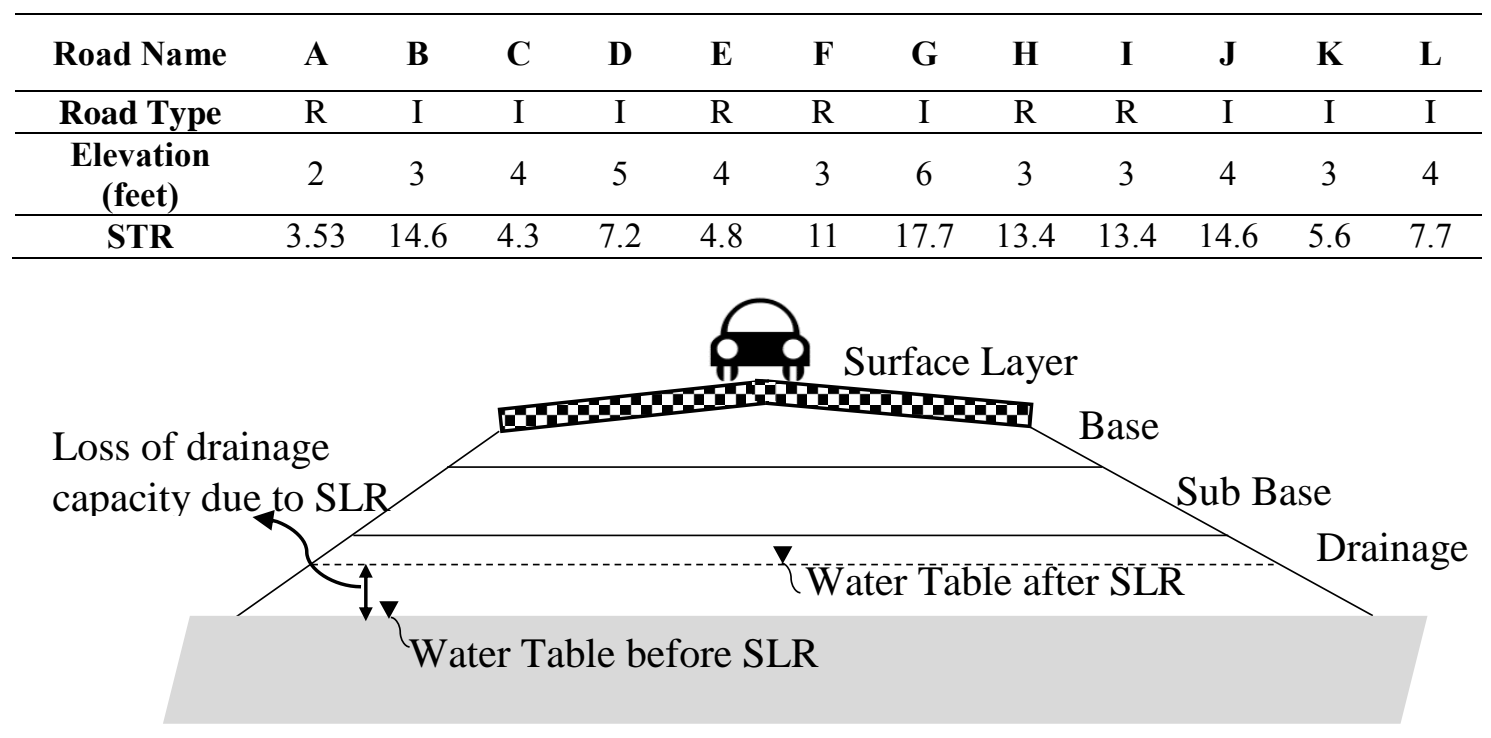

Figure 4-3: Loss of drainage capacity due to SLR

The vulnerability of the road network to flood damage depends on the exposure and sensitivity of the roads. Flooding events affect a road only if the water table in the area rises higher than the road's elevation (Berry et al. 2012). Thus, the exposure of a road depends on the road's elevation. On the other hand, the sensitivity of a road to the potential flood is a function of the road's structural condition. In particular, thinner pavement layers are more sensitive to the impacts of flooding damage and show greater reduction of effective structural number when they get flooded (Zhang et al. 2008). Due to the flooding 
damages, the roads experience a more accelerated decay. Hence, the damage caused by flooding induced by sea-level rise can increase the preservation cost of the entire network. The administrative agency can mitigate these impacts by making adaptation investments to reduce the vulnerability of the network or increasing the $M \& R$ funding to implement more extensive treatments. Accordingly, the value of adaptation investments can be determined through the use of the proposed framework.

\subsubsection{Identifying Sea-Level Rise Scenarios}

The information related to sea-level rise projections was used in the analysis. Southeast Florida is threatened by a minimum of $1.6 \mathrm{ft}$. and a maximum of $4.9 \mathrm{ft}$. sea-level rise by 2100 with $3.3 \mathrm{ft}$. being the most likely scenario (Compact 2011). These scenarios are referred to as slow, fast, and moderate sea-level rise, respectively. The Climate Central recently translated the slow, moderate, and fast sea-level rise scenarios into annual risk of 1-10 feet flooding. The flooding risks used in the present study are taken from the Climate Central report as shown in Figure 4.4 (Strauss et al. 2013).

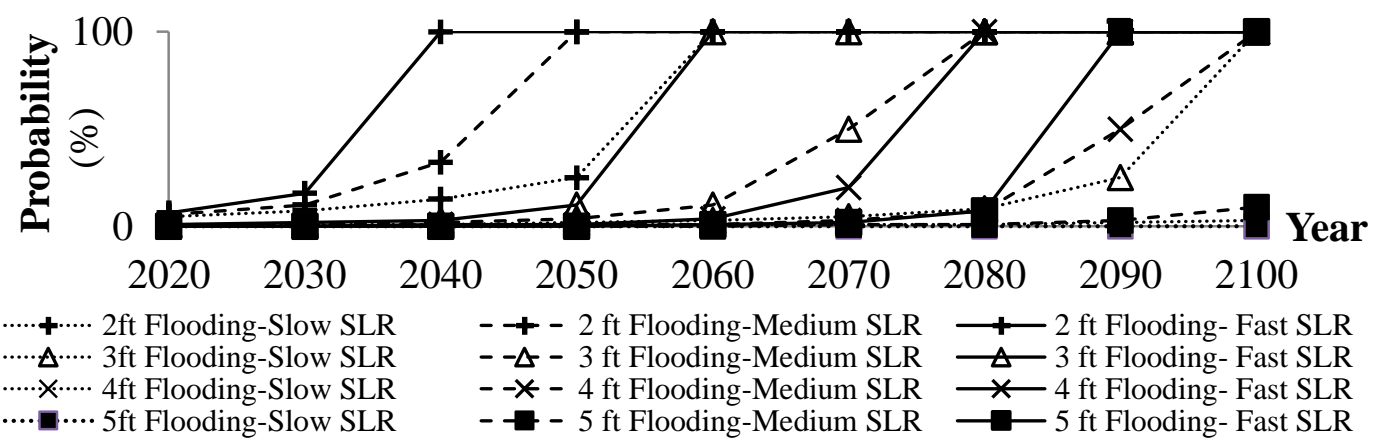

Figure 4-4: Annual risk of flooding associated with SLR scenarios

\subsubsection{Selecting Adaptation Alternatives}


The key action to reduce the vulnerability of roadway assets to flood damage is to keep their base layer dry. If the base layer stays dry, the pavement will not be affected by the increased water tables. Thus, improving the flood control and drainage systems could be used to mitigate the flooding damage caused by sea-level rise (Berry et al. 2012). Since a flooding greater than four feet is not likely in Southeast Florida in the next forty years (Strauss et al. 2013) and the minimum elevation of the case study network is $2 \mathrm{ft}$. (look at Table 1), increasing the drainage capacity of the network to cope with a $2 \mathrm{ft}$. flooding is considered as a feasible adaptation investment. Installing well point system, a series of small wells and pump stations along the affected roadways, is a long-term option to improve the drainage of vulnerable roadway network (Berry et al. 2012).

\subsubsection{Simulating Cash Flows}

To enable calculating the preservation cost of the network with and without adaptation, an agent-based model was created to simulate timing and type of cash flows related to maintenance, rehabilitation or reconstruction of the pavement assets. The model is composed of four classes of objects as shown in the class diagram in Figure 4.5 (details in Batouli and Mostafavi 2014). The Main class is where the simulation environment and the other three classes of objects interact. The Agency and the Environment class of objects are modeled as agents. The behavior of the Agency agent is modeled using action charts capturing the decision constraints and the micro-behaviors of the agent. The Environment object stores the active sea-level rise scenario and its flooding impact as a probabilistic function. The Roadway object consists of a mathematical simulation model capturing the performance of the roadway links in the network. Present Serviceability Rating (PSR) is 
used for quantifying the performance of the network within the Roadway object. PSR is a widely used indicator of pavement condition which theoretically varies between a low value of 0 representing the worst condition, and a maximum value of 5 for perfect condition. In real world modeling 4.5 is considered as the highest practical PSR (Chootinan et al., 2006). The value of the PSR is dynamically calculated from a simplified pavement performance model created by Lee et. al. (1993). The PSR model includes age-related and traffic-related variables to account for the deterioration of pavements under normal condition (i.e. without flooding). In addition, flooding makes structural damage to the subbase, base and surface layers of pavements. The extent of structural damage depends on the type and initial conditions of the pavement. The impact of flooding was captured by adjusting the value of structural number in the PSR model. The flooding-induced damages to the pavements' structural numbers were obtained from (Zhang et al. 2008).

When a pavement decays, the agency interferes to restore the pavement's performance condition. The agency follows certain decision rules for allocating M\&R funding. Under a condition-based policy, a road link is only considered for maintenance if its PSR value is below 4 and maintenance treatment is only applied if it can restore the pavement to excellent condition. Moreover, urban and rural pavements are considered irremediable if they reach PSR values of 2.2 and 2, respectively (Elkinz et. al. 2013). If a pavement reaches the irremediable condition, the agency has to reconstruct it (i.e. the agency cannot leave a road on a failed condition). On all other situations the roads with the lowest PSR will be prioritized for maintenance funding allocation if M\&R funding is available. The outcome of step 3 was used to simulate the timing of M\&R cash flows for 
each road. This information was then used to determine the annual cost of each road and the network using the methodology presented in Batouli et al. (2015).

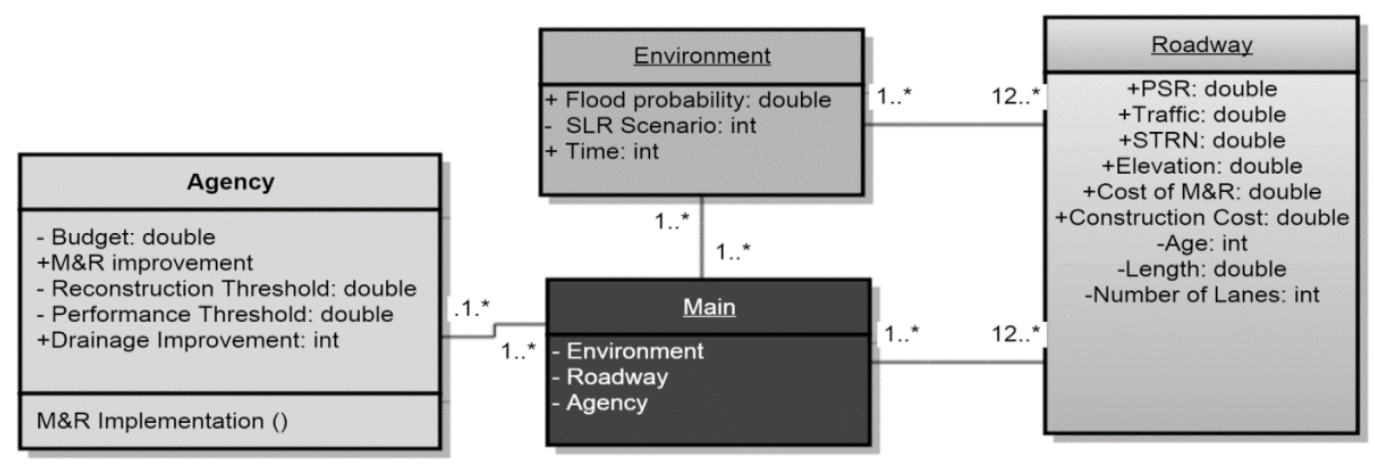

Figure 4-5: Class diagram of the agent-based model

\subsubsection{Calculating the Present Value of the Adaptation Investment}

In this step, the value of adaptation at each year was determined based on difference between the annual network costs for the adaptation scenario compared to no adaptation scenario. The value of adaptation at each year was then discounted to the present value to determine the present value of adaptation. Consistent with the Federal Highway Administration guidance, a real discount rate of $4 \%$ was used in determining the present value of adaptation (Walls and Smith, 1998).

\subsection{Model Verification and Validation}

The simulation model was verified using different approaches. First, all model parameters (such as performance, cost, and timing and type of M\&R activities) were represented graphically to enable face validation of model outcomes. Second, the behaviors of model entities (e.g., abrupt changes in the level of performance of the roads) were followed to identify unusual model behaviors. Whenever an unusual behavior was 
observed the model logic was checked to ensure that the behavior is not due to unreasonable assumptions or flawed logic. Third, several random replications of the model were compared to check for the consistency of the results (Xiang et al. 2005).

\subsection{RESULTS}

The results of the analysis are twofold: (1) determining the value of adaptation investments; and (2) prioritizing and timing of adaptation implementation on different roads in the network.

\subsubsection{Evaluating the Effectiveness of Adaptation Investments}

The simulation model was used to model the annual costs for each road as well as the entire network during a forty-year analysis horizon. Figure 4.6 depicts the simulated network cost under slow and fast sea-level rise for two scenarios: (1) no adaption was implemented; and (2) a $2 \mathrm{ft}$ storm water drainage improvement was implemented. As shown in Figure 4.6, implementation of the adaptation strategy significantly reduces the annual cost growth of the network under both fast and slow sea-level rise. In total, over the fortyyear analysis horizon, the present value of adaptation investment is $\$ 2,514,269$ under the fast sea-level rise scenario and $\$ 864,401$ under slow sea-level rise per lane-mile of the network. If no adaptation is implemented, under both fast and slow sea-level rise scenarios, the network cost grows exponentially over the analysis horizon. Without any adaptation, the annual cost in the network in the final year of analysis grows to six times and three times under fast and slow sea-level rise scenarios, respectively. However, when the adaptation is implemented the annual cost of the network only grows twice under fast sea- 
level rise. Hence, implementation of adaptation reduces the increase of annual network costs under sea-level rise scenarios.

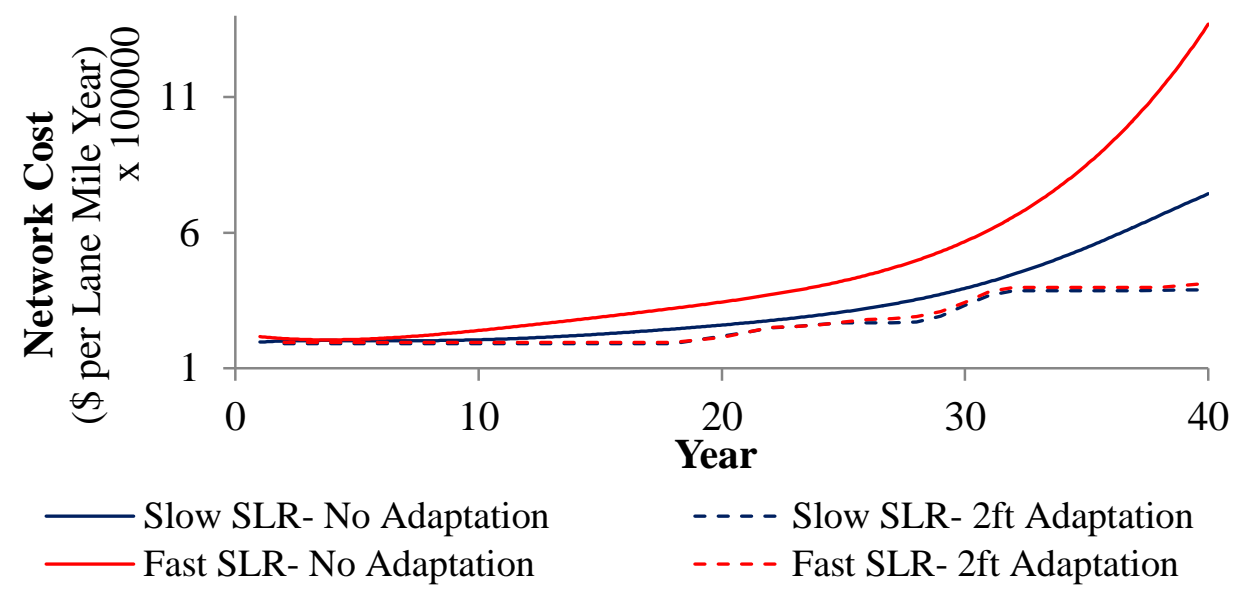

Figure 4-6: The impact of adaptation investment on network cost

\subsubsection{Prioritizing and Timing of Adaptation Implementation}

Another outcome of the analysis was prioritization of roads for adaptation and determining the timing of adaptation investments for different roads in the network. The prioritization of roads for adaptation investment is based on the present value of adaptation under different sea-level rise scenarios. The greater the present value of an adaptation investment is, the higher the priority of a road for the adaptation investment becomes. As shown in Figure 4.7(a), under fast sea-level rise, roads A, F, I, K, and H have the greatest priority for adaptation investment, respectively. Under slow sea-level rise, road A remains the top priority for adaptation, while road $\mathrm{G}$ becomes the second highest priority road for adaptation.

The simulated results also highlight the appropriate timing for implementation of adaptation investments for each road. The best timing for implementation of adaptation is 
when the annual value of adaptation grows positively. For example, as shown in Figure 4.7.b making the $2 \mathrm{ft}$. adaptation investment on asset I does not generate significant value until year 23. However, after year 23, the adaptation value for asset I grows under both fast and slow sea-level rise. Hence, year 23 is considered as the ideal time for implementing the adaptation investment on asset I based on the available information. As new information regarding sea-level rise becomes available, the analysis can be repeated to evaluate the timing of adaptation on road I. Anticipation of uncertainty is particularly important to identify flexible adaptation pathways that enable re-evaluation of plans when new information becomes available. For example, as shown in Figure 4.7, under slow sealevel rise scenario the value of adaptation for road A continues to grow for the entire analysis horizon. However, under fast sea-level rise the adaptation value for road A starts to decrease in year 18 after a sharp initial growth. In this case, adaptation may be implemented to cope with slow sea-level rise. Within the first twenty years and when new information becomes available, the agency can reevaluate its adaptation strategy. For the case of asset A, the framework suggests that after a window of 18 years, when more reliable data about future sea-level rise scenarios is available, the agency has to reevaluate adaptation options if the fast scenario occurs (Figure 4.7). 


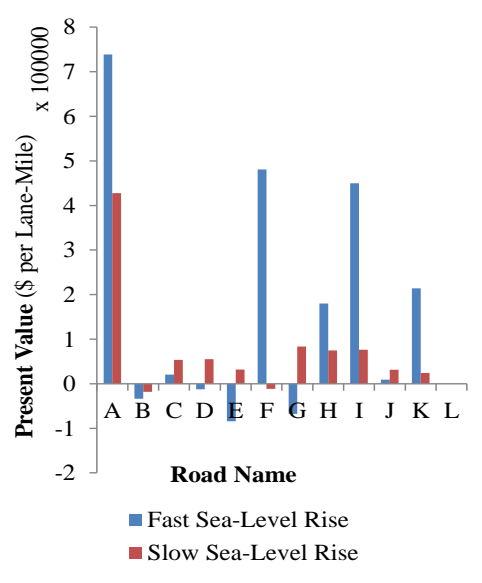

a. Present Value of Adaptation

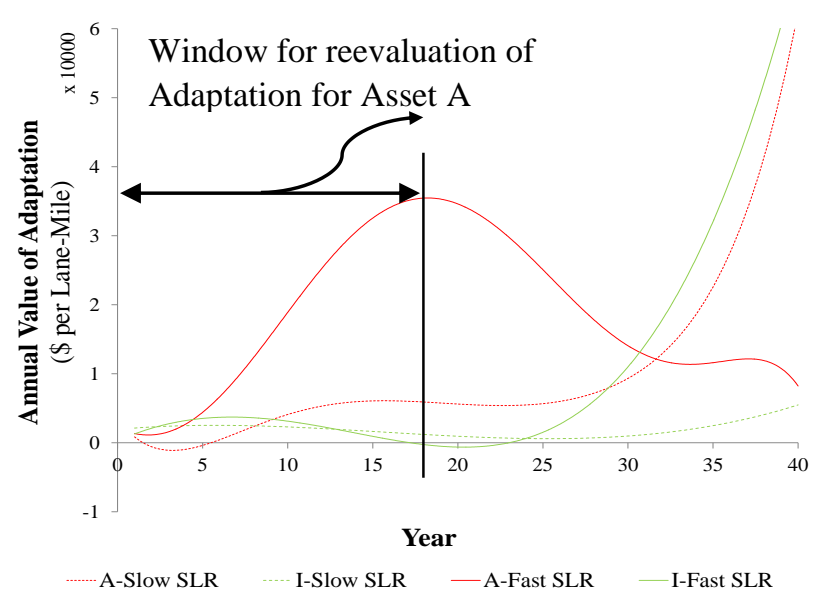

b. Annual Saving due to Adaptation

Figure 4-7: Present value of the adaptation investment

\subsection{CONCLUSION}

Evaluation of the effectiveness of adaptation actions is critical to avoid maladaptation. Maladaptation is failure to change behaviors and undertake timely actions such that the infrastructure systems on which a society is depended become unable to provide the required level of service. Maladaptation may occur due to failure to take timely actions and anticipate uncertainty. In order to create a scientific approach to inform adaptation decision-making under uncertainty, this paper created and tested a simulation framework that captures the dynamic interactions between conditions of physical network, network's vulnerability, and decision-making behaviors of the institutional agencies. The outcomes of the proposed simulation framework provide important insights for adaptation decision-making in various ways: (1) the results enable evaluation of the value of adaptation for infrastructure networks under future uncertain sea-level rise scenarios in order to provide a quantitative basis for decision analysis and avoid maladaptation; (2) the 
results enable prioritizing infrastructure assets for adaptation based on the value of adaptation in order to optimize the allocation of constrained resources and reduce the vulnerability of networks to sea-level rise impacts; and (3) the results identify the appropriate timing for adaptation investments for each infrastructure asset in order to maximize the value of adaptation for the network. These results are essential for decisionmakers in coastal urban areas in order to implement robust adaptation strategies to mitigate the impacts of sea-level rise on infrastructure system under uncertainty. 


\section{A Complex Adaptive Modeling of Road Infrastructure Resilience to Sea-Level Rise Impacts in Coastal Urban Areas}

\subsection{Abstract}

The objective of this study was to examine the long-term resilience of road infrastructure under sea-level rise impacts. Transportation agencies in coastal urban areas face a significant challenge to enhance the long-term resilience of their networks to flooding and storm surge events exacerbated by sea level rise. In this context, a holistic assessment of infrastructure resilience is contingent upon understanding the twin effects of sea-level rise risks on the physical condition of roadway infrastructure, as well as the decision-making priorities of institutional agencies. To this end the present study created a dynamic stochastic modeling framework based on the theoretical underpinnings of complex adaptive systems to investigate the long-term resilience of road infrastructure under various adaptation planning strategies and sea level rise scenarios. The three components of the proposed modeling framework integrates the following elements: (i) stochastic simulation of sea-level rise stressors based on the data obtained from downscaled climate studies pertaining to future projections of sea-level and precipitation; (ii) dynamic modeling of roadway conditions by considering regular decay of roadways, as well as structural damages caused by storm surge events; and (iii) a decision-theoretic modeling of agency infrastructure management and adaptation processes based on cognitive psychology, bounded rationality, and regret theories. In this framework, resilience is examined based

on trend changes in the network performance measures (e.g., life cycle costs and performance). The created framework and model were tested in a case study related to the 
road network of the city of Miami-Beach, which global assessments rank first among the world's urban areas most exposed to sea-level rise risks. The results indicated that: (i) SLR Adaptation investment and life cycle costs of roadway infrastructure are negatively correlated. In addition, it was shown that the sensitivity of network's life cycle cost to actual sea-level rise scenario decreases when adaptation investment increases. These finding emphasize the importance of proactive improvement of the network resilience to alleviate the long-term costs of sea-level rise. (ii) When funding is sufficient for all required adaptation actions, mid-term adaptation planning yields lower life cycle cost. When funding is insufficient, aggregated investment in long-term adaptation planning intervals yields lower network LCC. These findings imply that different adaptation planning approaches should be taken for different levels of adaptation investment. (iii) The agency's perception of SLR and risk attitude do not have significant effect on life cycle cost of roadway networks. Hence, implementation of adaptation action based on any perception of sea-level rise and risk attitude can significantly reduce the life cycle costs of roadway networks under the impacts of SLR. (iv) The devised performance target has negative correlation with life cycle cost of a roadway network affected by SLR impacts. Therefore, compromising the network performance condition will never result in lower life cycle costs.

\subsection{Introduction}

Global mean sea-level has risen on an average rate of $17 \mathrm{~mm}$ per year from 1901 to 2010 and it is projected that sea-level will continue to rise with an accelerated rate for the foreseeable future (Church et al. 2013). Rising sea level reduces the freeboard of coastal infrastructure and thus increases the risk of flooding during extreme events such as king 
tides and heavy precipitation (Tebaldi et al. 2012). Flooding of infrastructure causes public inconveniences such as frequent road closures and overwhelmed storm drains, and increases the long-term cost of maintenance and rehabilitation of infrastructure systems. The key element to reduce the potential impacts of sea-level rise (SLR) on coastal infrastructure systems is to plan and implement cost effective adaptation measures. On the other hand, making adaptation decisions is a complex task that requires substantial investments under significant uncertainty. Also, making adaptation decisions would require making trade-offs between the normal condition and sea-level rise requirements over the long-term. Hence, making robust adaptation decisions is contingent upon evaluation of the long-term transformation of infrastructure systems under different adaptation strategies and sea-level rise scenarios. This important knowledge is missing in the existing body of knowledge. To address this knowledge gap, the objective of the study presented in this paper is to create and test a framework for evaluation of infrastructure adaptation under uncertainty to enable informed decision-making for optimizing adaptation investments in coastal communities. Reducing impacts of sea-level rise (SLR) and building resilient infrastructure is contingent upon evaluation of the long-term transformation of infrastructure systems under different adaptation strategies and sea-level rise scenarios. This important knowledge is missing in the existing body of knowledge. To address this knowledge gap, the objective of the study presented in this paper is to create and test a framework for evaluation of infrastructure adaptation under uncertainty to enable informed decision-making for optimizing adaptation investments in coastal communities. 


\subsection{Conceptual Framework}

The key element to evaluate the impacts of SLR on infrastructure systems is to understand how physical networks transform under the compound effects of environmental stressors, and the adaptive behaviors of institutional actors who design, manage, and operate infrastructure systems. Throughout this paper these institutional actors (e.g., city managers, utility infrastructure agencies, regional planners, emergency managers, coastal protection, and developer companies) are collectively referred to as agency.

The environment affects physical network through two types of processes as shown in Figure 5.1: i) chronic environmental stressors such as weathering of infrastructure assets cause gradual deterioration of infrastructure via a mechanism known as aging. The agency takes preservation actions including maintenance, rehabilitation, and reconstruction of assets to preserve the functionality and performance of an aging infrastructure. ii) SLRrelated stressors such as storm surges may cause structural damage to the assets. The agency anticipates the adverse effects of SLR stressors and takes adaptation actions to prevent or minimize the damage they can cause. Complex interrelations exist between the processes triggered by SLR and chronic environmental stressors. For example, an aged infrastructure is more vulnerable to structural damage caused by SLR stressors. On the other hand, SLR-related structural damages accelerate aging of infrastructure. 


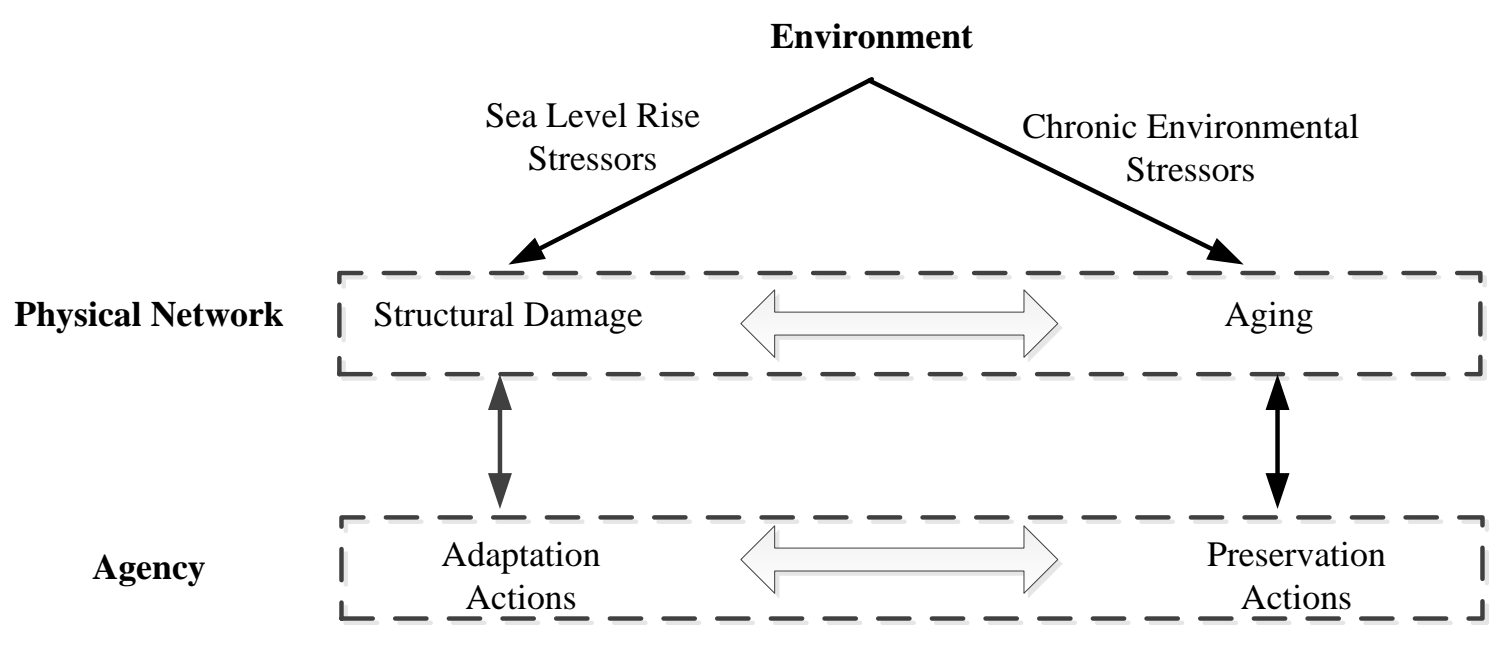

Figure 5-1: Different types of environmental stressors and reaction of physical network and agency to them

To enable understanding the complex interactions among environment, physical network, and agency a system of systems framework is created based on the theories of complex dynamic systems (Bar-Yam 2002). In this framework (shown in Figure 5.2) each of the environment, physical network, and agency is a dynamic system that evolves over time due to interactions with other systems and their own parts. At any given time, each system has a state that represents its existing conditions and is given by a set of parameters known as state variables or state parameters. The evolution of the state of each system is captured with a function that describes what future states follow from the current state.

The state of physical network is a combination of the physical and functional conditions of all assets. The state of physical network evolves through internal mechanisms such as aging of assets as well as interactions with the surrounding environment and the agency. The way in which the state of environment evolves affects the functionality and performance of the network by causing physical damage. However, the extent of the damage depends on the structural condition of assets. Similarly, the agency perceives the 
risk associated with the state of environment as well as the existing performance conditions of the assets to make decisions pertaining to adaptation investments and preservation (i.e. maintenance and rehabilitation) actions. The adaptation investments make the infrastructure less vulnerable to the threats posed by the state of environment. Finally, the preservation actions improve the state of network in terms of physical conditions of assets (structural and performance). The conceptual process related to abstracting the state and evolution of the environment, physical network, and agency systems are explained in the rest of this section.

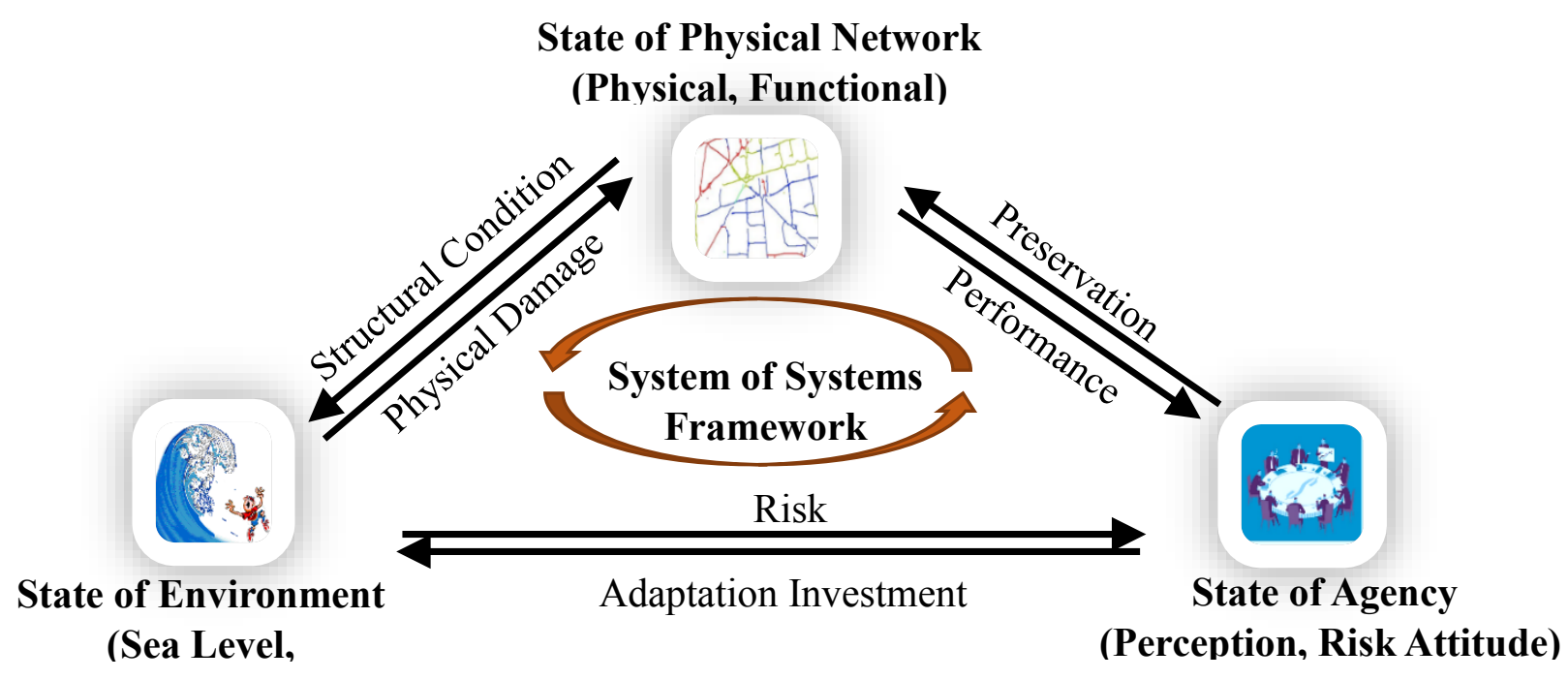

Figure 5-2: The System of Systems Framework for Capturing the Long-Term Transformation of Infrastructure Systems under Sea Level Rise 


\subsubsection{Abstraction of the environment system}

The state of environment determines the intensity of SLR stressors to infrastructure systems. Long term changes in the state of environment depend on various anthropogenic and natural forces that could alter the climate over the coming decades (Stocker et al. 2013). Therefore, a great deal of uncertainty exists in projections of the future state of the environment (Church et al. 2013). To be able to cope with this level of uncertainty, it is advisable to consider a number of alternative scenarios for different trajectories of climate change (Stocker et al. 2013). Following the common practice of climate change literature, slow, moderate, and fast changes in the state of environment are considered in the present study. Let $S_{t}$ be the state of environment at any given time t. Then:

$$
S_{t} \in\left\{S_{t}^{S}, S_{t}^{M}, S_{t}^{F}\right\}
$$

where $S_{t}^{S}, S_{t}^{M}, S_{t}^{F}$ represent the state of environment at time t given the slow, moderate, or fast sea level rise scenarios happen, respectively. The immediate SLR stressors on infrastructure systems are the submergence and increased flooding of low-lying coastal lands due to storm surges and stormwater runoff (Nicholls and Cazenave 2010). The storm surge flooding happens when the water level (sum of sea level and precipitation at any given time) exceeds sum of the elevation of a road and its drainage capacity. In mathematical terms:

if: $\quad S L_{t+1}+P_{t+1}>E_{j, t}+D_{j, t} \quad$ Then: $\quad$ Flooding $_{j, t+1}=$ True Equation (2)

Where $S L_{t+1} \in\left[S_{t+1, \min }, S_{t+1, \max }\right]$ 
In Equation 2, $S L_{t+1}$ denotes the sea level at time $t S_{t+1, \min }$ and $S_{t+1, \max }$ (both in millimeters) are the minimum and maximum likely sea levels at time $t+1$ if the state of environment from $t$ to $t+1$ was $S_{t}$. In addition, $P_{t+1}$, also in millimeters, is a stochastic variable that represents the likely amount of precipitation at $t+1$. According to the fifth assessment report of intergovernmental panel on climate change (Stocker et al. 2013), the changes in amount of precipitation due to climate change are of secondary importance relative to interannual variations in amount of precipitation. Therefore, $P_{t+1}$ could be calculated based on historic precipitation data using a Poisson distribution. Finally, $E_{j, t}$ and $D_{j, t}$ represent elevation and drainage capacity of road $\mathrm{j}$ (both in millimeters), respectively.

On the other hand, stormwater runoff happens when amount of precipitation exceeds the drainage capacity of a road. This could be formally presented with Equation 3:

$$
\text { if: } P_{t}>D_{j, t} \quad \text { Then: } \quad \text { Flooding } g_{j, t}=\text { True } \quad \text { Equation (3) }
$$

Flooding caused by either storm surge or stormwater runoff will create structural damage to infrastructure assets. In addition, the perceived risk of flooding may trigger adaptive behavior of the agency.

\subsubsection{Abstraction of the physical network system}

The state of physical network represents the physical and functional condition of infrastructure assets. The physical condition of an infrastructure asset connotes its structural resiliency and its ability to withstand different types of stressors. On the other hand, the functionality of infrastructure indicates its ability to serve its intended function 
at the desired level of quality. For example, in the context of road infrastructure, structural conditions such as design characteristics of the base, subbase, and surface layers as well as cracking, spalling and deformations of the pavement are some indicators of the physical condition while the level of traffic and quality of ride could be two indicators of functionality. The problem of modeling the state of physical network is very context specific (Brownjohn 2007). However, in essence, it involves identifying indicators of physical and functional conditions of an asset and then integrating them into a unified performance measure (Ben-Akiva and Gopinath 1995). The performance measure quantifies the state of an infrastructure asset at any given time $t$ based on "explanatory variables" such as design characteristics of the asset, asset's age at $t$, ambient climate, and service load of the asset in the period ending at $t$ (Ben-Akiva and Gopinath 1995). Equation 4 shows how the state of one asset is quantified. Let $C_{i, t}$ be the state of asset $i$ at time $t$ and $E V_{j, t}$ be the value of $\mathrm{j}^{\text {th }}$ explanatory variable related to physical and functional condition of the asset $i$ at $t$. Then $C_{i, t}$ is calculated from Equation 4 .

$$
C_{i, t}=F\left(E V_{1, t}, E V_{2, t}, \ldots, E V_{n, t}\right)
$$

The state of a network consisting of $\mathrm{n}$ infrastructure assets could be then defined as the set of the states of all assets in the network (Equation 5).

$$
N_{i, t}=\left\{C_{1, t}, C_{2, t}, \ldots, C_{n, t}\right\}
$$




\subsubsection{Abstraction of the agency system}

The state of agency encompasses underlying behavioral factors that determine the decision making process of the agency. To cope with the complex and uncertain impacts of environmental stressors on infrastructure system the agency makes the preservation and adaptation decisions under the constraints of limited knowledge, resources, and time. Theory of bounded rationality explains the behavior of human and institutional agents under such constraints (Simon 1979; Simon 1991; Simon 1982). Based on this theory, decision makers who are bounded to imperfect information, confined time, and limited resources seek satisfactory solutions rather than optimal solution. Since the decision making processes of the agency have all traits of bounded rational decision making, the theory of bounded rationality is used here to model the behaviors of the agency system. Figure 5.3 illustrates the processes leading to adaptation decisions of the agency. The agency is bounded to certain points of time to make the preservation and adaptation decisions. In Figure 5.3, $t_{i-1}, t_{i}$, and $t_{i+1}$ show these decision points. Each decision point represents a point of time when annual maintenance budget is prepared or multi-year capital improvement programs are devised (Wooldridge et al. 2001). At each decision point the agency has imperfect information about the current and future states of environment and network. The information about the state of network is imperfect because it is typically acquired via subjective assessment of asset conditions and empirical performance prediction models (Kong and Frangopol 2003). With regards to the state of environment, the agency's information is imperfect for decision making first because of its deep uncertainty and second because it provides a range of likely future scenarios rather than an exact projection. 


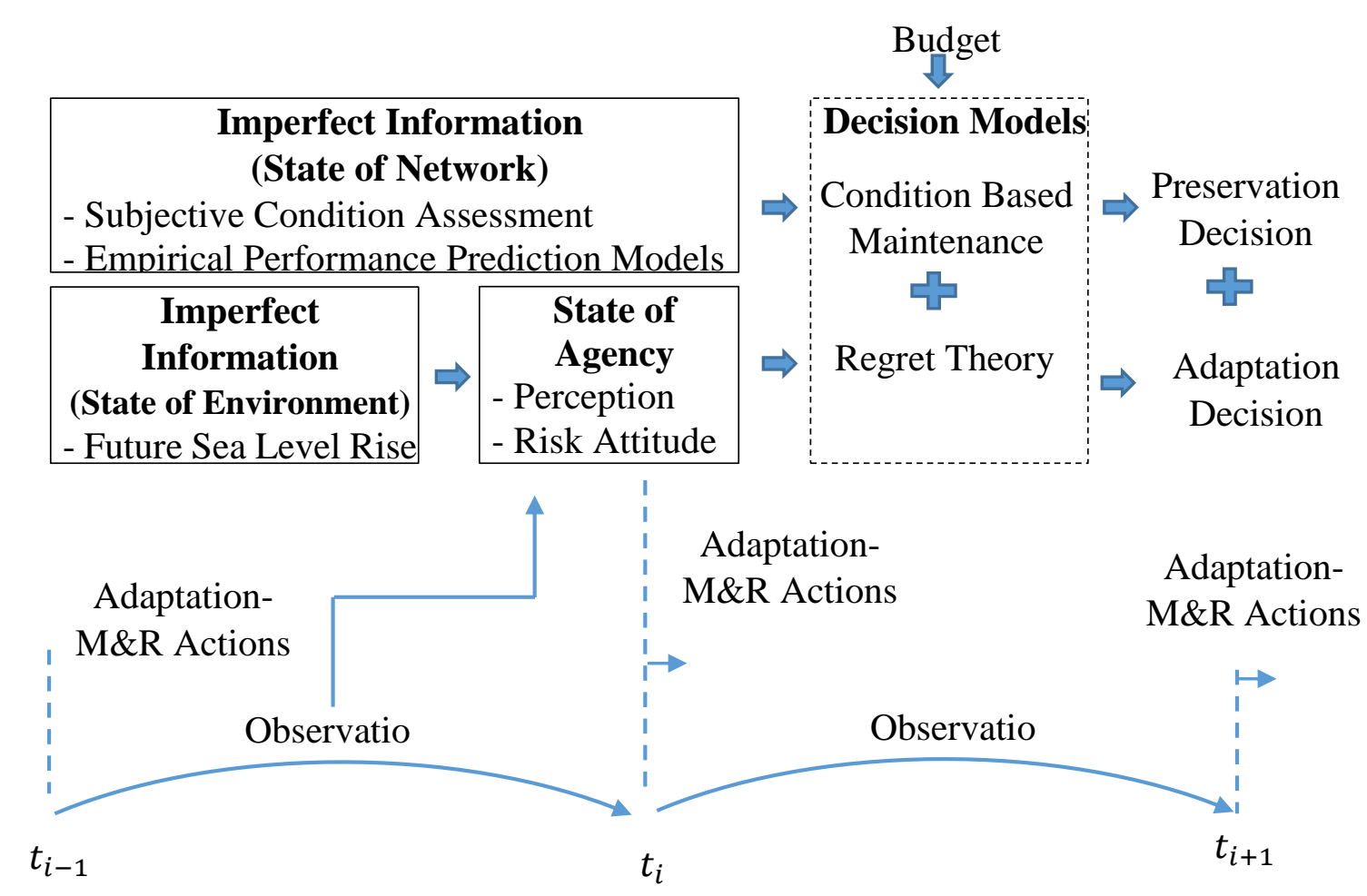

Figure 5-3: The decision making processes of the agency

Due to having imperfect information, as well as limited time, resources, and capability for identifying the optimal actions, the agency makes maintenance decisions that are satisfactory rather than optimal. To model this behavior of the agency, Condition-based maintenance $(\mathrm{CBM})$ model is used in the present study. CBM models are predominant approaches used for preservation of infrastructure assets (Saha and Ksaibati 2015). According to CBM models, the agency monitors the actual condition of the asset to decide what maintenance needs to be done. In other words, the decision to implement a maintenance treatment is made when certain indicators of asset condition show sign of decreasing performance or risk of failure. 
Having imperfect information about future state of environment causes agency to make the adaptation decision based on their own state. The state of agency consists of the agency's perception of the future state of environment and the risk attitude of the agency towards likely impacts of sea level rise on the network (Equation 6):

$$
A_{t}=\left\{P S L_{t+1}, R_{t}\right\}
$$

In Equation 6, the state of agency at time $t$ is shown as $A_{t} . P S L_{t+1}$ represents the agency's perception of sea level rise at $t+1$. Finally, $R_{t}$ denotes the risk attitude of the agency at $t$ which includes three possible risk attitudes as shown in Equation 7.

$$
R_{t-1} \in\{\text { Risk Averse, Risk Neutral, Risk Taking }\} \quad \text { Equation (7) }
$$

Previous research has shown that the climate change perception and risk attitude are formed based on past experience and observation rather than being based on fully rational analytic models (Leiserowitz 2006). In other words, the agency expects sea level rise similar to what they experienced in past and are less (more) risk taking if they underestimated (overestimated) SLR impacts in past. Equations 8 and 9 summarize this behavior of the agency.

$$
P S L_{t+1}=S L_{t}+\left(S L_{t}-S L_{t-1}\right)=2 \times S L_{t}-S L_{t-1}
$$

If $P S L_{t} \in\left[S_{t-1, \min }, S_{t-1, \max }\right]$ Then: $R_{t}=R_{t-1}$

Otherwise: update $R_{t}$

After the state of agency is modeled, the agency's choice among different adaptation action alternatives is captured using the theory of regret (Loomes and Sugden 1982). The regret theory explains how individuals make choices among different 
alternatives when they face decisions under uncertainty. Let $\{$ Alt 1, Alt $2, \ldots$, Alt $n\}$ be the adaptation action space from which the agency wants to select one action. Each adaptation alternative Alt $i$ has a cost of implementation $I_{i}$. In addition, depending on the future amount of precipitation, an alternative action may or may not lead to flooding of assets. Let $F_{i, j}$ be the cost of flooding for Alt $\mathrm{i}$ under jth scenario of precipitation. Then total cost of Alt $\mathrm{i}$ under jth scenario of precipitation is calculated from Equation 10.

$$
C_{i, j}=I_{i}+F_{i, j}
$$

Table 1 shows a schematic view of the alternative adaptation actions and their expected cost under different precipitation scenarios.

Table 5-1: Expected cost of alternative adaptation actions under different precipitation scenarios

\begin{tabular}{|c|c|c|c|}
\hline & Precipitation & Precipitation & Precipitation \\
& Scenario 1 & Scenario 2 & Scenario 3 \\
\hline Alt 1 & $C_{1,1}=I_{1}+F_{1,1}$ & $C_{1,2}=I_{1}+F_{1,2}$ & $C_{1,3}=I_{1}+F_{1,3}$ \\
\hline Alt 2 & $C_{2,1}=I_{2}+F_{2,1}$ & $C_{2,2}=I_{2}+F_{2,2}$ & $C_{2,3}=I_{2}+F_{2,3}$ \\
\hline$\ldots$ & & & \\
\hline Alt n & $C_{n, 1}=I_{n}+F_{n, 1}$ & $C_{n, 2}=I_{n}+F_{n, 2}$ & $C_{n, 3}=I_{n}+F_{n, 3}$ \\
\hline
\end{tabular}


A risk taking decision maker (i.e. $R_{t}=\{$ Risk Taking $\}$ ) looks into optimistic outcome of all alternatives and selects the alternative with lowest optimistic outcome. Let $\min _{A l t_{i}}$ be the optimistic outcome of Alt i (Equation 11).

$$
\begin{aligned}
& \min _{A l t_{i}}=\min \left(C_{i, 1}, C_{i, 2}, C_{i, 3}\right) \\
& \text { if } \min _{A l t_{i}}=\min \left\{\min _{A l t_{1}}, \min _{A l t_{2}}, \ldots, \min _{A l t_{n}}\right\}
\end{aligned}
$$

\section{Then: Optimistic Choice $=A l t_{i}$}

Conversely, a risk averse decision maker (i.e. $R_{t}=\{$ Risk Averse $\}$ ) wants to minimize the cost under worst case scenario (Equation 12):

$$
\begin{aligned}
& \max _{A l t_{i}}=\max \left(C_{i, 1}, C_{i, 2}, C_{i, 3}\right) \\
& \text { if } \max _{A l t_{i}}=\min \left\{\max _{A l t_{1}}, \max _{A l t_{2}}, \ldots, \max _{\text {Alt }_{n}}\right\}
\end{aligned}
$$

Then: Pessimistic Choice $=A l t_{i}$

Finally, a neutral decision maker anticipates the possibility of feeling regret after the uncertainty in future environmental conditions is resolved. Therefore, they select the alternative that provides lowest regret under all precipitation scenarios. Let $C_{m, k}$ be the minimum possible cost among all alternatives if precipitation scenario k occurs (Equation 13).

$$
C_{m, k}=\min \left(C_{1, k}, C_{2, k}, \ldots, C_{n, k}\right)
$$

Then, the regret of selecting Alt $\mathrm{i}$ if precipitation scenario $\mathrm{K}$ happens (denoted by $\operatorname{Reg}_{i, k}$ ) could be then defined as the difference between cost of Alt i under scenario K (i.e $C_{i, k}$ ) 
and the minimum possible cost of all alternatives under scenario $\mathrm{K}$ (i.e $C_{m, k}$ ) (Equation 14):

$$
\operatorname{Reg}_{i, k}=C_{i, k}-C_{m, k}
$$

The maximum regret if Alt $\mathrm{i}$ is selected could be calculated from Equation 15:

$$
\begin{aligned}
& \operatorname{MaxReg}_{i}=\max \left\{\operatorname{Reg}_{i, 1}, \operatorname{Reg}_{i, 2}, \operatorname{Reg}_{i, 3}\right\} \\
& \text { if } \operatorname{MaxReg}_{i}=\min \left\{\operatorname{MaxReg}_{1}, \operatorname{MaxReg}_{2}, \ldots, \operatorname{MaxReg}_{3}\right\}
\end{aligned}
$$

Then: Neutral Choice $=A l t_{i}$

After the agency implemented the adaptation action they will observe the actual changes in the state of environment until the next decision point. At the next decision point the perception and risk attitude of the agency will be updated based on the new information that has become available. The entire process will be then repeated to make new adaptation decisions.

\subsection{Computational Model}

For purposes of this research, a simulation-based computational model was created for assessing the transformation of roadway infrastructure systems under the impacts of sea level rise. The first element of the computational model is an agent based simulation model that captures the transformation of roadway infrastructure systems under the impacts of sea level rise. The simulation model is comprised of seven classes of objects: Main, SeaLevel, Rainfall, Agency, Road, RoadType and RoadTreatment. The class diagram of the simulation model is demonstrated in Figure 5.4. The Main class is where the simulation environment and the other three classes of objects are defined. The Sea-Level, Rainfall, 
Agency, and Road class of objects are modeled based on the abstracted behaviors of environment, agency, and physical network systems. The RoadType and RoadTreatment objects store the input data and outcomes of maintenance, rehabilitation, and reconstruction treatments. The sequence diagram of the simulation model (Figure 5.5) shows how different objects of the model operate and interact with one another.

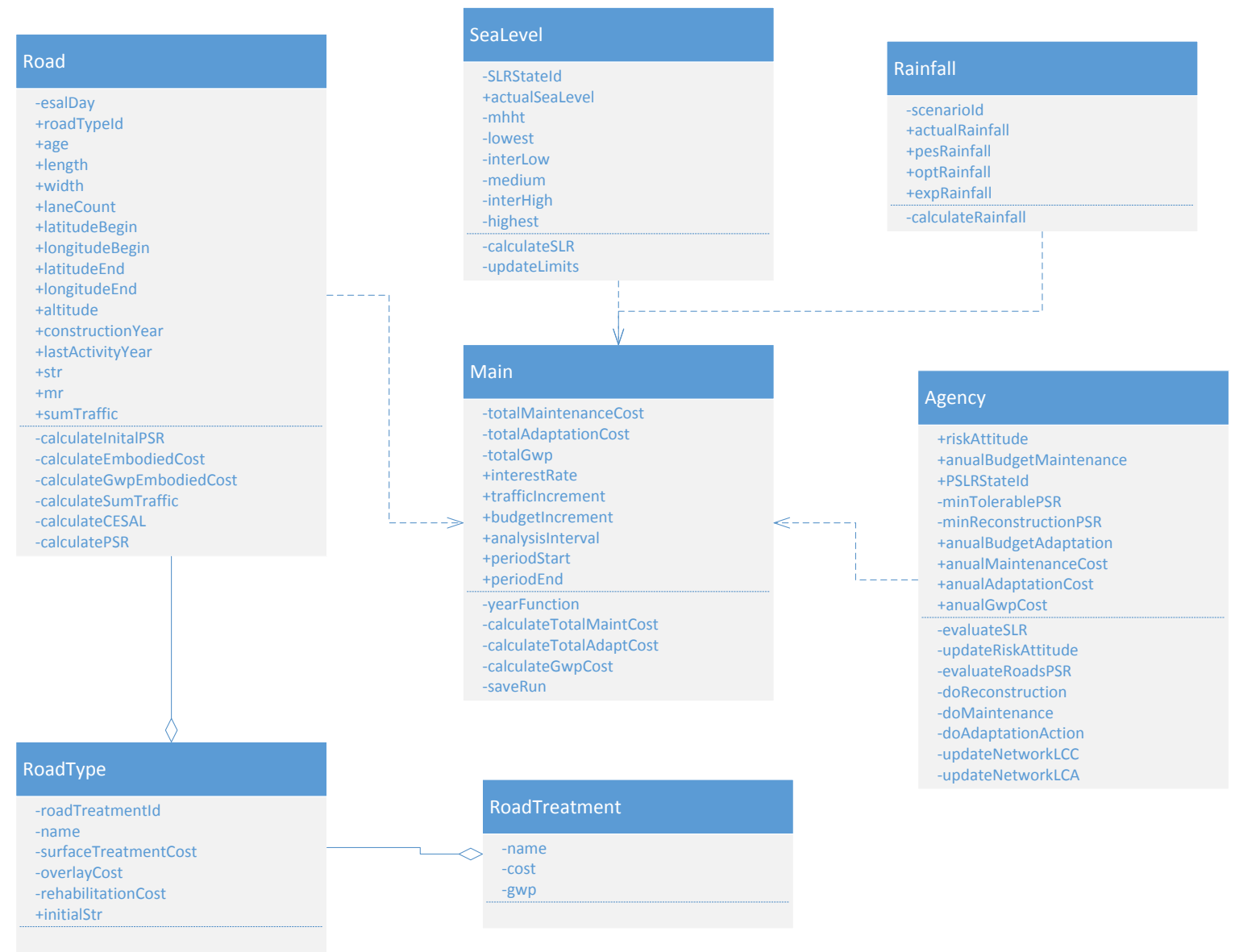

Figure 5-4: Class diagram of the simulation model 


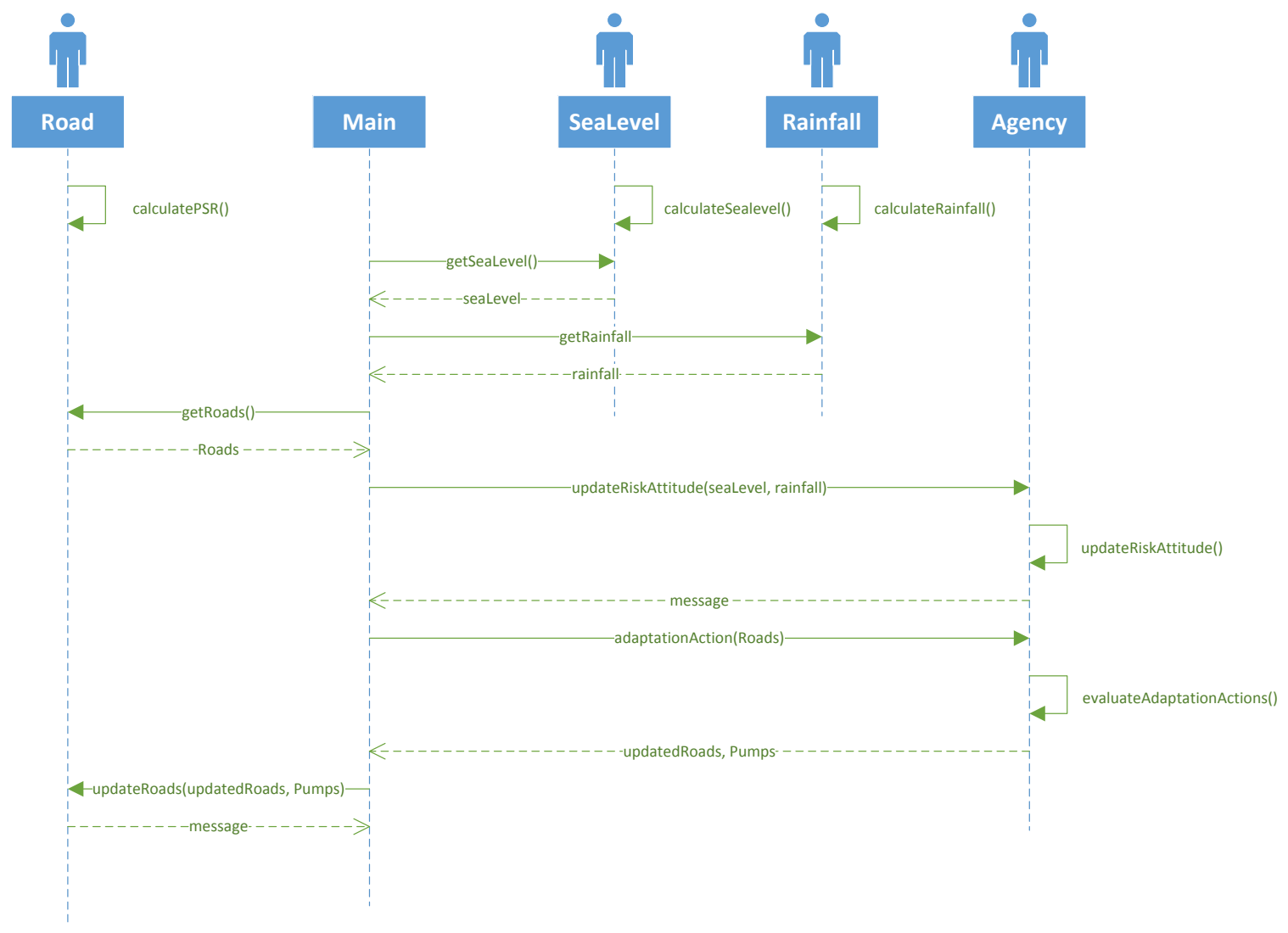

Figure 5-5:Sequence diagram of the simulation Model

The outcomes of the simulation model include timing and type of preservation and adaptation actions related to a certain set of exploratory variables such as actual and perceived scenarios of sea-level rise, the agency's risk attitude, the planning interval, adaptation budget, and performance target. The outcomes of the simulation model are used in a network-level life cycle cost analysis model developed by Batouli et. al. (2015) to identify the life cycle costs of the network under each set of variables. In order to deal with the inherent uncertainty in the life cycle costs related to each simulation scenario, each scenario was randomly repeated a thousand times using a Monte Carlo method. The results were analyzed using a classification and regression analysis tree analysis to identify the 
exploratory variables with highest importance in affecting the life cycle cost of the network. Figure 5.6 shows different components of the computational model.

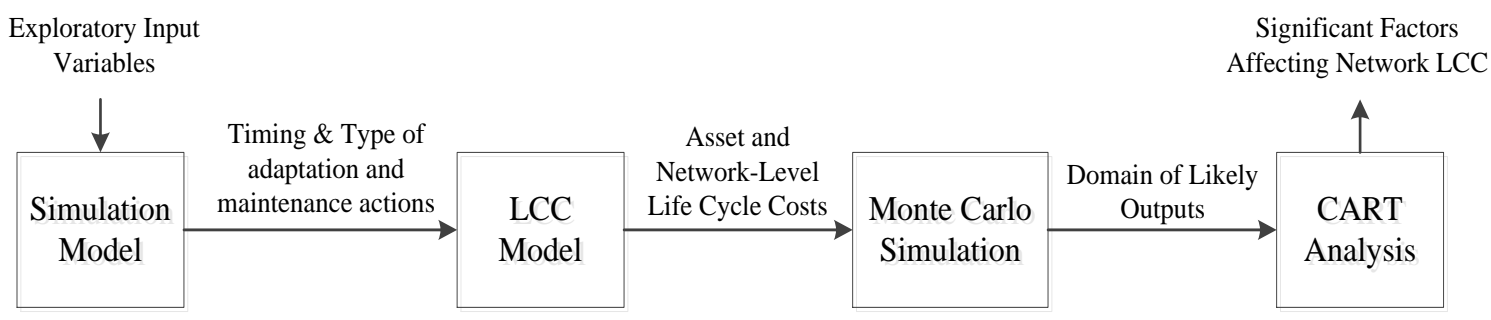

Figure 5-6: Components of the computational model

\subsection{Case study}

The proposed research framework and computational model were used to study the impacts of SLR and SLR adaptation on a subset of the roadway network in the city of Miami Beach, which global assessments rank first among coastal urban regions in having the highest value of infrastructure at risk of sea level rise impacts. The case study network includes 11 major roads in the South Miami Beach. Figure 5.7 shows the case study area. The life cycle costs of the case study network were calculated over a 50-year analysis horizon for 1080 scenarios related to different actual and perceived sea-level rise, the agency's risk attitude, adaptation budget, adaptation planning approach, and target performance. Table XX summarizes the considered scenarios. 


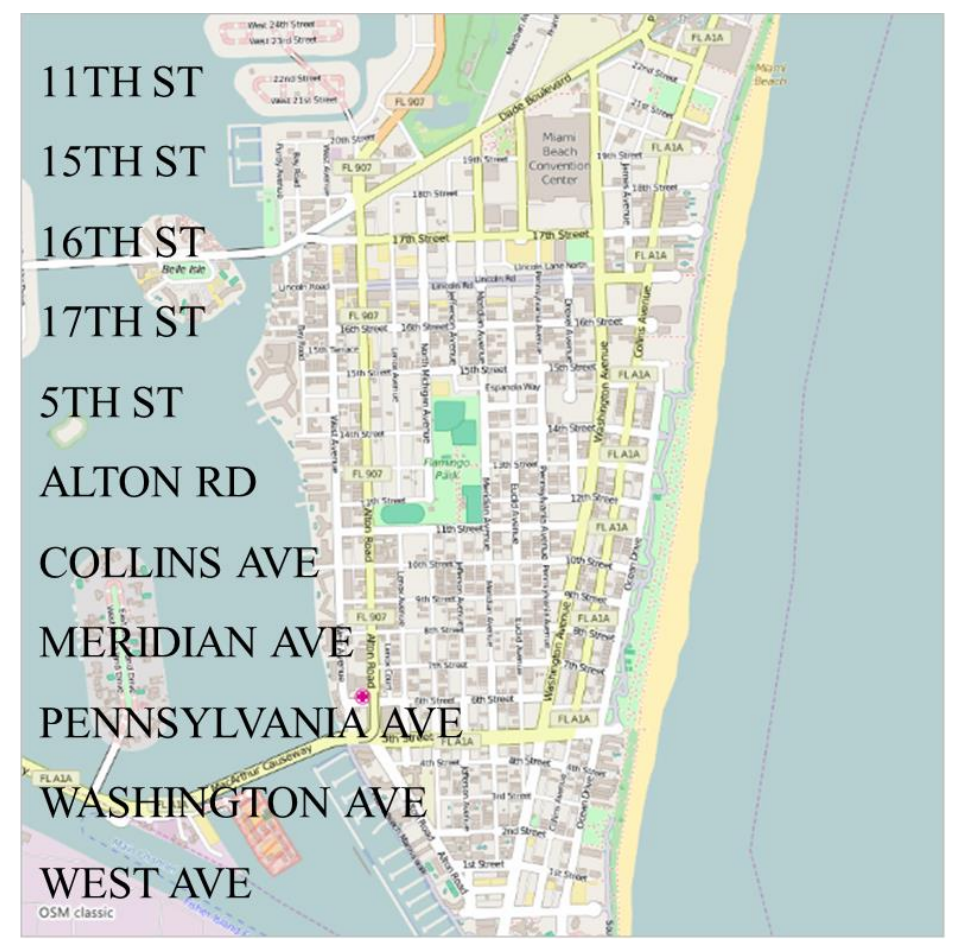

Figure 5-7: The case study area

Table 5-2: Investigated Scenarios

\begin{tabular}{|c|c|c|}
\hline Exploratory Variable & Scenarios Considered & Number of Scenarios \\
\hline Actual Sea-level Rise & Slow, Moderate, Fast & 3 \\
\hline $\begin{array}{c}\text { Perception of Sea-level } \\
\text { Rise } \\
\end{array}$ & Slow, Moderate, Fast & 3 \\
\hline Agency's Risk attitude & Optimistic, Pessimistic & 2 \\
\hline Adaptation Budget & $\begin{array}{c}\text { Very Low }(\$ 5,000,000) \\
\text { Low }(25,000,000) \\
\text { Moderate }(50,000,000) \\
\text { High }(75,000,000) \\
\text { Very High }(500,000,000)\end{array}$ & 5 \\
\hline $\begin{array}{c}\text { Adaptation Planning } \\
\text { Approach }\end{array}$ & $\begin{array}{l}\text { Short-term } 2 \text { Year } \\
\text { Mid-term } 5 \text { Year } \\
\text { Mid-term } 10 \text { Year } \\
\text { Long-term } 25 \text { Year }\end{array}$ & 4 \\
\hline Target Performance & $\begin{array}{c}\text { Perfect }(\mathrm{PSR}=4.5) \\
\text { Good }(\mathrm{PSR}=4.0) \\
\text { Acceptable }(\mathrm{PSR}=3.6)\end{array}$ & 3 \\
\hline \multicolumn{2}{|c|}{ Total Number of Scenarios } & 1080 \\
\hline
\end{tabular}


Data related to physical characteristics of the network, structural design of the roads, level of service (i.e. annual traffic), adaptation actions, and cost of different maintenance, rehabilitation, and adaptation actions were collected from the case study network mostly from different resources provided by the city of Miami Beach and Florida Department of Transportation. The data collected and their sources are shown in Table XX.

Table 5-3: Data categories and sources

\begin{tabular}{|c|c|c|}
\hline Data Category & Example of Data Collected & Data Source \\
\hline $\begin{array}{c}\text { Physical } \\
\text { Chacteristics of } \\
\text { the Network }\end{array}$ & $\begin{array}{c}\text { Facility type (arterial, collector), Number } \\
\text { of lanes, Length and elevation of links, } \\
\text { Pavement type, Pavement age, Other } \\
\text { features (such as one-way or two-way } \\
\text { facility) }\end{array}$ & $\begin{array}{c}\text { Street network shapefile } \\
\text { for Miami Beach }\end{array}$ \\
\hline $\begin{array}{c}\text { Structural Design of } \\
\text { the Roads }\end{array}$ & $\begin{array}{c}\text { Thickness of base/subbase/surface layers, } \\
\text { Material Used, Maintenance/rehabilitation } \\
\text { actions }\end{array}$ & FDOT Design Guideline \\
\hline $\begin{array}{c}\text { Level of Service } \\
\text { (annual traffic) }\end{array}$ & $\begin{array}{c}\text { Annual Average Daily Traffic } \\
\text { Weekly Axle Factor }\end{array}$ & $\begin{array}{c}\text { FDOT Traffic Online } \\
\text { Adaptation Actions }\end{array}$ \\
\hline $\begin{array}{c}\text { Type of adaptation actions } \\
\text { Utility of Adaptation Actions }\end{array}$ & $\begin{array}{c}\text { City of Miami Beach } \\
\text { Public Works }\end{array}$ \\
\hline Cost & $\begin{array}{c}\text { Cost of Preservation Activities } \\
\text { Cost Adaptation Actions }\end{array}$ & $\begin{array}{c}\text { FDOT Project Bids and } \\
\text { City of Miami Beach } \\
\text { Public Works }\end{array}$ \\
\hline
\end{tabular}




\subsection{Results and discussion}

Data collected from the case study was used in the computational model to investigate the effects of adaptation budget size, planning approach (i.e. long-term or shortterm planning for adaptation actions), and decision making behaviors of the agency on life cycle cost of the network. To this end, the results related to the 1080 scenarios of the case study was classified using CART analysis to identify the significance each of the budget size, planning approach, and behavioral factors on life cycle cost of the network.

\subsubsection{Impacts of the size of adaptation budget}

The results of CART analysis show that the size of adaptation budget has the highest impact on life cycle cost of the case study network under all scenarios of slow, moderate, and fast sea-level rise. Figure 5.8 shows the relationship between the size of adaptation budget and the life cycle cost of the network under different sea level rise scenarios. under a certain adaptation budget and sea-level rise scenario, the life cycle cost of the network may vary due to different planning approaches and decision making behaviors of the agency. The variations in the amount of life cycle costs, caused by different planning approaches and decision making behaviors, are depicted with error bars in Figure 5.8. As shown in Figure 5.8, increasing the adaptation budget leads to reducing the life cycle cost of the network. Increasing adaptation budget by $\$ 70$ million dollars (from $\$ 5$ million to $\$ 75$ million) results in \$316 million and \$528 million saving in life cycle costs over a 50-year horizon under slow and fast sea level rise, respectively. The savings in life cycle costs indicate between $452 \%$ and $754 \%$ return on investment for the adaptation actions based on different sealevel rise scenarios. 


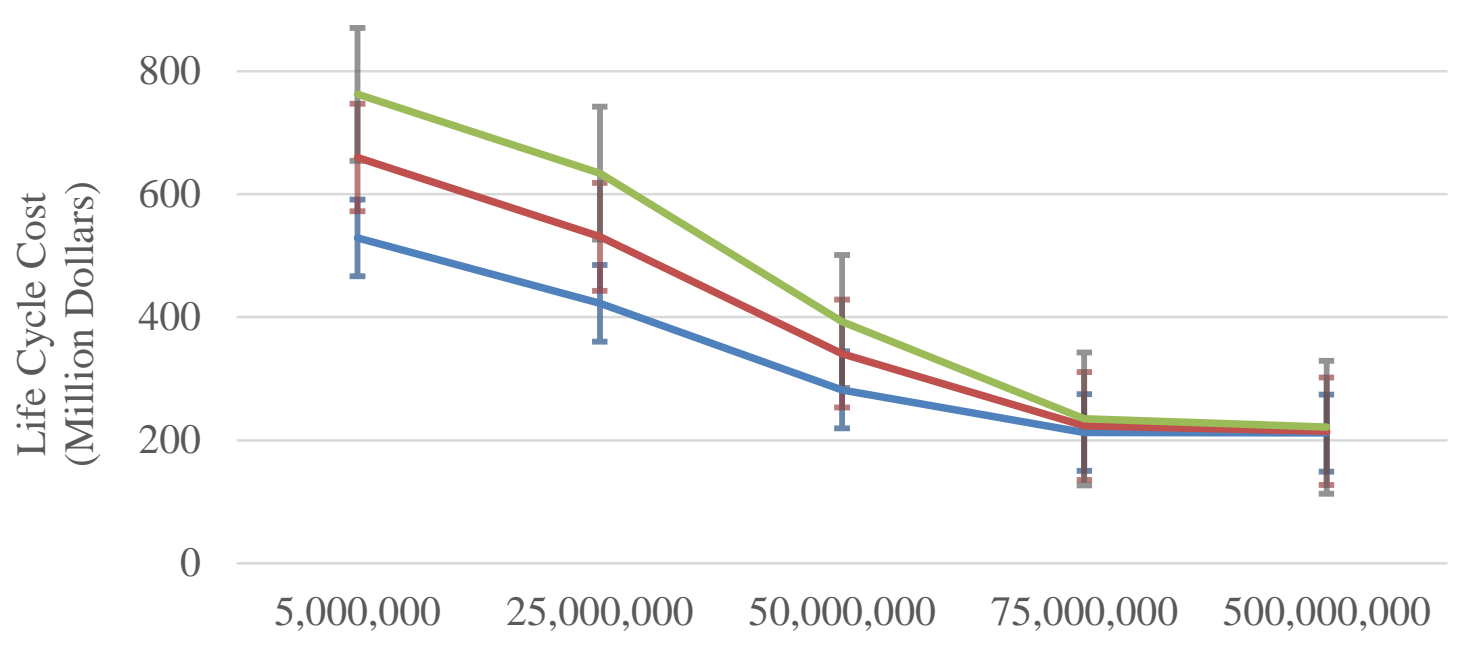

Adaptation Budget (\$)

- Slow —Moderate - Fast

Figure 5-8: Impact of adaptation budget on life cycle cost of the network

In addition, comparing the life cycle costs of the network under different adaptation budgets and sea level rise scenarios attests that the sensitivity of the network cost to different sea level rise scenarios decreases at higher levels of adaptation budget. This result implies that increasing the amount of investment on adaptation actions not only alleviates the long-term economic impacts of sea-level rise, but also reduces the uncertainty regarding the possible future consequences of sea level rise.

\subsubsection{Impacts of adaptation planning approach}

The impact of adaptation planning approach on life cycle costs of the network is different for different amounts of adaptation budget. When funding is sufficient for all required adaptation actions, mid-term adaptation planning (i.e. 5 to 10 years) yields lower 
life cycle cost compared to both short term (i.e. 2 years) and long-term (i.e. 10 years) planning. Figure 5.9 shows the life cycle cost of the network under different adaptation planning approaches and sea level rise scenarios with sufficient adaptation budget (i.e. equal or more than $\$ 75$ million). According to results, the life cycle cost of the network is virtually the same with 5-years and 10-year planning intervals (with variations within a range of $3 \%$ of life cycle cost under different scenarios). On the other hand, the LCC is 8 to $20 \%$ and 12 to $16 \%$ higher for 2-year and 25-year planning intervals, respectively.

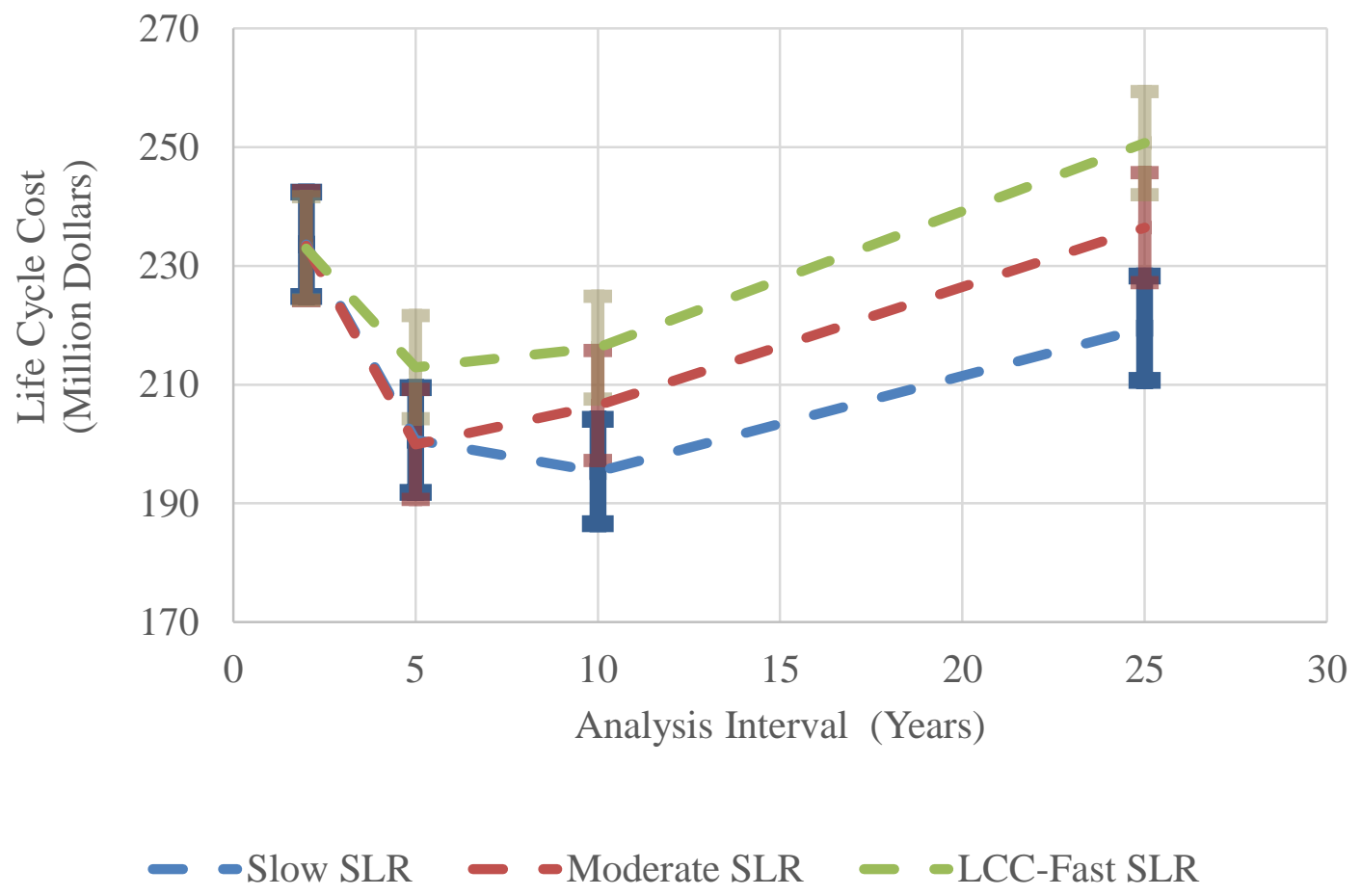

Figure 5-9: Life cycle cost of the network with adaptation equal or more than $\$ 75$ million 


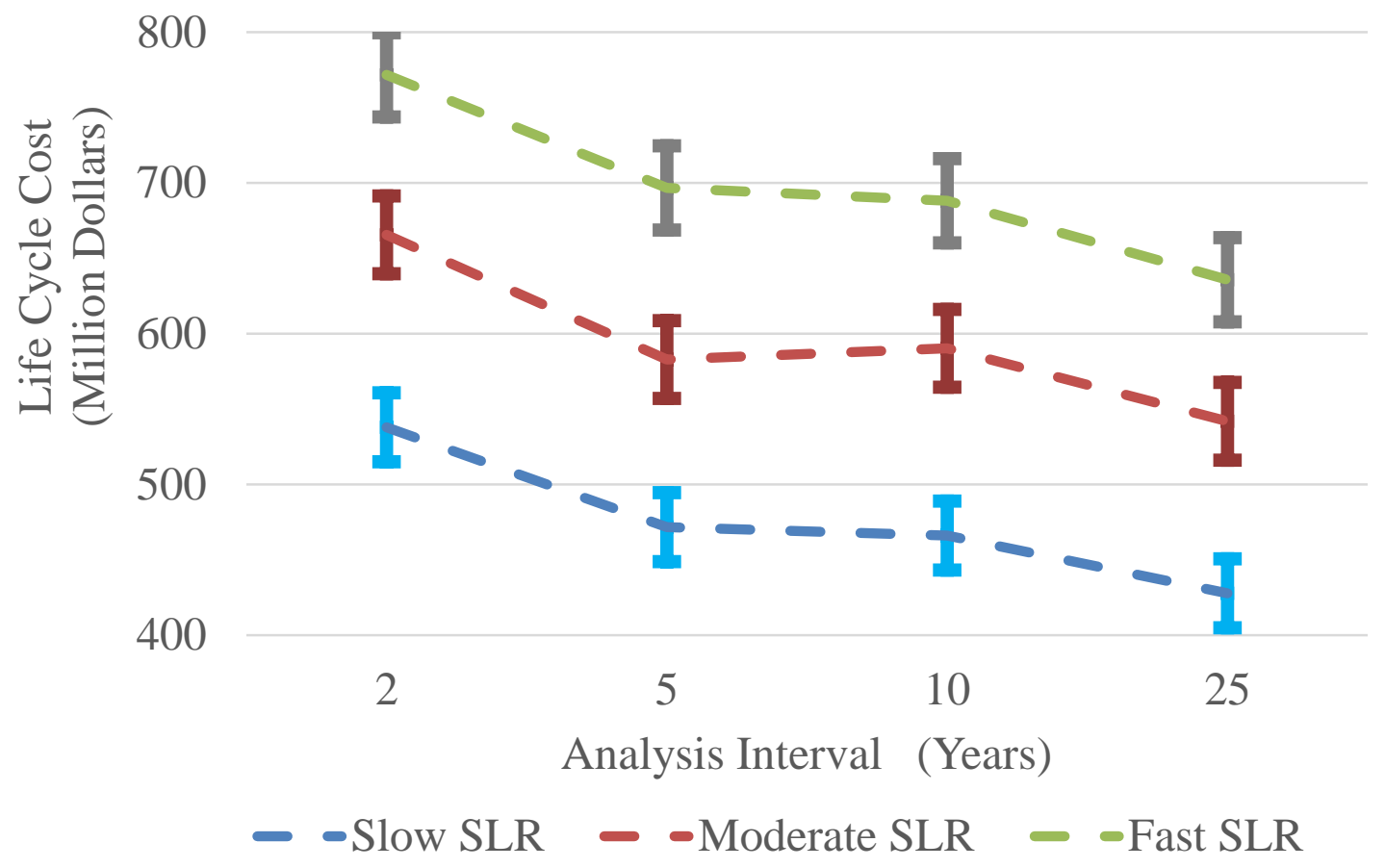

Figure 5-10: Life cycle cost of the network with adaptation equal or less than $\$ 25$ million

On the other hand, when funding is insufficient for the required adaptation actions, long-term adaptation planning intervals consistently yield lower network LCC (Figure 5.10). The reason for this behavior is that long-term planning equates with fewer number of investments which in turn translates to greater funding at each instance of investment. For example, a $\$ 25$ million funding could be spent as two packages of $\$ 12.5$ million dollars (one spent in year 0 and one in year 25) or 25 packages of $\$ 1$ million (one package every other year). The former planning approach enables implementation of the costlier capital improvement projects which will create larger impact on the total life cycle cost of the network. 


\subsubsection{Impacts of decision making behaviors}

The impacts of agency's behavioral traits on life cycle cost of the network were studied. The results show that agency's perception of SLR and risk attitude do not have significant effect on life cycle cost of roadway networks (Figures 5.11 and 5.12). This result indicates that even though there is a great deal of uncertainty in future sea level rise, implementing adaptation actions based on any perception of sea-level rise and with any risk attitude will eventually provide a significant benefit in terms of reducing the life cycle cost of the network.

The impact of the performance target on life cycle cost of the network is presented in Figure 5.13. The performance target is the performance threshold below which the agency considers implementation of maintenance and rehabilitation actions. According to the results the devised performance target has negative correlation with life cycle cost of a roadway network affected by SLR impacts. This finding indicates the importance of applying preventive maintenance even when the roadways are affected by frequent structural damages caused by SLR-related flooding. 


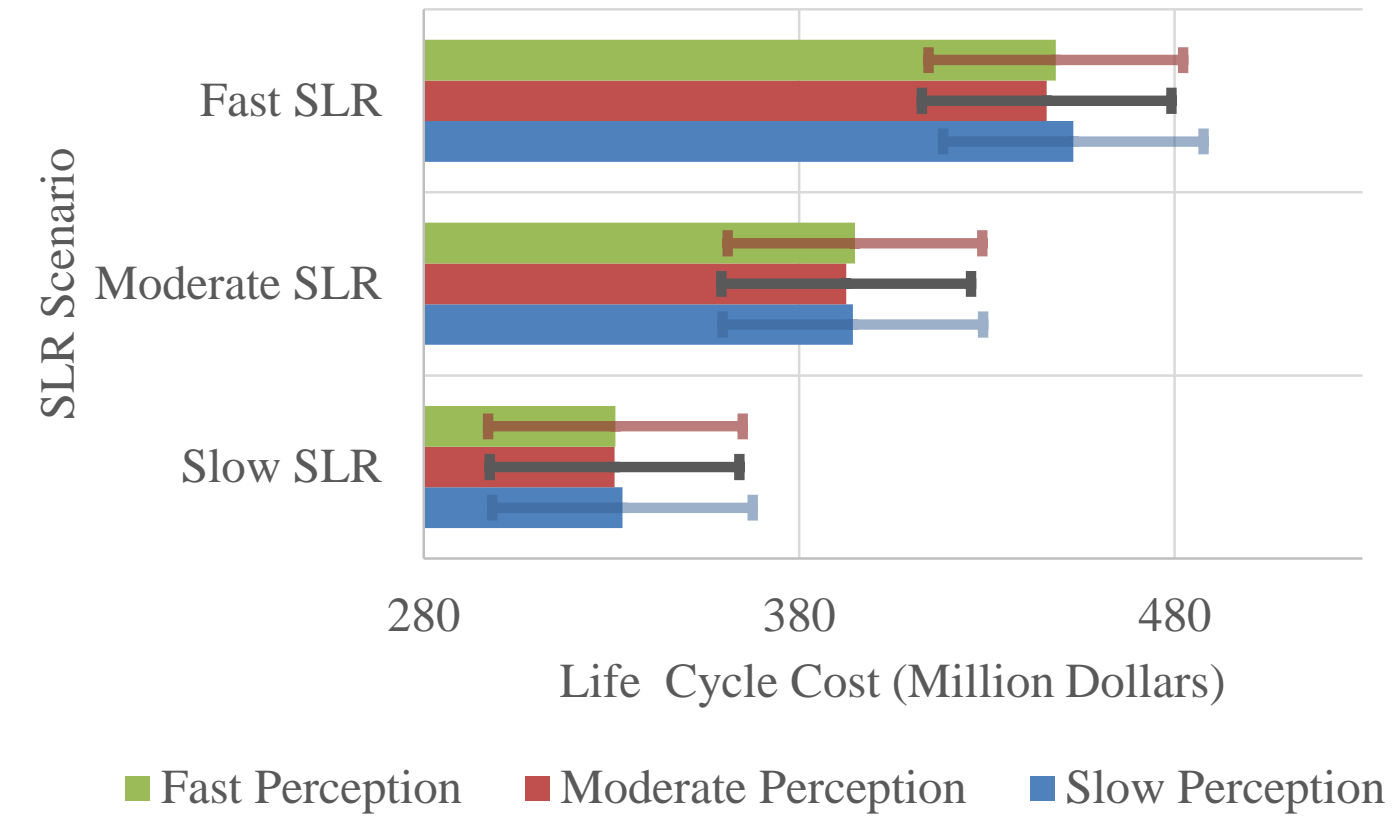

Figure 5-11: The impact of SLR perception on life cycle costs of the network

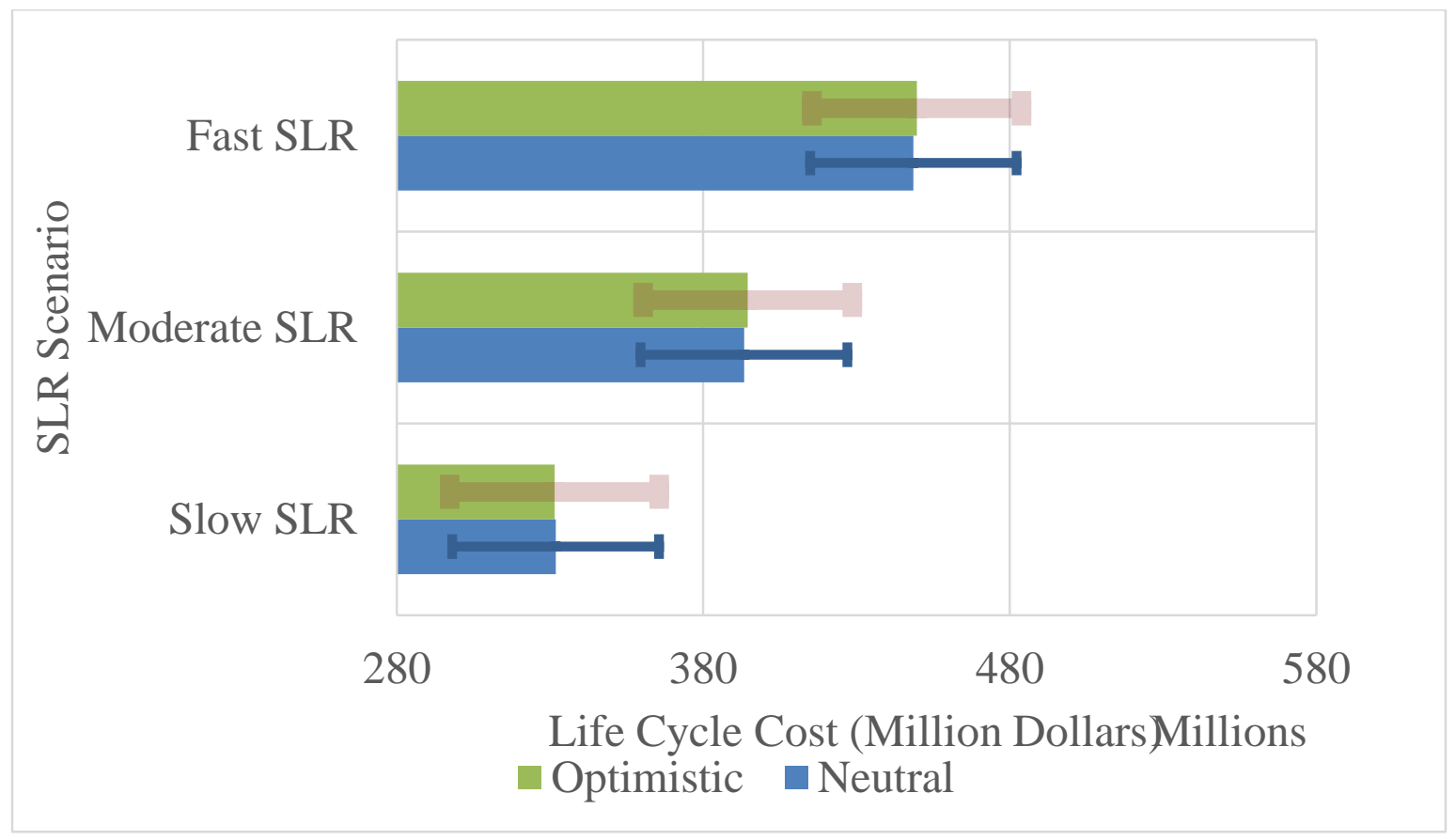

Figure 5-12: Impact of risk attitude on life cycle cost of the network 


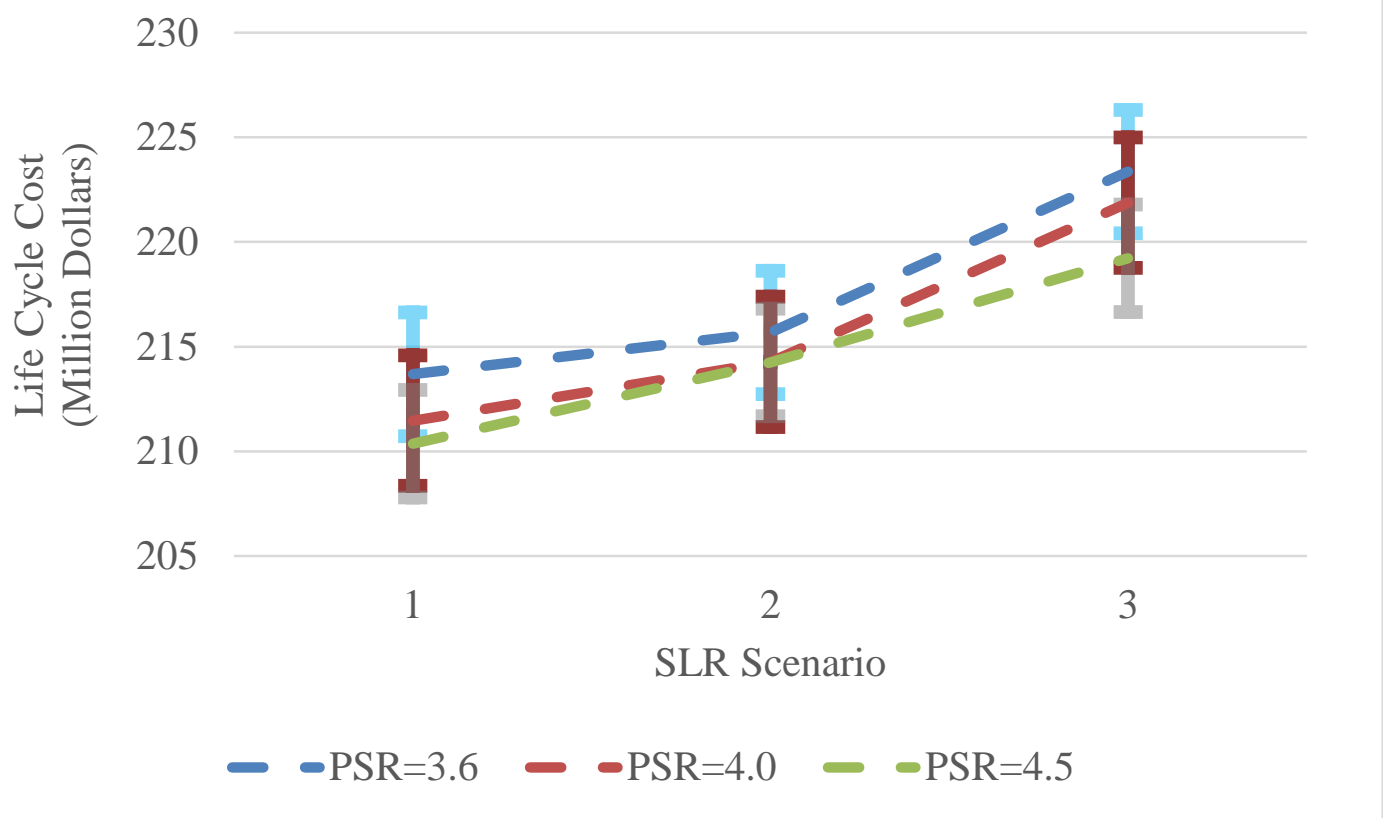

Figure 5-13: Impact of performance target

\subsection{Conclusion}

This paper presented a new framework for conceptualization and quantitative assessment of the impacts of sea-level rise and sea-level rise adaptation on roadway infrastructure systems. The contributions of the research presented in this paper are threefold. First, a system of systems framework was created to enable consideration of the effects of evolving conditions of infrastructure assets and adaptive behaviors of decision makers on life cycle costs of the roadway networks under the uncertain impacts of sealevel rise. Second, a simulation based computational model was created that captures the determinants of the agency decision making behaviors based on several decision theoretic elements. Third, simulation experimentation was conducted for a case study related to a subset of the roadway network in city of Miami Beach to advance our understanding of the 
sea-level rise adaptation. In particular, this study came up to three important theoretical constructs:

(i) SLR Adaptation investment and life cycle costs of roadway infrastructure are negatively correlated. In addition, it was shown that the sensitivity of network's life cycle cost to actual sea-level rise scenario decreases when adaptation investment increases. These finding emphasize the importance of proactive improvement of the network resilience to alleviate the longterm costs of sea-level rise.

(ii) When funding is sufficient for all required adaptation actions, mid-term adaptation planning yields lower life cycle cost. When funding is insufficient, aggregated investment in long-term adaptation planning intervals yields lower network LCC. These findings imply that different adaptation planning approaches should be taken for different levels of adaptation investment.

(iii) The agency's perception of SLR and risk attitude do not have significant effect on life cycle cost of roadway networks. Hence, implementation of adaptation action based on any perception of sea-level rise and risk attitude can significantly reduce the life cycle costs of roadway networks under the impacts of SLR.

(iv) The devised performance target has negative correlation with life cycle cost of a roadway network affected by SLR impacts. Therefore, compromising the network performance condition will never result in lower life cycle costs. 


\section{Conclusion}

\subsection{Summary}

Transportation agencies in coastal urban areas face a significant challenge to enhance the long-term resilience of their networks to flooding and storm surge events exacerbated by sea level rise. To moderate the potential impacts of sea-level rise on infrastructure systems, planning and implementation of effective adaptation strategies is critical. On the other hand, the problem of sea-level rise adaptation is characterized by deep uncertainty that makes it complex to assess the value of adaptation investments. Evaluation of the effectiveness of adaptation actions is critical to avoid maladaptation in infrastructure systems. Also, making adaptation decisions would require making trade-offs between the normal condition and sea-level rise requirements over the long-term. Hence, making robust adaptation decisions is contingent upon evaluation of the long-term transformation of infrastructure systems under different adaptation strategies and sea-level rise scenarios. This important knowledge is missing in the existing body of knowledge. To address this knowledge gap, the objective of the present research is to provide a better understanding of sea-level rise impacts on roadway infrastructure in order to facilitate proactive mitigation of the potential impacts. In particular, this research contributes to the body of knowledge by developing the theoretical and methodological foundations needed for assessing the economic, environmental, and social value of sea-level rise adaptation strategies.

Specifically, three hypotheses are tested in the present research: (1) There is an optimal balance between investments in adaptation actions and accepting potential future 
sea-level rise impacts on roadway infrastructure systems. (2) Life cycle cost of roadway networks threatened by the impacts of sea-level rise is sensitive to the adaptation planning approach (short-term vs. long-term planning). (3) Life cycle cost of roadway networks threatened by the impacts of sea-level rise is sensitive to adaptation-related decision making behaviors including SLR-perception, risk attitude and performance target.

To enable testing these hypotheses and accomplish the aforementioned objectives of this study, a dynamic stochastic modeling framework was created based on the theoretical underpinnings of complex adaptive systems. The proposed framework integrates: (i) stochastic simulation of sea-level rise stressors based on the data obtained from downscaled climate studies pertaining to future projections of sea-level and precipitation; (ii) dynamic modeling of roadway conditions by considering regular decay of roadways, as well as structural damages caused by storm surge events; and (iii) a decision-theoretic modeling of agency infrastructure management and adaptation processes based on cognitive psychology, bounded rationality, and regret theories. In this framework, the effectiveness of adaptation investments is examined based on trend changes in the network performance measures (e.g., life cycle costs, environmental impacts, and performance). In addition, due to several limitations of existing LCA and LCC methodologies, methodological improvements are suggested for assessing life cycle cost and environmental impacts of infrastructure systems.

The created framework and model were tested in a case study related to the road network of the city of Miami-Beach, which global assessments rank first among the world's 
urban areas most exposed to sea-level rise risks. The results indicated the following conclusions:

1) Contingent upon adequacy of adaptation budget mid-term (5-10 years) planning for adaptation investments will provide the maximum value for the network across different scenarios of sea-level rise regardless of the perception and risk attitude of the agency towards SLR impacts.

2) However, in existence of budget deficit, investment of limited budget on larger chunks is likely to improve long-term performance and reduce long-term costs and environmental impacts of the network.

3) Overestimation or underestimation of future sea-level rise impacts do not have significant impact over the long-term.

4) Under no scenario, the network performance could be traded for lower cost or environmental impacts. In fact, there is a positive correlation between network performance and life cycle cost that makes preservation of the network more expensive if the performance is compromised.

\subsection{Model Verification and validation}

Verification and validation of the computational models were crucial in this study. Various internal and external validation techniques (e.g., predictive and face validation) were employed to verify the data, logic, and computational algorithms related to the simulation model. The different techniques used for verification and validation of the model and its results are shown in Figure 6.1. First, the initial conditions and the ranges of the parameters were compared to the existing empirical data to ensure the reliability of the parameters in 
the model (Werker and Brenner, 2004). For example, the parameters related to the physical network (such as structural number of pavements and the thickness of different layers) were compared to the actual pavement data related to another network. Second, the behaviors of model entities (e.g., abrupt changes in the level of performance of the roads) were followed to identify unusual model behaviors. Whenever an unusual behavior was observed the model logic was checked to ensure that the behavior is not due to unreasonable assumptions or flawed logic. Third, several random replications of the model were compared to check for the consistency of the results (Xiang et al. 2005). Fourth, the outputs related to each model specification were compared to the existing data. For example, the simulated deterioration rates of the pavements (i.e. trends of PSR values) were compared to the real values related to decay of pavements based on historical data. In addition, sensitivity analysis was conducted to further verify the model parameters and outputs.

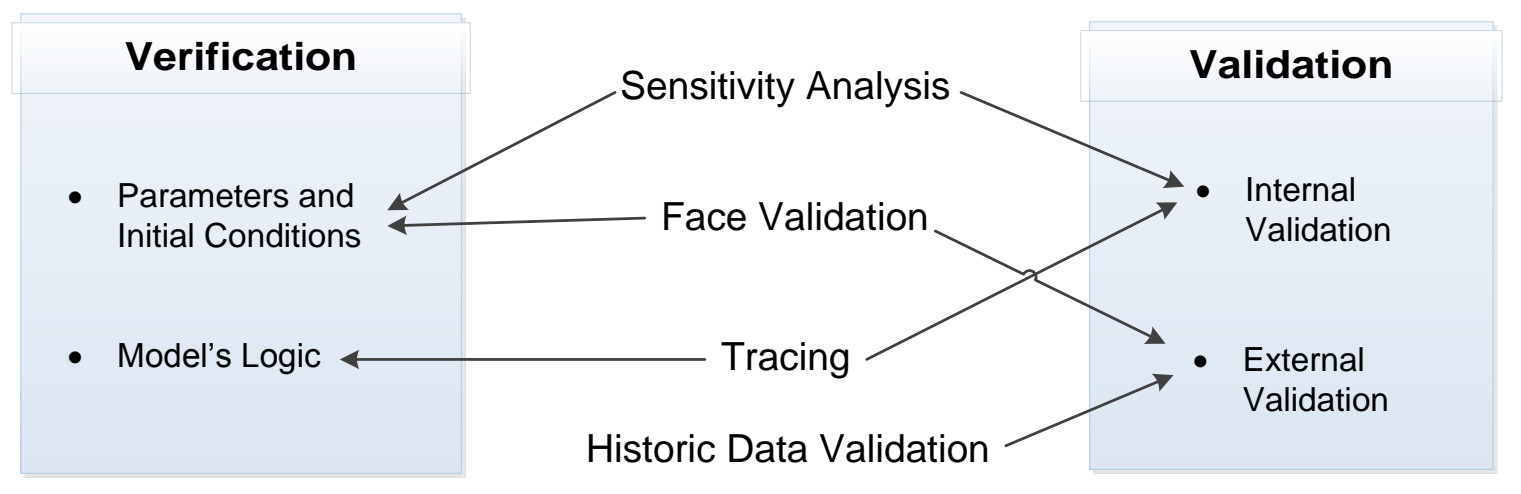

Figure 6-1: Verification and validation of the research components Significantly, the reliability of the collected data, validity of conceptual framework and the computational model, and operability of the research outcomes were verified by experts in the in the city of Miami Beach and Florida department of transportation, through 
face validation, at which time the expert panels assessed whether the simulation results are reasonable and consistent with the behaviors and processes in the network. To this end, 3 separate face to face meetings (each taking 2 hours) were set with a total of 12 experts (including $4 \mathrm{PhDs}$ and highly experienced individuals) from the City of Miami Beach and FDOT District 4. All model parameters (such as performance, cost, and timing and type of M\&R activities) were represented graphically to facilitate face validation of model outcomes. At the end, a questionnaire survey was filled by the experts to evaluate different research components on a scale of 1 to 5 in which 1 and 5 respectively, represent the lowest and highest levels of validity. As shown in Table 6.1, on average, the experts evaluated different research components with scores between 4.2 and 5.0.

Face validity ensured the four features (4Cs) of modeling quality: completeness, consistency, coherence, and correctness (Pace 2000).

Table 6-1: Results of face validity

\begin{tabular}{|c|c|c|}
\hline & Model Features & $\begin{array}{c}\text { Average } \\
\text { Score }\end{array}$ \\
\hline $\begin{array}{c}\text { Conceptual } \\
\text { Model } \\
\text { Validity }\end{array}$ & $\begin{array}{c}\text { The components of the model represent the most important } \\
\text { features of the system }\end{array}$ & 4.8 \\
\cline { 2 - 3 } & $\begin{array}{c}\text { The abstraction of the components and interactions in the } \\
\text { model is complete }\end{array}$ & 4.8 \\
\cline { 2 - 3 } & The behavior of the components of the model is reasonable & 4.9 \\
\hline $\begin{array}{c}\text { Simulation } \\
\text { Model } \\
\text { Validity }\end{array}$ & The model explains the dynamics of the system & 4.8 \\
\cline { 2 - 3 } & $\begin{array}{c}\text { The theories and assumptions underlying the model are correct } \\
\text { structure, logic, and mathematical and causal relationships are } \\
\text { reasonable. }\end{array}$ & 4.7 \\
\hline $\begin{array}{c}\text { Data } \\
\text { Validity }\end{array}$ & $\begin{array}{c}\text { The assumptions regarding model's parameters, variables, } \\
\text { interactions and decision rules are reasonable. }\end{array}$ & 4.6 \\
\hline
\end{tabular}




\begin{tabular}{|c|c|c|}
\hline \multirow{2}{*}{$\begin{array}{c}\text { Output } \\
\text { Validity }\end{array}$} & $\begin{array}{c}\text { The level of detail and the relationships used for the model are } \\
\text { appropriate for the intended purpose }\end{array}$ & 4.2 \\
\cline { 2 - 3 } & $\begin{array}{c}\text { The output of the simulation model has the accuracy required } \\
\text { for the model's intended purpose. }\end{array}$ & 4.3 \\
\cline { 2 - 3 } & $\begin{array}{c}\text { The graphical/animation output of the model is appropriate for } \\
\text { the intended audiences }\end{array}$ & 5.0 \\
\cline { 2 - 3 } & The model could be helpful in the domain of its applicability & 4.9 \\
\hline
\end{tabular}

\subsection{Contributions}

The contributions of this research are twofold. First, this research advances the science of sustainability and resilience in infrastructure systems. Second, the theoretical constructs can be used by decision-makers and practitioners to better manage their infrastructure networks under the uncertain impacts of sea-level rise.

\subsubsection{Contributions to the body of knowledge}

This research made methodological and theoretical contributions to the body of knowledge. With regards to theoretical contributions, this research contributed to the theory of sustainable and resilient infrastructure systems. The theory of sustainable and resilient infrastructure has recently developed. However, our understanding of the resilience of infrastructure systems under the long-term impacts of sea-level rise is rather limited. Through this research, a better understanding of different theoretical elements related to long-term resilience of infrastructure systems was obtained. In particular, this research enabled understanding the twin effects of the evolving sea-level rise stressors and adaptive behaviors of decision makers on resilience of infrastructure systems. In addition, the use of classification and regression techniques (i.e. CART analysis) enabled exploratory 
evaluation of infrastructure resilience across numerous scenarios of sea-level rise, perception, risk attitude, performance, and budget to come up to findings that are applicable under all possible alternative development pathways of infrastructure.

With regards to the methodological contributions, this study enabled consideration of the evolving levels of service and performance in assessment of life cycle cost and environmental impacts of infrastructure networks. Also, a simulation approach for quantitative assessment of the long-term transformation of infrastructure systems under the impacts of sea-level rise was created. Thus, this research filled the important gap in knowledge pertaining to infrastructure resilience to the impacts of sea-level rise.

\subsubsection{Contributions to the body of practice}

The models and theoretical constructs created in this research could significantly enhance the ability of decision-makers and practitioners in planning for adaptation investments and management of infrastructure systems affected by the impacts of sea-level rise. In particular, practitioners could use the findings of this research to:

(1) Assess and visualize the long-term impacts of sea-level rise on their infrastructure networks. Practitioners can use the simulation models developed in this research to predict the likely costs of sea-level rise and hence make informed decisions about budget allocation and preservation of the networks.

(2) The findings of this study enables identifying the most appropriate analysis interval for making adaptation investments. Decision makers who have adequate resources are advised to plan for adaptation investment based on 5-10 year projections of sea-level rise. 
On the other hand, those who are facing with budget crunch are advised to accumulate budget and invest on costlier projects when budget becomes available rather than investing on low cost-low consequence impacts of sea-level rise.

(3) The results also show that in general overestimation or underestimation of sea-level rise impacts won't make significant impacts on the long-term cost and impacts of adaptation actions. Hence, it is of critical importance for decision makers to make adaptation investments as early possible rather than waiting for more accurate projections of sea-level rise.

(4) The results show that compromising the performance of the network won't help with reducing the long-term costs or environmental impacts of infrastructure systems. Hence, practitioners should continue to keep their networks at highest possible level of performance despite the frequent damages caused by flooding and storm surges of roadway networks.

\subsubsection{Limitations and future work}

There are some limitations in this research, which should be addressed in future studies.

First, sea-level rise may cause flooding due to groundwater breaks caused by high water tables below the subbase layers of the roads. The impacts of groundwater-induced flooding are not considered in the present study and could be investigated in future works.

Second, the duration of adaptation projects is not considered in this study. A future

work is to study the impact of the delay between making adaptation decision and completion of adaptation projects on the effectiveness of adaptation actions. 
Third, the adaptation decision making could be improved if the remaining service life of road assets are taken into consideration when adaptation investments are made. For example, elevating a newly constructed road will cause waste of the initial construction investment. Therefore, a future work is to prioritize the adaptation investment to projects considering the remaining service life of different assets.

Forth, the present study did not consider the criticality of different links in functionality of a roadway network. A future study is to enable optimization of adaptation actions with the constraint of prioritizing critical links.

Fifth, roadway infrastructure has several interdependencies with other infrastructure systems that are not considered in this study. For example, synchronizing adaptation projects with the rehabilitation of underground pipelines may reduce the total costs of the water and roadway systems. A future work is to incorporate the interdependencies of different infrastructure systems in the decision making process for adaptation to sea-level rise. 


\section{REFERENCES}

Bakker, J. D., Van Der Graaf, H. J., \& Van Noortwijk, J. M. (1999). Model of lifetimeextending maintenance. In Proceedings of the 8th international conference on structural faults and repair, London, United Kingdom.

Barnes, G., and Langworthy, P. (2003). "The per-mile costs of operating automobiles and trucks."

Batouli, M., \& Mostafavi, A. (2015). Assessment of network-level environmental sustainability in infrastructure systems using service and performance adjusted life cycle analysis, ICSC15 - The Canadian Society for Civil Engineering's 5th International/11th Construction Specialty Conference

Batouli, M., \& Mostafavi, A. (2014, December). "A hybrid simulation framework for integrated management of infrastructure networks". In Simulation Conference (WSC), 2014 Winter (pp. 3319-3330). IEEE.

Batouli, M., Swei, O. A., Zhu, J., Gregory, J., Kirchain, R., \& Mostafavi, A. (2015, June). "A Simulation Framework for Network Level Cost Analysis in Infrastructure Systems". In 2015 International Workshop on Computing in Civil Engineering.

Batouli, S. M., \& Zhu, Y. (2014). A Framework for Assessing Environmental Implications of an Urban Area, Construction Research Congress 2014

Berry, L., Arockiasamy, M., Bloetscher, F., Kaisar, E., Rodriguez-Seda, J., Scarlatos, P., Teegavarapu, R., and Hammer, N. (2012). "Development of a Methodology for the Assessment of Sea Level Rise Impacts on Florida's Transportation Modes and Infrastructure."

Bhamidipati, S. (2014a). "A simulation framework for asset management in climatechange adaptation of transportation infrastructure." ETC 2014: European Transport Conference, Frankfurt, Germany, 29 September-1 October 2014, Association for European Transport (AET).

Calkins, M. (2008). Materials for sustainable sites: a complete guide to the evaluation, selection, and use of sustainable construction materials. John Wiley \& Sons.

Carlin, T. M. (2005). "Debating the impact of accrual accounting and reporting in the public sector." Financ.Account.Manage., 21(3), 309-336.

Chertoff, M. (2009). "National infrastructure protection plan." Department of Homeland Security (DHS), Washington, DC.

Chootinan, P., A. Chen, M. R. Horrocks and D. Bolling. 2006. "A Multi-year Pavement Maintenance Program Using a Stochastic Simulation-based Genetic Algorithm Approach." Transportation Research Part A: Policy and Practice 40(9): 725-743. 
Compact, Southeast Florida Regional Climate Change. (2011). "Analysis of the Vulnerability of Southeast Florida to Sea Level Rise." SFRCC Inundation Mapping and Vulnerability Assessment Work Group.

Council, Southeast Florida Regional Planning. (2013). "Adaptation Action Areas: Policy Options for Adaptive Planning for Rising Sea Levels."

Crowell, M., Coulton, K., Johnson, C., Westcott, J., Bellomo, D., Edelman, S., and Hirsch, E. (2010). "An estimate of the US population living in 100-year coastal flood hazard areas." J.Coast.Res., 201-211.

Domingues, C. M., Church, J. A., White, N. J., Gleckler, P. J., Wijffels, S. E., Barker, P. M., and Dunn, J. R. (2008). "Improved estimates of upper-ocean warming and multidecadal sea-level rise." Nature, 453(7198), 1090-1093.

Elkins, G. E., Thompson, T. M., Groeger, J. L., Visintine, B., and Rada, G. R. (2013). Reformulated Pavement Remaining Service Life Framework, .

Finnveden, G., Hauschild, M. Z., Ekvall, T., Guinee, J., Heijungs, R., Hellweg, S., Koehler, A., Pennington, D., and Suh, S. (2009). "Recent developments in life cycle assessment." J.Environ.Manage., 91(1), 1-21.

Foley, J., De Haas, D., Hartley, K., \& Lant, P. (2010). Comprehensive life cycle inventories of alternative wastewater treatment systems. Water research, 44(5), 1654-1666.

Frangopol, D. M., Lin, K. Y., \& Estes, A. C. (1997). Life-cycle cost design of deteriorating structures. Journal of Structural Engineering, 123(10), 1390-1401.

Gallivan, F., Bailey, K., and O'Rourke, L. (2009). "Planning for impacts of climate change at US ports." Transportation Research Record: Journal of the Transportation Research Board, (2100), 15-21.

Hartmann, D., Klein Tank, A., Rusicucci, M., Alexander, L., Broenniman, B., Charabi, Y., Dentener, F., Dlugokencky, E., Easterling, D., and Kaplan, A. (2013). Observations: atmosphere and surface. In: Climate Change 2013: The Physical Science Basis. Contribution of Working Group I to the Fifth Assessment Report of the Intergovernmental Panel on Climate Change

Hayes, R. H., and Garvin, D. A. (1982). "Managing as if tomorrow mattered." Harv.Bus.Rev., 60(3), 70-79.

Haas, R. (2008). "The ICMPA7 investment analysis and communication challenge for road assets." Prepared for the 7th Int. Conf. on Managing Pavement Assets, Calgary.

Hendrickson, C., and Horvath, A. (2000). "Resource use and environmental emissions of US construction sectors." J.Constr.Eng.Manage., 126(1), 38-44.

Inyim, P., Pereyra, J., Bienvenu, M., \& Mostafavi, A. (2016). Environmental assessment of pavement infrastructure: A systematic review. Journal of environmental management, $176,128-138$. 
ISO 14040, I. (2006). "14040 Environmental management-life cycle assessment-principles and framework." London: British Standards Institution.

ISO 14044, I. (2006). "14044: environmental management—life cycle assessmentrequirements and guidelines." International Organization for Standardization.

Jorion, P. (1999). "Risk management lessons from long-term capital management." Available at SSRN 169449.

Karl, T. R., Melillo, J. M., and Peterson, T. C. (2009). Global climate change impacts in the United States. Cambridge University Press.

Kharrazi, A., Kraines, S., Hoang, L., and Yarime, M. (2014). "Advancing quantification methods of sustainability: A critical examination emergy, exergy, ecological footprint, and ecological information-based approaches." Ecol.Ind., 37 81-89.

Kleinosky, L. R., Yarnal, B., and Fisher, A. (2007). "Vulnerability of Hampton Roads, Virginia to storm-surge flooding and sea-level rise." Nat.Hazards, 40(1), 43-70.

Koetse, M. J., and Rietveld, P. (2009). "The impact of climate change and weather on transport: An overview of empirical findings." Transportation Research Part D: Transport and Environment, 14(3), 205-221.

Kwon, Y. K. (1990). "Accrual versus cash-basis accounting methods: An agency-theoretic comparison." J.Account.Public Policy, 8(4), 267-281.

Labi, S., \& Sinha, K. C. (2005). "Life-cycle evaluation of flexible pavement preventive maintenance." Journal of Transportation Engineering, 131(10), 744-751.

Labi, S. (2014). Introduction to Civil Engineering Systems: A Systems Perspective to the Development of Civil Engineering Facilities. John Wiley \& Sons.

Lankao, P. R., and Qin, H. (2011). "Conceptualizing urban vulnerability to global climate and environmental change." Current Opinion in Environmental Sustainability, 3(3), 142149.

Lassaux, S., Renzoni, R., \& Germain, A. (2007). Life cycle assessment of water from the pumping station to the wastewater treatment plant. International Journal of Life Cycle Assessment, 12(2), 118.

Lee,Y., A. Mohseni and M.I. Darter. 1993. "Simplified Pavement Performance Models." Transportation Research Record 1993: 7-7.

Li, W., Mills, L., and McNeil, S. (2011). "The Implications of Climate Change on Pavement Performance and Design, University of Delaware University." Transportation Center (UD-UTC).

Loijos, A., Santero, N., and Ochsendorf, J. (2013). "Life cycle climate impacts of the US concrete pavement network." Resour.Conserv.Recycling, 72 76-83. 
Lundin, M., Bengtsson, M., \& Molander, S. (2000). Life cycle assessment of wastewater systems: influence of system boundaries and scale on calculated environmental loads. Environmental Science \& Technology, 34(1), 180-186.

Markard, J., Raven, R., \& Truffer, B. (2012). Sustainability transitions: An emerging field of research and its prospects. Research Policy, 41(6), 955-967.

Miller, S. A., Moysey, S., Sharp, B., and Alfaro, J. (2013). "A stochastic approach to model dynamic systems in life cycle assessment." J.Ind.Ecol., 17(3), 352-362.

Mostafavi, A., Abraham, D., and DeLaurentis, D. (2013). "Ex-ante policy analysis in civil infrastructure systems." J.Comput.Civ.Eng., 28(5).

Muench, S. T. (2010). "Roadway Construction Sustainability Impacts." Transportation Research Record: Journal of the Transportation Research Board, 2151(1), 36-45.

Nikolic, I., \& Dijkema, G. P. (2010). On the development of agent-based models for infrastructure evolution. International journal of critical infrastructures, 6(2), 148-167.

NOAA. (2015). "National coastal population report, population trends from 1970 to 2020." National Oceanic and Atmospheric Administration, Department of Commerce, Developed in Partnership with the US Census Bureau.Retrieved in Pdf from: Http://Stateofthecoast.Noaa.Gov/Features/Coastal-Population-Report.Pdf, Last Accessed On, 9.

Noshadravan, A., Wildnauer, M., Gregory, J., \& Kirchain, R. (2013). Comparative pavement life cycle assessment with parameter uncertainty. Transportation Research Part D: Transport and Environment, 25, 131-138.

Parris, A., Bromirski, P., Burkett, V., Cayan, D. R., Culver, M., Hall, J., Horton, R., Knuuti, K., Moss, R., and Obeysekera, J. (2012). Global sea level rise scenarios for the United States National Climate Assessment. US Department of Commerce, National Oceanic and Atmospheric Administration, Oceanic and Atmospheric Research, Climate Program Office.

Peter Van Der Hoek, M. (2005). "From cash to accrual budgeting and accounting in the public sector: The Dutch experience." Public Budgeting \& Finance, 25(1), 32-45.

Pope, J., Annandale, D., and Morrison-Saunders, A. (2004). "Conceptualising sustainability assessment." Environ.Impact Assess.Rev., 24(6), 595-616.

Reap, J., Roman, F., Duncan, S., and Bras, B. (2008b). "A survey of unresolved problems in life cycle assessment." The International Journal of Life Cycle Assessment, 13(5), 374388.

Reza, B., Sadiq, R., and Hewage, K. (2014). "Emergy-based life cycle assessment (EmLCA) for sustainability appraisal of infrastructure systems: a case study on paved roads." Clean Technologies and Environmental Policy, 16(2), 251-266.

Rhein, M., Rintoul, S., Aoki, S., Campos, E., Chambers, D., Feely, R., Gulev, S., Johnson, G., Josey, S., and Kostianoy, A. (2013). "Observations: ocean. In: Climate Change 2013: 
The Physical Science Basis. Contribution of Working Group I to the Fifth Assessment Report of the Intergovernmental Panel on Climate Change."

Roshani, A., Mirfenderesk, H., Rajapakse, J., and Gallage, C. (2013). "Groundwater table response to sea level rise and its impact on pavement structure." 9th Annual International Conference of the International Institute for Infrastructure Renewal and Reconstruction, Risk-informed Disaster Management: Planning for Response, Recovery and Resilience, Queensland University of Technology.

Sahin, O., and Mohamed, S. (2013). "A spatial temporal decision framework for adaptation to sea level rise." Environmental Modelling \& Software, 46 129-141.

Santero, N. J., Masanet, E., and Horvath, A. (2011). "Life-cycle assessment of pavements. Part I: Critical review." Resour.Conserv.Recycling, 55(9), 801-809.

Sathaye, N., Horvath, A., \& Madanat, S. (2010). Unintended impacts of increased truck loads on pavement supply-chain emissions. Transportation Research Part A: Policy and Practice, 44(1), 1-15.

Stripple, H. (2001). Life cycle assessment of road. A pilot study for inventory analysis. Rapport IVL Swedish Environmental Research Institute, 96.

Stocker, T., Qin, D., Plattner, G., Tignor, M., Allen, S., Boschung, J., Nauels, A., Xia, Y., Bex, B., and Midgley, B. (2013). "IPCC, 2013: climate change 2013: the physical science basis. Contribution of working group I to the fifth assessment report of the intergovernmental panel on climate change."

Strauss, B., Tebaldi, C., Kulp, S., Cutter, S., Emrich, C., Rizza, D., and Yawitz, D. (2013). "Florida and the Surging Sea: A Vulnerability Assessment With Projections for Sea Level Rise and Coastal Flood Risk." Climate Central, Princeton, NJ.

Suarez, P., Anderson, W., Mahal, V., and Lakshmanan, T. (2005). "Impacts of flooding and climate change on urban transportation: A systemwide performance assessment of the Boston Metro Area." Transportation Research Part D: Transport and Environment, 10(3), 231-244.

Tol, R. S., Klein, R. J., and Nicholls, R. J. (2008). "Towards successful adaptation to sealevel rise along Europe's coasts." J.Coast.Res., 432-442.

Udo de Haes, H. (2006). "How to approach land use in LCIA or, how to avoid the Cinderella effect?" The International Journal of Life Cycle Assessment, 11(4), 219-221.

Vanier, D. “. (2001). "Why industry needs asset management tools." J.Comput.Civ.Eng., $15(1), 35-43$.

Van Noortwijk, J. M. (1998, May). Optimal replacement decisions for structures under stochastic deterioration. In Proceedings of the Eighth IFIP WG (Vol. 7, No. 5, pp. 273280). 
van Noortwijk, J. M., \& Frangopol, D. M. (2004). Two probabilistic life-cycle maintenance models for deteriorating civil infrastructures. Probabilistic Engineering Mechanics, 19(4), 345-359.

Weber, C. L., Jaramillo, P., Marriott, J., \& Samaras, C. (2010). Life cycle assessment and grid electricity: what do we know and what can we know?. Environmental science \& technology, 44(6), 1895-1901.

Wu, S., Najjar, R., and Siewert, J. (2009). "Potential impacts of sea-level rise on the Midand Upper-Atlantic Region of the United States." Clim.Change, 95(1-2), 121-138.

Xu, X., Gregory, J., \& Kirchain, R. (2015). Role of the Use Phase and Pavement-Vehicle Interaction in Comparative Pavement Life Cycle Assessment. In Transportation Research Board 94th Annual Meeting (No. 15-4011).

Zaabar, I., and Chatti, K. (2010). "Calibration of HDM-4 models for estimating the effect of pavement roughness on fuel consumption for US conditions." Transportation Research Record: Journal of the Transportation Research Board, 2155(1), 105-116.

Zapata, P., and Gambatese, J. A. (2005). "Energy consumption of asphalt and reinforced concrete pavement materials and construction." J Infrastruct Syst, 11(1), 9-20.

Zhang, H., Keoleian, G. A., and Lepech, M. D. (2012). "Network-Level Pavement Asset Management System Integrated with Life-Cycle Analysis and Life-Cycle Optimization." J Infrastruct Syst, 19(1), 99-107.

Zhang, Z., Wu, Z., Martinez, M., and Gaspard, K. (2008). "Pavement structures damage caused by Hurricane Katrina flooding.” J.Geotech.Geoenviron.Eng., 134(5), 633-643. 
VITA

\section{MOSTAFA BATOULI}

\section{EDUCATION}

PhD Candidate in Civil and Environmental Engineering (to be graduated in December 2016)

Florida International University, G.P.A: 4/4

Master of Public Administration (2015)

Florida International University, G.P.A: 4/4

Graduate Certificate in Homeland Security and Emergency Management (2015)

Green School of International and Public Affairs, Florida International University, G.P.A: 4/4

M.Sc. in Construction Engineering and Management (2008)

Islamic Azad University, Science and Research Branch, Tehran, Iran, G.P.A: 18.35/20.00

B.Sc. in Surveying and Geomatics Engineering (2005)

University of Tehran, Tehran, Iran

> Dissertation Year Fellowship, Florida International University, 2016

> Third Place Best PhD Poster Award, Construction Research Congress, 2016

> Student Government Association Graduate Scholarship Award, 2015

$>$ Graduate Student Appreciation Week (GSAW) Scholarly Forum Third Poster Award, 2015

$>$ University Wide Scholarship Award, Florida International University, 2014

\section{PUBLICATION}

1. Batouli, S. M., Zhu, Y., Nar, M., \& D'Souza, N. A. (2014). Environmental Performance of Kenaf-fiber Reinforced Polyurethane: a Life Cycle Assessment Approach. Journal of Cleaner Production, 66, 164-173.

2. Batouli, Mostafa, Mostafavi, Ali (2016). Service and Performance Adjusted Life Cycle Assessment: A Methodology for Dynamic Assessment of Environmental Impacts in Infrastructure Systems (Under second review, journal of Sustainable and Resilient Infrastructure)

3. Batouli, Mostafa, Bienvenu, Michael, Mostafavi, Ali (2016). Putting Sustainability Theory into Roadway Design Practice: Implementation of LCA and LCCA Analysis for Pavement Type Selection in Real World Decision Making (Under review, journal of Transportation Research Part D)

4. Batouli, Mostafa, Mostafavi, Ali (2016). Formalization and Assessment of Roadway Infrastructure Adaptation to the Impacts of Sea-Level Rise (In Preparation)

5. Batouli, M., Bienvenu, M.\& Mostafavi, A. (2016). Development of Life-Cycle Assessment (LCA) and Life-Cycle Cost Analysis (LCCA) for Pavement-Type Selection for SR-836 Extension, Research Study for the Miami-Dade Expressway Authority (MDX)

6. Orgut,R; Batouli, M.; Zhu,J; Jaselskis,E; Mostafavi, A (2016) "Metrics That Matter: Improving Project Progress and Performance Assessment, Research Study for the Construction Industry Institute

7. Batouli, M., \& Mostafavi, A. (2016). Assessment of Sea-Level Rise Adaptation in Coastal Infrastructure Systems: Robust Decision-Making under Uncertainty, Proceedings of Construction Research Congress 2016

8. Batouli, M., \& Mostafavi, A. (2016). A Simulation Framework for Sustainability Assessment in Evolving Socio-Technical Infrastructure Systems, ICSDEC16 - International Conference on Sustainable Design, Engineering and Construction 
9. Orgut, R., Batouli, M., Zhu, J., Mostafavi, A., Jaselskis, J.. (2016). Metrics that Matter: Evaluation of Metrics and Indicators for Project Progress Measurement, Performance Assessment, and Performance Forecasting during Construction, Proceedings of Construction Research Congress 2016

10. Carmenatea,T., Inyim, P, Pachekara, N., Chauhana, G., Bobadillaa, L., Mostafavi,A., Batouli, M. (2016). Modeling Occupant-Building-Appliance Interaction for Energy Waste Analysis, ICSDEC16 - International Conference on Sustainable Design, Engineering and Construction

11. Batouli, M., \& Mostafavi, A. (2015). Assessment of network-level environmental sustainability in infrastructure systems using service and performance adjusted life cycle analysis, ICSC15 - The Canadian Society for Civil Engineering's 5th International/11th Construction Specialty Conference

12. Batouli, M., Swei, O. A., Zhu, J., Gregory, J., Kirchain, R., \& Mostafavi, A. (2015, June). A Simulation Framework for Network Level Cost Analysis in Infrastructure Systems. In International Workshop on Computing in Civil Engineering.

13. Orgut, R. E., Zhu, J., Batouli, M., Mostafavi, A., \& Jaselskis, E. J. (2015). A review of the current knowledge and practice related to project progress and performance assessment, The Canadian Society for Civil Engineering's 5th International/11 th Construction Specialty Conference 14. Batouli, M., Mostafavi, A. (2014). A hybrid simulation framework for integrated infrastructure management, Winter Simulation Conference 2014.

15. Batouli, M., Swei, O. A., Zhu, J., Gregory, J., Kirchain, R., \& Mostafavi, A. (2015, June). A $\underline{\text { Simulation Framework for Network Level Cost Analysis in Infrastructure Systems. In International }}$ Workshop on Computing in Civil Engineering.

16. Batouli, S. M., Zhu, Y. (2013). Comparative Life-Cycle Assessment Study of Kenaf Fiber-Based and Glass Fiber-Based Structural Insulation Panels. In ICCREM 2013@Construction and Operation in the Context of Sustainability (pp. 377-388). ASCE.

17. Batouli, S. M., \& Zhu, Y. (2014). A Framework for Assessing Environmental Implications of an Urban Area, Construction Research Congress 2014

18. Batouli, S. M., \& Zhu, Y. (2014). Using Accrual Accounting Life Cycle Assessment as an Indicator of Urban Sustainability, International Conference on Computing in Civil and Building Engineering 2014

19. Batouli,M; Vesali, N.; Ghoddousi,P (2010)"Contractor Selection Criteria: Investigation of Opinions of Iran Construction Practitioners", 6th International project Management Conference, Tehran, Iran

20. Vesali, N.; Batouli, M.; Hosseinalipour, M. (2010) "Factors Influencing Bid/No-Bid Decision of Iranian Construction Contractors", 6th International project Management Conference, Tehran, $\underline{\text { Iran }}$

21. Batouli, M.; Vesali, N.; Hosseinalipour, M. (2008) "Multi-parameter contracting and prequalification: A comparative study", 2nd National Conference on Projects Procurement System, Tehran, Iran

22. Vesali, N.; Batouli, M.; Hosseinalipour, M. (2008) "Factors affecting mark-up decisions among $\underline{\text { large contractors in Iran", 2nd National Conference on Projects Procurement System, Tehran, Iran }}$ 